\title{
Central venous oxygen saturation and venous to arterial carbon dioxide gap as resuscitation targets in hemorrhagic shock
}

\author{
Márton Ferenc Németh MD
}

\author{
Department of Anesthesiology and Intensive Therapy \\ University of Szeged
}

Supervisor: Prof. Zsolt Molnár MD, PhD, DEAA

$\mathrm{PhD}$ Thesis

Szeged 


\section{Publications related to the topic}

1. Németh M, Tánczos K, Demeter G, Erces D, Kaszaki J, Mikor A, Molnár Z. Central venous oxygen saturation and carbon dioxide gap as resuscitation targets in a hemorrhagic shock. Acta Anaesthesiol Scand. 2014;58:611-9.

\section{IF: 2.322}

2. Tánczos K, Németh M, Trásy D, László I, Palágyi P, Szabó Z, Varga G, Kaszaki J. Goal-Directed Resuscitation Aiming Cardiac Index Masks Residual Hypovolemia: An Animal Experiment.Biomed Res Int. 2015;2015:160979.

\section{IF: 2.134}

3. Tánczos K, Németh $\mathbf{M}$, Molnár Z. The multimodal concept of hemodynamic stabilization. Front Public Health. 2014;2:34.

\section{IF: 1.96}

\section{Other publications}

4. Tánczos K, Németh M, Molnár Z. What's new in hemorrhagic shock? Intensive Care Med. 2015;41:712-4.

\section{IF: 10.125}

5. Mikor A, Trásy D, Németh MF, Osztroluczki A, Kocsi S, Kovács I, Demeter G, Molnár Z. Continuous central venous oxygen saturation assisted intraoperative hemodynamic management during major abdominal surgery: a randomized, controlled trial. BMC Anesthesiol. 2015;15:82.

\section{IF: 1.375}

6. Palágyi P, Kaszaki J, Rostás A, Érces D, Németh M, Boros M, Molnár Z. Monitoring Microcirculatory Blood Flow with a New Sublingual Tonometer in a Porcine Model of Hemorrhagic Shock. Biomed Res Int. 2015;2015:847152.

\section{IF: 1.579}

7. Trásy D, Tánczos K, Németh M, Hankovszky P, Lovas A, Mikor A, László I, Hajdú E, Osztroluczki A, Fazakas J, Molnár Z; EProK study group. Early procalcitonin kinetics and appropriateness of empirical antimicrobial therapy in critically ill patients: A prospective observational study. J Crit Care. 2016;34:50-5.

\section{IF: 1.995}


8. Trásy D, Tanczos K, Németh M, Hankovszky P, Lovas A, Mikor A, Hajdu E, Osztroluczki A, Fazakas J, Molnar Z. Delta Procalcitonin is a Better Indicator of Infection than Absolute Procalcitonin Values in Critically Ill Patients: A prospective observational study. J Immunol Res2016;2016:3530752.

IF: 2.812

Total IF: 24.302 


\section{Table of contents}

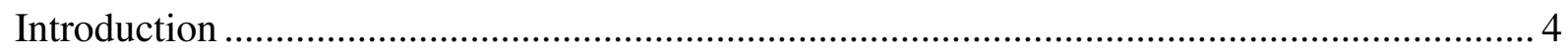

Imbalance of oxygen delivery and consumption in the high risk patients ............................ 5

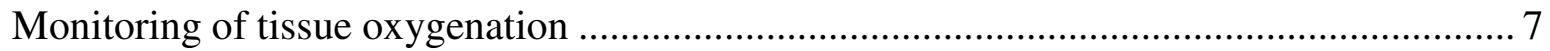

Mixed venous oxygen saturation - Central venous oxygen saturation ............................. 7

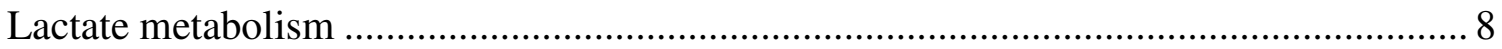

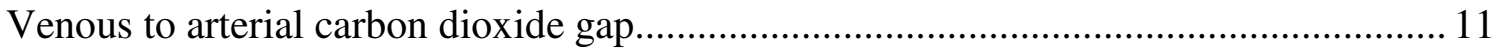

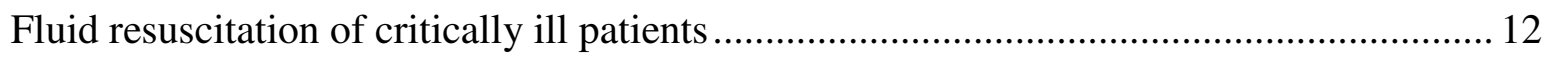

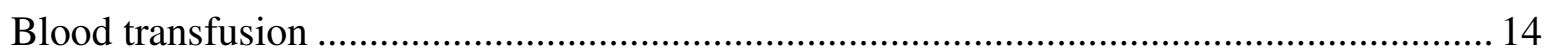

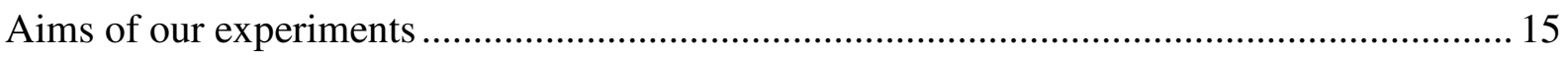

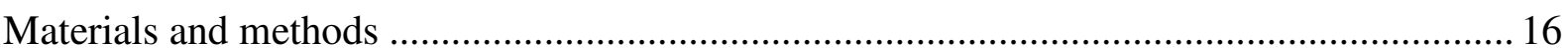

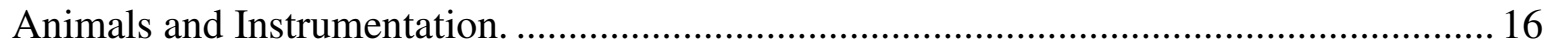

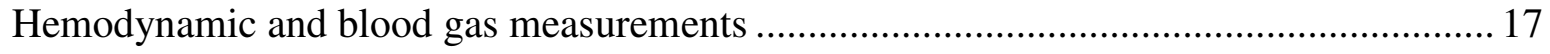

Stroke volume guided bleeding and fluid resuscitation:Experiment-1 ….......................... 17

Stroke volume guided bleeding and cardiac index targeted fluid resuscitation:Experiment-2 18

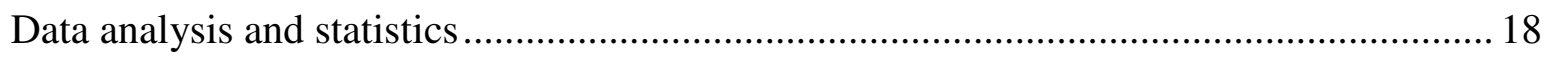

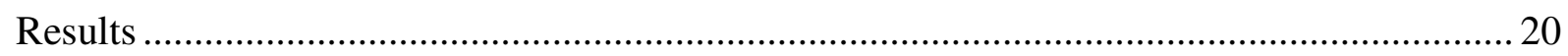

Stroke volume based fluid resuscitation : Experiment-1 ............................................ 20

Cardiac index based resuscitation: Experiment-2 ….................................................. 24

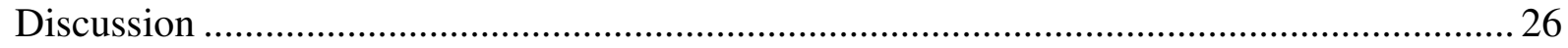

Changes of $\mathrm{ScvO}_{2}$ during stroke volume and cardiac index controlled hemorrhage and

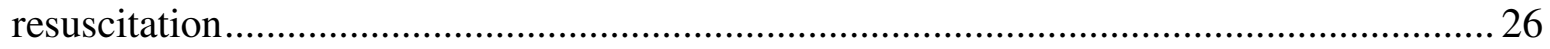

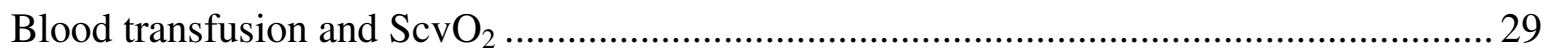

Kinetics of $\mathrm{dCO}_{2}$ during stroke volume and cardiac index based hemorrhage and fluid

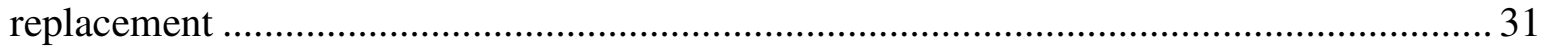

Lactate clearance as resuscitation endpoint during hemorrhage .................................... 33

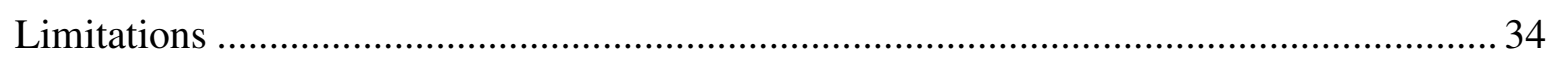

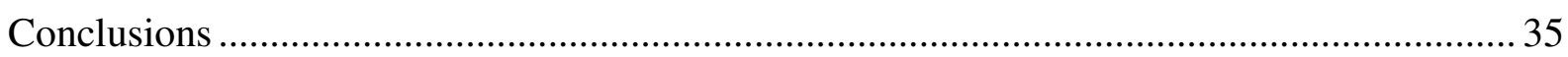

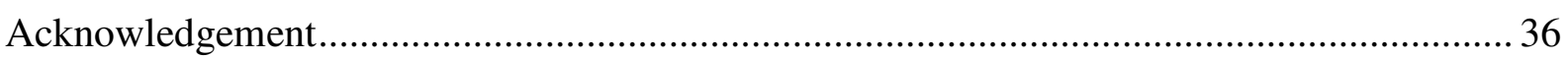

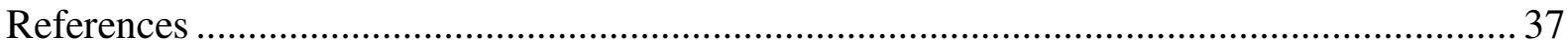




\section{Introduction}

An estimated, 234 million operations are performed annually worldwide, of whom high risk surgical patients undergoing major surgery exhibit a significant risk of morbidity and mortality (Weiser et al., 2008). Despite implementation of pulse oxymetry and capnometry, in daily routine as compulsory safety measures in the 1980's, in developed countries perioperative morbidity varies between $3 \%$ and $17 \%$, while mortality ranges between $0.4 \%$ and $0.8 \%$ in the whole surgical population (Kable et al., 2002). As it has been revealed in postoperative follow up studies, patients undergoing surgical porcedures has higher risk of death after 1 year compared to age- and sex-matched normal populations, furthermore, patients who are higher "resource consumers", has more perioperative complications and require longer in hospital length of stay (Niskanen et al., 2001).

Preoperative anemia (Karkouti et al., 2008) and intraoperative blood loss are two of the most important risk factors (Wen et al., 2012). When bleeding occurs physicians can replace the loss of intravascular blood volume with fluids or may also indicate blood tansfusion. However, adminsitration of blood products carries significant risks such as hemolysis (Harvey et al., 2008), and transmission of serious infections (Rhode et al., 2014). On the other hand, fluid resuscitation is also a double edged sword. Giving less fluid than needed, which is termed "under resuscitation", results decreased oxygen delivery and impaired tissue perfusion, which leads to cellular hypoxia and organ dysfunction. Administering too much fluid, also termed as "over-resuscitation", can cause interstitial edema, which increases the risk of complications, like anastomotic leakage (Schnüringer et al., 2011), secondary abdominal compartment syndrome (Balogh et al., 2002), acute lung injury (Demling et al., 1980) and is accompanied by increased risk of mortality (Brandstrup et al., 2003, Vincentet al., 2006). 


\section{Imbalance of oxygen delivery and consumption in the high risk patients}

Hemodynamic optimization therefore, is fundamental in the treatment of critically ill patients in both the operating room and in the intensive care unit. Under physiological circumstances tissue oxygenation is the net product of oxygen delivery and oxygen consumption:

$$
\begin{gathered}
\mathrm{DO}_{2}=\mathrm{SV} \times \mathrm{HR} \times\left(\mathrm{Hb} \times 1.34 \times \mathrm{SaO}_{2}+\left(0.003 \times \mathrm{PaO}_{2}\right)\right)=\mathrm{CO} \times \mathrm{CaO}_{2} \\
\mathrm{VO}_{2}=\mathrm{CO} \times\left(\mathrm{CaO}_{2}-\left(\mathrm{Hb} \times 1.34 \times \mathrm{SvO}_{2}+\left(0.003 \times \mathrm{PvO}_{2}\right)\right)\right)=\mathrm{CO} \times\left(\mathrm{CaO}_{2}-\mathrm{CvO}_{2}\right) \\
\mathrm{OER}=\mathrm{VO}_{2} / \mathrm{DO}_{2}
\end{gathered}
$$

$\mathrm{DO}_{2-}$ oxygen delivery, $\mathrm{SV}$ - stroke volume, $\mathrm{HR}$ - heart rate, $\mathrm{Hb}$ - hemoglobin, $\mathrm{SaO}_{2}-$ arterial oxygen saturation, $\mathrm{PaO}_{2}$ - partial pressure of oxygen in the arterial blood, $\mathrm{CO}$ - cardiac output, $\mathrm{CaO}_{2}$ - arterial oxygen content, $\mathrm{VO}_{2}$ - oxygen consumption, $\mathrm{SvO}_{2}$ - mixed venous oxygen saturation, $\mathrm{CvO}_{2}$ - venous oxygen content.

Taking a $75 \mathrm{~kg}$ healthy adult man when resting,the relationship between $\mathrm{DO}_{2}$ and $\mathrm{VO}_{2}$ can be estimated as:

Oxygen delivery:

$$
\begin{gathered}
\mathrm{CO}=70 \mathrm{ml} \times 70 / \mathrm{min} \sim 5000 \mathrm{ml} / \mathrm{min} \\
\mathrm{CaO}_{2}=(150 \mathrm{~g} / \mathrm{L} \times 1.34 \mathrm{ml} \times 1.00)+(0.003 \times 100 \mathrm{mmHg}) \sim 200 \mathrm{ml} / \mathrm{L} \\
\mathrm{DO}_{2} \sim 1000 \mathrm{ml} / \mathrm{min}
\end{gathered}
$$

Oxygen consumption:

$$
\begin{gathered}
\mathrm{CO}=70 \mathrm{ml} \times 70 / \mathrm{min} \sim 5000 \mathrm{ml} / \mathrm{min} \\
\mathrm{CvO}_{2}=(150 \mathrm{~g} / \mathrm{L} \times 1.34 \mathrm{ml} \times 0.75)+(0.003 \times 40 \mathrm{~mm} \mathrm{Hg}) \sim 150 \mathrm{ml} / \mathrm{L} \\
\operatorname{VO}_{2}=5 \mathrm{l} / \mathrm{min} \times(200 \mathrm{ml} / \mathrm{L}-150 \mathrm{ml} / \mathrm{L}) \sim 250 \mathrm{ml} / \mathrm{min}
\end{gathered}
$$

Oxygen extraction:

OER: $250 \mathrm{ml} / \mathrm{min} / 1000 \mathrm{ml} / \mathrm{min} \times 100=25 \%$ 
Looking at these equations it becomes obvious that the main difference between $\mathrm{DO}_{2}$ and $\mathrm{VO}_{2}$ is the oxygen content $\left(\mathrm{CaO}_{2}\right.$ vs. $\left.\mathrm{CvO}_{2}\right)$, especially the venous oxygen saturation (this can either be mixed venous, $\mathrm{SvO}_{2}$, or central venous, $\mathrm{ScvO}_{2}$ ), which is the most prominent parameter that is different on the venous side, therefore, theoretically it can be useful to assess the imbalance between $\mathrm{DO}_{2}$ and $\mathrm{VO}_{2}$, often present in the critically ill patients. For more details, please see the following paragraphs. The most common causes of these disturbances are listed in Figure 1.

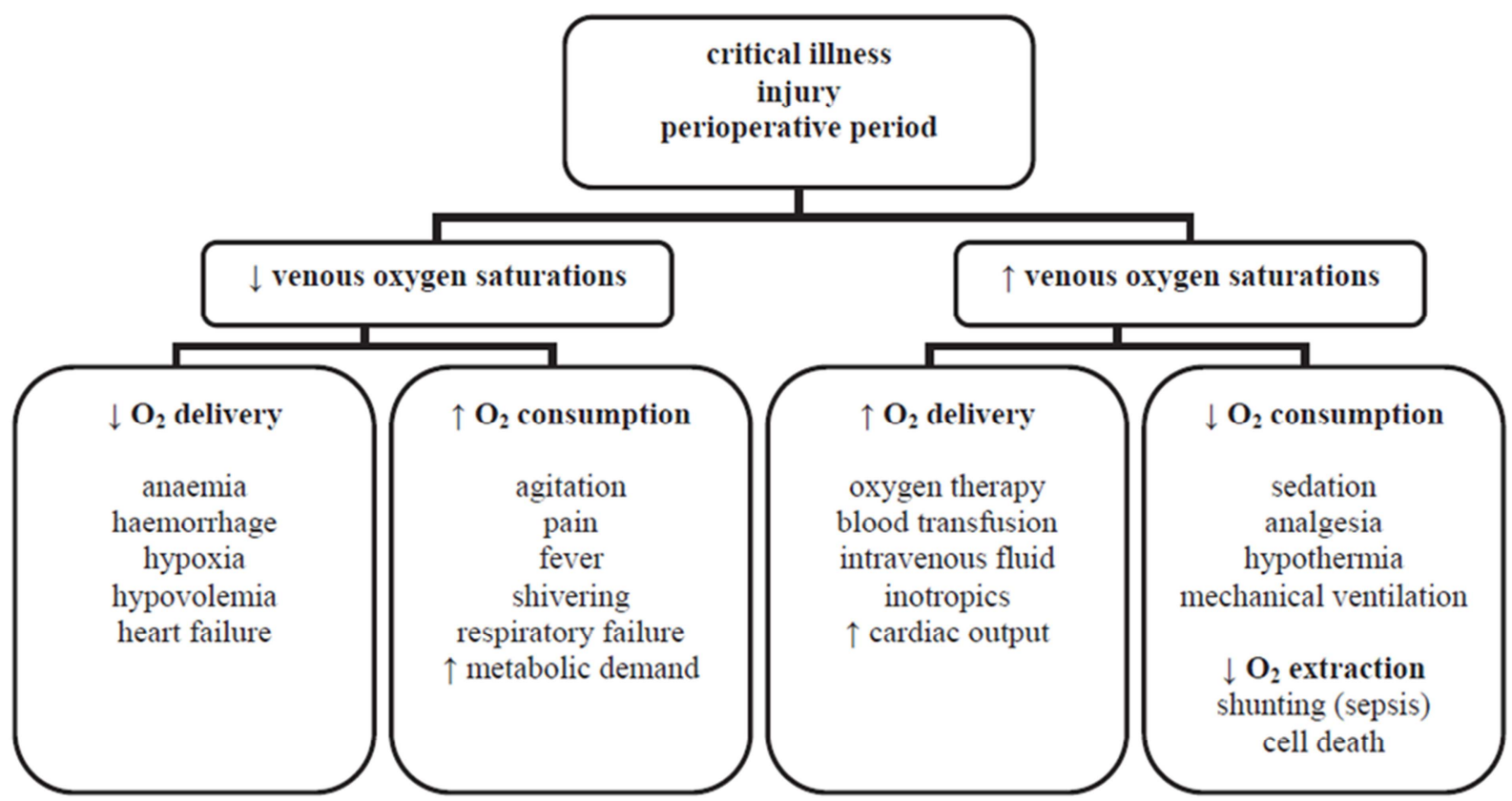

Figure 1. Multiple physiologic, pathologic and therapeutic factors may influence the value of central venous oxygen saturation.

Figure 1. Determinants of disturbances in oxygen utilization (Van Beest et al., 2011)

When $\mathrm{DO}_{2}$ is decreasing, due to several compensatory mechanisms, oxygen extraction is maintained for a considerable length of time. However, after a certain period compensatory mechanisms become exhausted, and beyond that critical point $\mathrm{VO}_{2}$ becomes delivery dependent (Figure 2). On this steep part of the oxygen extraction curve, $\mathrm{ScvO}_{2}$ is decreasing, while anaerobic processes are overwhelmed. Due to this processes lactate production increases, and if urgent intervention is delayed, tissue hypoxia and organ disfunction can develop (Figure 2). 


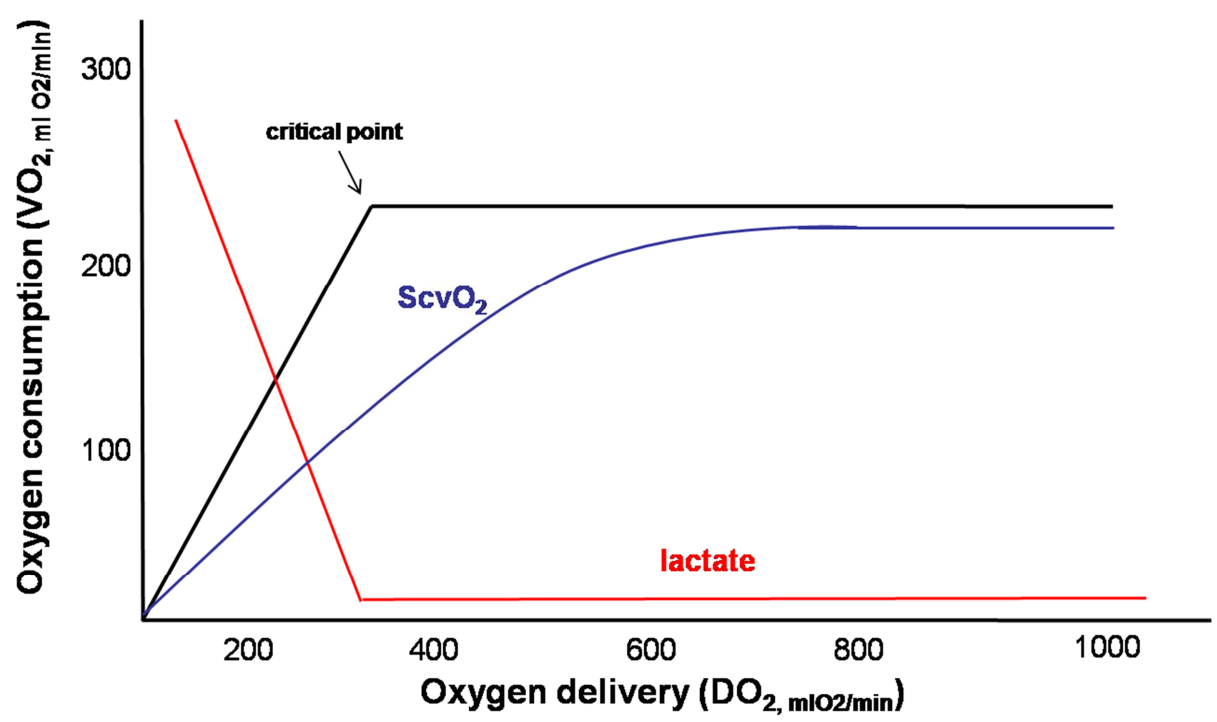

Figure 2: Relationship between oxygen delivery and consumption. $\mathrm{DO}_{2}$ - oxygen delivery, $\mathrm{VO}_{2}-$ oxygen consumption, $\mathrm{ScvO}_{2}$ - central venous oxygen saturation, (Rivers et al., 2012)

\section{Monitoring of tissue oxygenation}

\section{Mixed venous oxygen saturation - Central venous oxygen saturation}

Mixed venous oxygen saturation $\left(\mathrm{SvO}_{2}\right)$ is the fraction of oxygenated hemoglobin to hemoglobin content measured in the pulmonary artery, which detects changes in the balance between $\mathrm{DO}_{2}$ and $\mathrm{VO}_{2}$ of the whole body (Rivers et al., 2001). Measurement of $\mathrm{SvO}_{2}$ is not feasible in the everyday clinical practice, because for sampling, a pulmonary artery catheter must be placed in situ, which is a time consuming, complicated procedure with significant risks (Evans et al., 2009). On the contrary, central venous oxygen saturation $\left(\mathrm{ScvO}_{2}\right)$ measured in the superior vena cava is a good alternative of $\mathrm{SvO}_{2}$ and has become a daily routine not only in intensive and critical care medicine but in anesthesiology as well (Dueck et $a l$. 2005). It requires a central venous catheter in the subclavian or internal jugular vein. The tip of the catheter must be positioned at the superior vena cava a couple of centimeters above the right atrium. The normal value of $\mathrm{ScvO}_{2}$ ranges between $67-77 \%$ which is $5-8 \%$ higher compared to $\mathrm{SvO}_{2}$ (Reinhart et al., 2004). Although in absolute values these are not interchangeable, but their trends show good correlation in various disease states (Reinhart et $a l ., 1989$ ). Both increased $\mathrm{VO}_{2}$ and decreased $\mathrm{DO}_{2}$ can lower $\mathrm{ScvO}_{2}$. Oxygen extraction can be described as: 


$$
\mathrm{OER}=\mathrm{VO}_{2} / \mathrm{DO}_{2}
$$

If we simplify the equations of oxygen delivery and consumption, what has already been mentioned in the previous paragraphs) we get the following:

$$
\mathrm{OER}=\left(\mathrm{SaO}_{2}-\mathrm{ScvO}_{2}\right) / \mathrm{SaO}_{2}
$$

if we suppose that $\mathrm{SaO}_{2}=1$, which is normally the case in healthy subjects, than:

$$
\mathrm{OER}=1-\mathrm{ScvO}_{2}
$$

This equation clearly shows, that central venous oxygen saturation can mirror the balance between $\mathrm{DO}_{2}$ and $\mathrm{VO}_{2}$ (Vallet et al., 2010).

\section{Lactate metabolism}

In a healthy person at about 1500 mmol lactate is produced daily, which is metabolized resulting in a steady state level of less than $2 \mathrm{mmol} / \mathrm{l}$ in the blood (Levy., 2006).High lactate levels are often present in critically ill patients and generally considered as a very important alarming sign of oxygen debt, hypoperfusion and shock. However, reasons of high lactate levels are multifactorial. Wood and Cohen classified hyperlactatemia to type-A, where lack of oxygen or low oxygen transport capacity is responsible, like in the different shock states. Hypoxia inhibits pyruvate dehydrogenase, the enzyme, responsible for transformation of pyruvate to acetyl coenzyme A, which can enter into the Szent-Györgyi-Krebs cycle (Figure 3). The overproduction of pyruvate shifts the breakdown processes to the formation of lactate. During this process only 2 molecules of adenosine triphospate and lactate are produced. Therefore, high blood lactate level mirrors intracellular hyperlactatemia. Among critically ill patients high lactate levels are strong predictors of morbidity and mortality (Mikkelsen et al., 2009). During type B hyperlactatemia patients have persistent high lactate levels without the evidence of cellular hypoxia. In type-B-1 due to underlying diseases, lactate production is generally increased. Malignant tumors and hematological malignancies are also accompanied with altered energy production, which is due to mitochondrial dysfunction (Friedenberg et al., 2007; Field et al., 1966; Baysal et al., 2000). There is growing evidence that pyruvate dehydrogenase is partially attenuated by the pyruvate dehydrogenase kinase, so various tissues can become lactate producers without oxygen debt, like the lungs during acute lung injury (Brown et al., 1996). 
Drugs and toxins are responsible for increased lactate production in the type-B-2 subgroup of hyperlactatemias. Among the most often used medications metformin, propofol, catecholamines can increase lactate production (Fodale et al., 2008; Misbin et al., 1977), while intoxications like acetaminophen, cocaine and amphetamine overdose and abuse can also increase lactate levels (Giammarco et al., 1987). Thiamine, biotin and iron deficiency may also cause augmented lactate production (Finch et al., 1979; Mukunda et al., 1999). During type-B-3 hyperlactatemia inborn errors of metabolism increase lactate levels. Mostly syndromes like MELAS (mitochondrial encephalomyopathy, lactic acidosis, and stroke syndrome), Pearson syndrome are in the background (DiMauro et al., 2003). During these pathophysiological states two molecules of adenosine triphosphate are produced, instead of conventional energy production where the net endproducts are 38 ATP molecules. Hyperlactatemia can also be present when its breakdown in the Cori-cycle, in the liver and the kidneys is impaired. During shock states, where the liver's perfusion is severely diminished, the liver becomes a huge lactate producing organ instead of a large consumer (Barrie et al., 2006). The kidneys are the other important organs involved in lactate metabolism. When kidney function is intact during exogenous hyperlactatemia $25-30 \%$ of lactate is eliminated by the kidneys (Mizock et al., 1992). During the clearance, lactate oxidation and gluconeogenesis plays a major, while urinary excretion only a minor role, because the excretion threshold is over $6 \mathrm{mmol} / \mathrm{l}$ (Barrie et al., 2006). Permanent hyperlactatemia can be seen by patients with severe acute liver failure or chronic end stage liver disease (Taurá et al., 2006). On the other side lactate can be considered as a very important intermediate energy source for many tissues, like neurons, cardiac striated muscles or brain where lactate dehydrogenase can convert it back to pyruvate. During the gluconeogenesis in the Cori-cycle, the liver and the kidneys converts lactate to glucose with energy investment (Levraut et al., 1998). So the summation of lactate production and breakdown determines the lactate clearance throughout the time course of the diseases. 


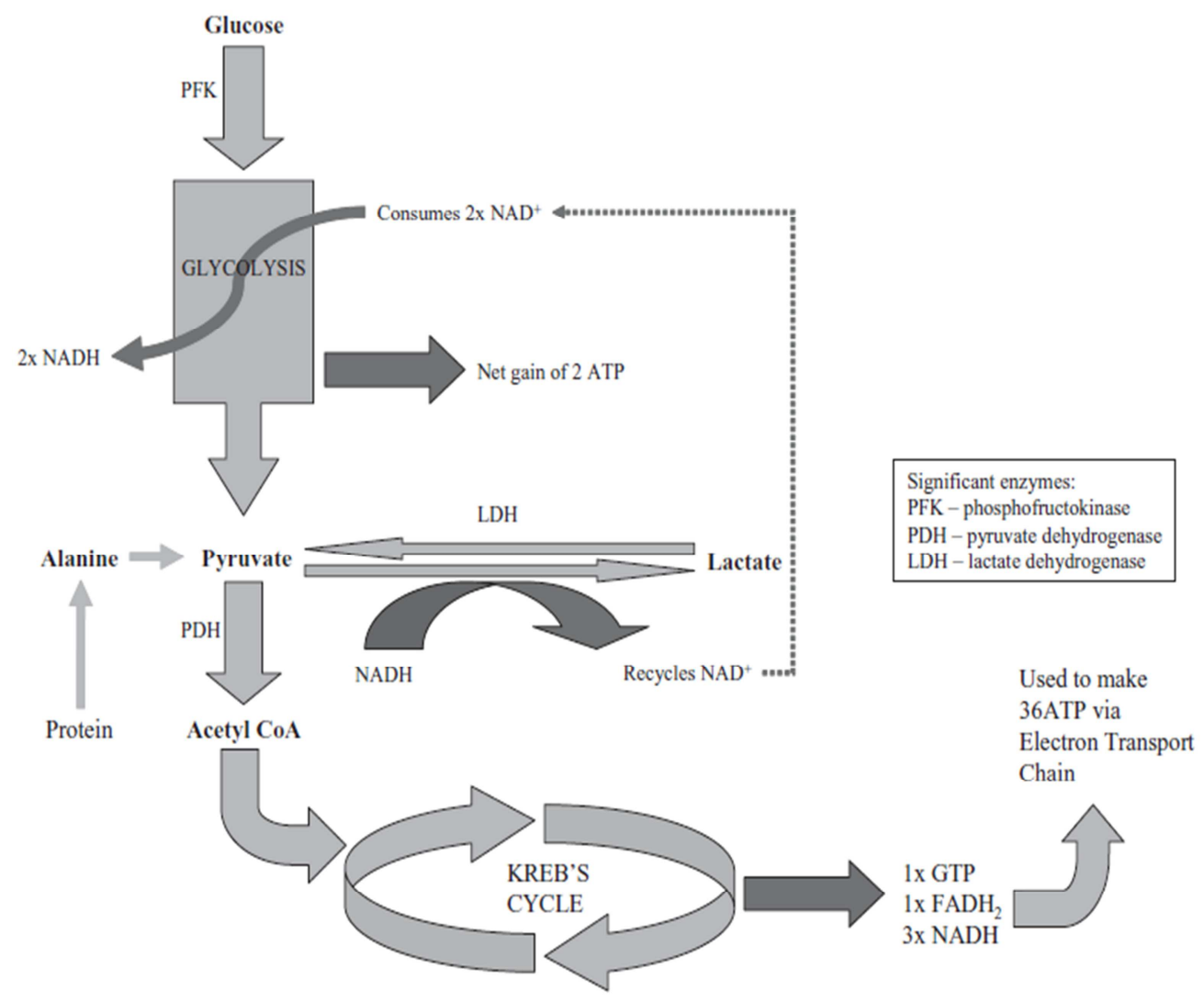

Figure 3: Energy production from glucose (Phypers et al., 2006). 


\section{Venous to arterial carbon dioxide gap}

Venous to arterial carbon dioxide gap $\left(\mathrm{dCO}_{2}\right)$ is an easily attainable blood gas driven parameter, when a central venous catheter and an arterial catheter are available. It can be calculated by extracting central venous partial pressure of carbon dioxide from the arterial partial pressure of carbon dioxide. Physiologically its value is under $6 \mathrm{mmHg}$ (Mekontso et $a l .$, 2002). The main determinants of $\mathrm{dCO}_{2}$ are carbon dioxide production, cardiac output and metabolism. Carbon dioxide is transported in the blood in dissolved forms as bicarbonate and bound to proteins. As carbon dioxide has a good solubility as compared to oxygen, the dissolved form plays more important role in the transport capacity as in the case of oxygen. The carbon dioxide-bicarbonate transformation is accelerated in the red blood cells by the carbonic anhydrase enzyme. Carbon dioxide is also bound to proteins, mainly to hemoglobin molecules. During the Haldane effect reduced hemoglobin has better affinity to carbon dioxide, compared to oxygenated hemoglobin. Due to this phenomenon carbon dioxide uptake in the tissues and transmission in the lungs are improved.

The Fick equation applied to carbon dioxide is as following:

$$
\mathrm{VCO}_{2}=\mathrm{CO} \times\left(\mathrm{CcvCO}_{2}-\mathrm{CaCO}_{2}\right)
$$

Under physiological circumstances there is a strong relationship between blood carbon dioxide content and the partial pressure of carbon dioxide (Giovannini et al., 1993). So $\mathrm{CvCO}_{2}-\mathrm{CaCO}_{2}$ can be replaced as $\mathrm{k} \times \mathrm{PcvCO}_{2}-\mathrm{PaCO}_{2}$ in the Fick equation and applied as following if " $\mathrm{k}$ " is constant:

$$
\begin{gathered}
\mathrm{VCO}_{2}=\mathrm{CO} \times \mathrm{k} \mathrm{x}\left(\mathrm{PcvCO}_{2}-\mathrm{PaCO}_{2}\right) \\
\mathrm{PcvCO}_{2}-\mathrm{PaCO}_{2}=\mathrm{k} \times \mathrm{VCO}_{2} / \mathrm{CO}
\end{gathered}
$$

This equation shows that $\mathrm{dCO}_{2}$ is proportional with carbon dioxide production and inversely related to cardiac output. The relationship is inverse and can be described as curvilinear. In high cardiac output states reduction of cardiac output results small changes in $\mathrm{dCO}_{2}$, whereas 
in low cardiac output states a small decrease in cardiac output leads to a huge increase in $\mathrm{dCO}_{2}$ (Lamia et al.,2006; Figure4).

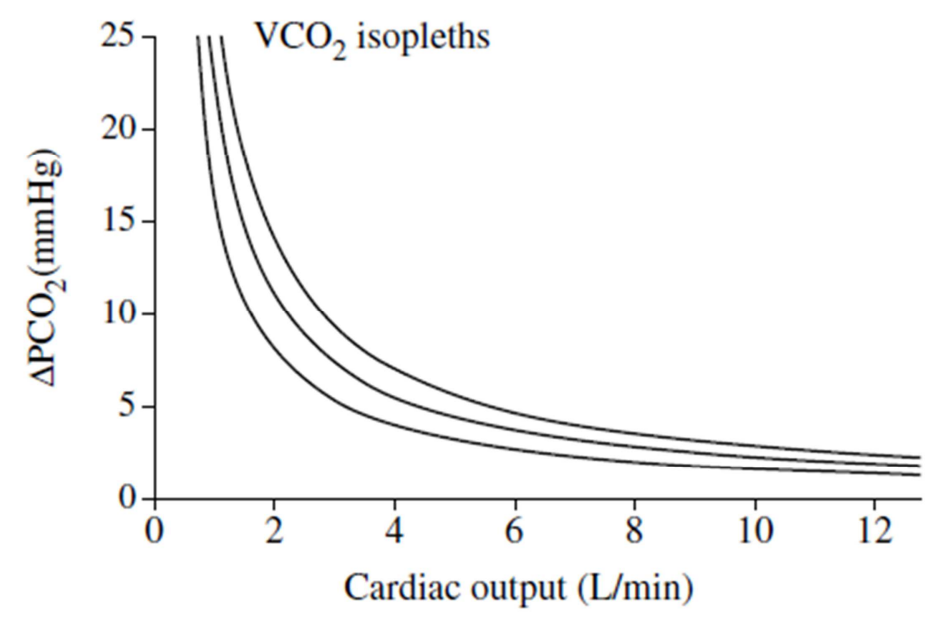

Figure 4: Modified Fick equation: relationship between $\mathrm{dCO}_{2}$ and cardiac output. The different isophleths represent these relationship in various metabolic states (various carbon dioxide production). (Lamia et al., 2006)

When sufficient oxygen is available, carbon dioxide is the end product of the Szent-GyörgyiKrebs cycle and terminal oxidation. In anaerobic conditions, under tissue hypoxia, hydrogen ions are in minority through lactate production and mainly by the hydrolysis of adenosine triphosphate. These hydrogen ions are buffered with the bicarbonate buffer system through the carbonic anhydrase enzyme. As mentioned above, under sufficient flow carbon dioxide is washed out from the tissues, resulting normal $\mathrm{dCO}_{2}$, while during low flow states blood has a longer transit time so it can take up more carbon dioxide. This is called the "stagnation phenomenon", hence the gap is increased (Neviere et al., 2002).

\section{Fluid resuscitation of critically ill patients}

One of the major determinants of $\mathrm{DO}_{2}$ is cardiac output, which is influenced by the changes of stroke volume and heart rate. According to the Frank-Starling law, the cardiac function curves are determined by the relationship between preload and stroke volume (Figure5). On the steep part of the curve, small changes of preload can increase or decrease stroke volume. This is called volume responsiveness (Figure 5., red dotted lines). When the operating point is on the flat part of the curves this influence is neglible, hence the patient is volume unresponsive (Figure 5., blue dotted lines). 


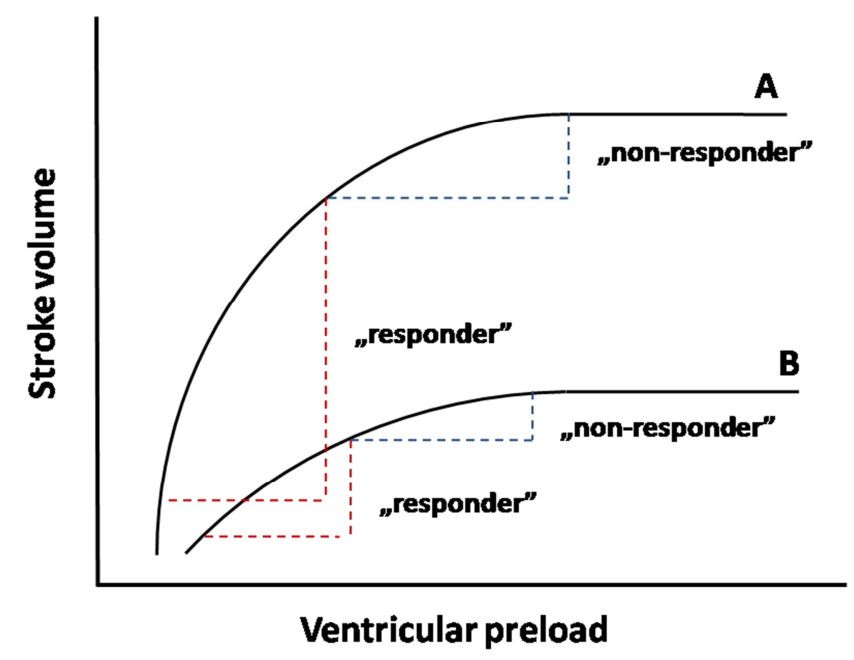

Figure 5: The relationship of fluid responsiveness and the Frank Starling law with different cardiac function curves on normal (A) and failing heart (B). See text for explanation.

This has major impact in our everyday clinical practice. As it was explained earlier, under-, and over-resusucitation can both be potentially harmful, therefore, as precise evaluation of the relationship of stroke volume and preload as possible is mandatory to assess fluid responsiveness, hence manage fluid resuscitation for the patients' actual needs. The main goal of fluid resuscitation is to increase stroke volume, hence cardiac output and eventually oxygen delivery. In other words, the only reason why patients need fluid is, that by improving stroke volume oxygen delivery to the cells is also increased. As it is nicely shown in Figure 5, the pattern of the patient's individual Frank-Starling curve, and also the position of the patient on this curve,fundamentally determine whether the patient will respond to fluid administration or not. If the patient is on the steep part of the Frank-Starling curve, then fluid boluses will increase both preload and stroke volume, hence these patients are "fluid responders". However, if the patient is on the flat part of the curve, fluid administration may increase the value of any preload parameter, but this change will not be accompanied by an increase in stroke volume, hence these are "fluid non-responders". This provides the physiological rationale and the importance of measuring cardiac output and stroke volume in certain high risk patients. 


\section{Blood transfusion}

When bleeding is persent, not only fluid, but also hemoglobin is lost. That plays a crucial role in the development of the imbalance between $\mathrm{DO}_{2}$ and $\mathrm{VO}_{2}$. Fluid replacement can restore the circulating blood volume, but due to hemodilution, the decreased hemoglobin level can also impair oxygen delivery. To restore $\mathrm{DO}_{2}$, packed red blood cell has to be administered, which is also a double edge sword. On the one hand it can be life saving, but carries all the risks of allogenic blood transfusion. Therefore, physicans face two very important questions: 1) which parameter to use as transfusion trigger, and 2) how to asses the efficacy of blood transfusion? In the past arbitrary cut offs were determined like the "10/30" rule, where the hemoglobin level had to be over $100 \mathrm{~g} / \mathrm{l}$, and the hematocrit over 30 percent (Wang et al., 2010). This regimen was replaced by a so called restrictive strategy, where hemoglobin levels were targeted to be between 70-100 g/l depending on disease etiology, i.e.: lower levels were accepted in healthy subjects and higher were aimed in patients with cardiac co-morbidities (Napolitano et al.,2009). Recent clinical investigations and experimental studies shows that alternative transfusion triggers like $\mathrm{ScvO}_{2}$, electrocardiogram ST-segment analysis, or regional tissue oxymetry can help the physicians to optimize the hemoglobin level according to the needs of specific organs in the cross section of blood loss, replacement and underlying diseases (Torella et al., 2002; Kocsi et al., 2014). 


\section{Aims of our experiments}

Despite all the above detailed pathophysiological rationale and decades of intensive research, there is no worldwide consensus about the goals, which should be targeted during fluid replacement. Therefore, we decided to design a bleeding-resuscitation experimental animal model and our aims were the following:

1. To describe the kinetics of $\mathrm{ScvO}_{2}, \mathrm{dCO}_{2}$ and lactate and to test their usefulness as therapeutic endpoints during a moderate hemorrhage and resuscitation animal experiment.

2. To investigate the role of $\mathrm{dCO}_{2}$ as hemodynamic parameter and $\mathrm{ScvO}_{2}$ as a marker of oxygen extraction as complementary tools for transfusion trigger during hemorrhage and fluid resuscitation.

3. To compare the effects of stroke volume index-, as compared to cardiac index-guided resuscitation on $\mathrm{ScvO}_{2}$ and $\mathrm{dCO}_{2}$ in a controlled hemorrhage and fluid resuscitation model. 


\section{Materials and methods}

The experiments were carried out in strict adherence to the NIH guidelines for the use of experimental animals and the study was approved by the Ethical Committee for the Protection of Animals in Scientific Research at the University of Szeged, with the license number: V./142/2013.

\section{Animals and Instrumentation}

The experiments were performed on Vietnamese mini-pigs. Anesthesia was induced by intramuscular injection of a mixture of ketamine $(20 \mathrm{mg} / \mathrm{kg})$ and xylazine $(2 \mathrm{mg} / \mathrm{kg})$ and maintained with a continuous infusion of propofol $(6 \mathrm{mg} / \mathrm{kg} / \mathrm{hr}$ i.v. $)$, while analgesia was maintained with nalbuphine $(0.1 \mathrm{mg} / \mathrm{kg})$. A tracheal tube was inserted and the animals' lungs were ventilated mechanically with Harvard Apparatus Dual Phase Control Respirator (Harvard Apparatus, South Natick, MA). The tidal volume was set at $10 \mathrm{ml} / \mathrm{kg}$, and the respiratory rate was adjusted to maintain the end-tidal carbon dioxide and partial pressure of arterial carbon dioxide in the range of $35-45 \mathrm{mmHg}$ and the arterial $\mathrm{pH}$ between 7.35 and 7.45. The adequacy of the depth of anesthesia was assessed by monitoring the jaw tone. After induction of anesthesia, the right jugular vein and the right femoral artery and vein were dissected and catheterized. The central venous catheter was positioned by the guidance of intracavital ECG. Animals were kept warm $\left(37 \pm 1^{\circ} \mathrm{C}\right)$ by an external warming device.

For invasive hemodynamic monitoring, a transpulmonary thermodilution catheter (PiCCO, PULSION Medical Systems SE, Munich, Germany) was placed in the femoral artery. The femoral artery served as the site for arterial blood gas sampling and the central venous line was used for taking central venous blood gas samples and for the injection of cold saline boluses for the thermodilution measurements. 


\section{Hemodynamic and blood gas measurements}

Stroke volume (SV), heart rate (HR), mean arterial pressure (MAP), cardiac output (CO), global end-diastolic volume (GEDV), stroke volume variation (SVV), pulse pressure variation (PPV), left ventricular contractility $(\mathrm{dPmx})$ and systemic vascular resistance (SVR) were measured by transpulmonary thermodilution and/or pulse contour analysis at baseline and after equilibration of each step. All hemodynamic parameters were indexed for body surface area. The average of three random measurements following $10 \mathrm{ml}$ bolus injections of ice-cold $0.9 \%$ saline were recorded. Central venous pressure (CVP) was measured invasively. Arterial and central venous blood gas samples were collected and analyzed simultaneously by cooximetry (Cobas b 221, Roche Ltd., Basel, Switzerland) at baseline and at the end of each step, $\mathrm{ScvO}_{2}$ and $\mathrm{dCO}_{2}$ were determined. From these parameters the following variables were calculated:

$$
\begin{gathered}
\text { Delivery of oxygen }\left(\mathrm{DO}_{2}\right)=\mathrm{CI} \times\left(\mathrm{Hb} \times 1.34 \times \mathrm{SaO}_{2}+0.003 \times \mathrm{PaO}_{2}\right) \\
\mathrm{DO}_{2}=\mathrm{CI} \times \mathrm{CaO}_{2} \\
\text { Oxygen consumption }\left(\mathrm{VO}_{2}\right)=\mathrm{CI} \times\left(\mathrm{CaO}_{2}-\left(\mathrm{Hb} \times 1.34 \times \mathrm{ScvO}_{2}+0.003 \times \mathrm{PcvO}_{2}\right)\right) \\
\text { Oxygen extraction }=\mathrm{VO}_{2} / \mathrm{DO}_{2}
\end{gathered}
$$

\section{Stroke volume guided bleeding and fluid resuscitation:Experiment-1}

The flowchart of the experiment is summarized in Figure 6. After catheterizations, animals were allowed to rest for 30 minutes after which baseline $\left(T_{b s l}\right)$ hemodynamic measurements, blood gas analysis and laboratory testing were performed. After these measurements, blood was drained until the stroke volume index (SVI) dropped by $50 \%$ of its baseline value $\left(\mathrm{T}_{0}\right)$, then measurements were repeated. The difference of the $\mathrm{SVI}_{\mathrm{bsl}}-\mathrm{SVI}_{\mathrm{T} 0}$ was divided into four equal target values, which was aimed to reach in 4 steps during fluid resuscitation $\left(\mathrm{T}_{1-4}\right)$ to reach the initial SVI by $\mathrm{T}_{4}$. Fluid replacement was carried out with boluses of balanced crystalloid Lactated Ringer (B. Braun AG., Melsungen, Germany). After reaching each step, 20 minutes were allowed for equilibrium, than hemodynamic and blood gas parameters were measured. 


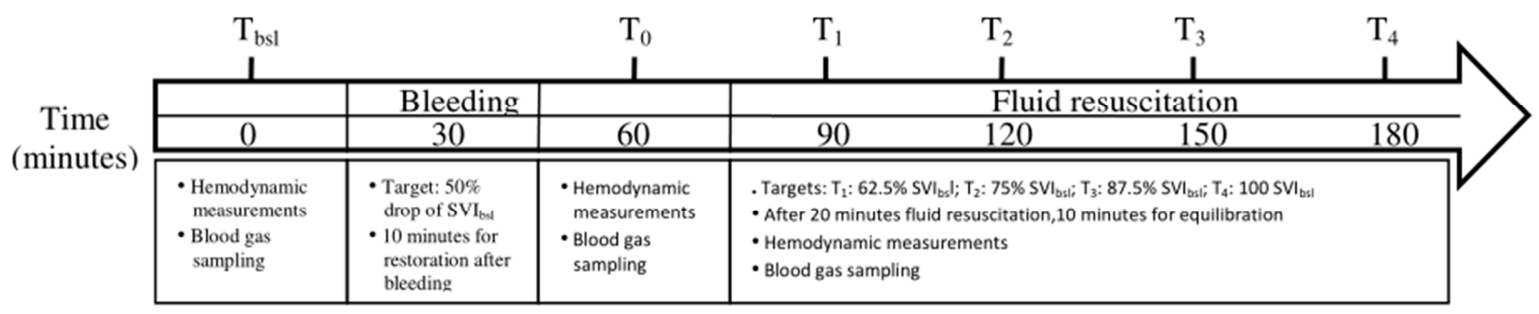

Figure 6. Schematic diagram illustrating the flow chart of the experiment. Following baseline measurements animals were bled until a 50\% drop in the stroke volume occured. After dividing the difference of the $\mathrm{T}_{\mathrm{bsl}}$ and $\mathrm{T}_{0}$ stroke volume in to 4 steps animals are resuscitated to $\mathrm{T}_{\mathrm{bsl}}$ stroke volume.

\section{Stroke volume guided bleeding and cardiac index targeted fluid resuscitation: Experiment-2}

The animals were instrumented and monitored the same way as described in the previous experiment. The flowchart is summarized in Figure 7. After the instrumentation, animals were allowed to rest for 30 minutes after which baseline $\left(\mathrm{T}_{\mathrm{bsl}}\right)$ hemodynamic, blood gas measurement, and laboratory testing were performed. Thereafter, blood was drained until the stroke volume index dropped by $50 \%$ of its baseline value $\left(\mathrm{T}_{0}\right)$; then measurements were repeated. Pigs were resuscitated in the same pattern as in Experiment- 1 except, this time baseline cardiac index was target of resuscitation.

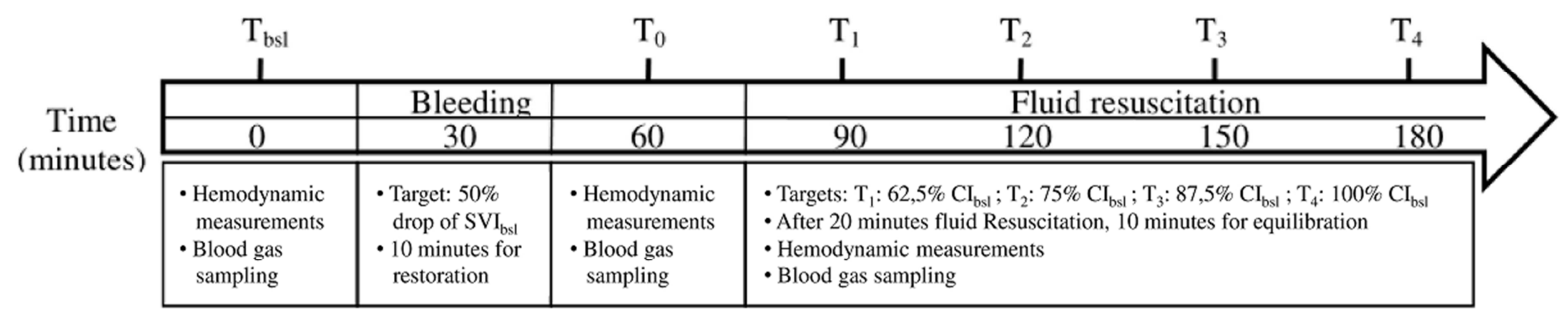

Figure 7.Schematic diagram illustrating the flowchart of the experimental protocol. After baseline measurement, animals were bled until the stroke volume index (SVI) decreased by $50 \%\left(\mathrm{~T}_{0}\right)$, then measurements were repeated and the difference of the $\mathrm{CI}_{\mathrm{Tbs}}{ }^{-}-\mathrm{I}_{\mathrm{T} 0}$ was divided into 4 target values and then the animals were resuscitated in 4 steps in order to reach the $\mathrm{CI}_{\mathrm{Tbsl}}$ by $\mathrm{T}_{4}$.

\section{Data analysis and statistics}

Data are presented as mean \pm standard deviations unless indicated otherwise. For testing normal distribution the Kolmogorov-Smirnov test was used. Changes in all parameters throughout the experiment were tested by repeated measures analysis of variance (RM 
ANOVA). For pairwise comparisons Pearson's correlation was used. Post hoc calculation showed a power of 0.90 with an effect of $10 \%$ drop in the $\mathrm{ScvO}_{2}$ following hemorrhage for a sample size of 12 and $\alpha<.05$. For statistical analysis SPSS version 18.0 for Windows (SPSS, Chicago, IL) was used and $\mathrm{p}<0.05$ was considered statistically significant. 


\section{Results}

\section{Stroke volume based fluid resuscitation: Experiment-1}

12 animals weighing $23 \pm 5 \mathrm{~kg}$ underwent a 6-hr fast preoperatively but with free access to water.During bleeding $314 \pm 65 \mathrm{ml}$ blood had to be drained to reach the target of $50 \%$ reduction in SVI. For resuscitation, $951 \pm 307 \mathrm{ml}$ crystalloid infusion was administered in total by $\mathrm{T}_{4}$ to achieve the target value obtained at $\mathrm{T}_{\mathrm{bsl}}$.

\section{Measures of Oxygen Debt}

Parameters of $\mathrm{DO}_{2}$ and $\mathrm{VO}_{2}$ are summarized in Table $1 . \mathrm{DO}_{2}$ decreased after bleeding and remained lower as compared to $\mathrm{T}_{\mathrm{bsl}}$ despite improvement during resuscitation. Hemoglobin levels also decreased from $\mathrm{T}_{\mathrm{bsl}}$ to $\mathrm{T}_{0}$, and remained lower at the end of resuscitation as compared to $\mathrm{T}_{\mathrm{bs}}$. $\mathrm{VO}_{2}$ increased after bleeding, and although remained elevated until the end of the experiment, it did not reach statistical significance. Oxygen extraction $\left(\mathrm{VO}_{2} / \mathrm{DO}_{2}\right)$ also increased by $\mathrm{T}_{0}$, and improved during resuscitation, however it did not return to its baseline value by $\mathrm{T}_{4}$. Lactate levels increased from $\mathrm{T}_{\mathrm{bsl}}$ to $\mathrm{T}_{0}$ and remained elevated throughout the experiment with a non-significant decrease from $\mathrm{T}_{0}$ to $\mathrm{T}_{4}$.

The pattern of $\mathrm{ScvO}_{2}$ showed similar trends as seen in $\mathrm{VO}_{2} / \mathrm{DO}_{2}$. Levels decreased from $\mathrm{T}_{\mathrm{bsl}}$ to $\mathrm{T}_{0}$ and increased by $\mathrm{T}_{4}$. Although $\mathrm{ScvO}_{2}$ normalized by $\mathrm{T}_{4}$, but it remained lower as compared to $\mathrm{T}_{\mathrm{bsl}}$ with a mean difference of $5 \%$.

$\mathrm{dCO}_{2}$ increased almost two fold of his initial value during hemorrhage and decreased gradually during fluid replacement. At the end of the experiment it returned to the physiological range.

There was significant correlation between stroke volume index and $\mathrm{ScvO}_{2}$ and $\mathrm{dCO}_{2}$ (Figure 8-9). There was also a strong significant negative correlation between $\mathrm{dCO}_{2}$ and oxygen extraction (Figure 10). 
Table 1 Blood gas parameters during stroke volume guided hemorrhage and fluid resuscitation

\begin{tabular}{|c|c|c|c|c|c|c|}
\hline & $\mathrm{T}_{\mathrm{bsl}}$ & $\mathrm{T}_{0}$ & $\mathrm{~T}_{1}$ & $\mathrm{~T}_{2}$ & $\mathrm{~T}_{3}$ & $\mathrm{~T}_{4}$ \\
\hline Stroke volume index $\left(\mathrm{ml} / \mathrm{m}^{2}\right)$ & $26.8 \pm 4.7$ & $13.4 \pm 2.3^{*}$ & $16.3 \pm 2.6^{* \#}$ & $19.2 \pm 3.5^{\#}$ & $22.3 \pm 4.1^{\#}$ & $26.6 \pm 4.1^{\#}$ \\
\hline Oxygen delivery index $\left(\mathrm{ml} / \mathrm{min} / \mathrm{m}^{2}\right)$ & $419 \pm 62$ & $272 \pm 56^{*}$ & $285 \pm 58^{*}$ & $305 \pm 47^{*}$ & $305 \pm 55^{*}$ & $341 \pm 62^{* \#}$ \\
\hline Oxygen consumption index $\left(\mathrm{ml} / \mathrm{min} / \mathrm{m}^{2}\right)$ & $77 \pm 26$ & $96 \pm 19^{*}$ & $89 \pm 15$ & $90 \pm 17$ & $82 \pm 31$ & $82 \pm 27$ \\
\hline Oxygen extraction $\left(\mathrm{VO}_{2} / \mathrm{DO}_{2}\right)$ & $0.20 \pm 0.07$ & $0.36 \pm 0.05^{*}$ & $0.33 \pm 0.07^{*}$ & $0.31 \pm 0.07^{*}$ & $0.28 \pm 0.09^{*}$ & $0.24 \pm 0.09^{*}$ \\
\hline Arterial $\mathrm{pH}$ & $7.50 \pm 0.63$ & $7.45 \pm 0.7$ & $7.42 \pm 0.6$ & $7.38 \pm 011^{*}$ & $7.44 \pm 0.42$ & $7.45 \pm 0.43$ \\
\hline Partial pressure of oxygen in arterial blood $(\mathrm{mm} \mathrm{Hg})$ & $84.5 \pm 8.1$ & $84.6 \pm 9.7$ & $84.9 \pm 11.8$ & $84.9 \pm 8.8$ & $83.0 \pm 8.8$ & $83.6 \pm 8.8$ \\
\hline Arterial oxygen saturation (\%) & $96.8 \pm 1.0$ & $96.2 \pm 1.7$ & $96.1 \pm 1.8$ & $96.5 \pm 1.1$ & $96.5 \pm 1.3$ & $96.4 \pm 1.4$ \\
\hline Venous to arterial carbon dioxide gap $(\mathrm{mmHg})$ & $5.3 \pm 2$ & $9.6 \pm 2.3^{*}$ & $8.9 \pm 1.7$ & $7.3 \pm 2.7$ & $6.7 \pm 2.6$ & $5.1 \pm 2.6^{\#}$ \\
\hline Lactate $(\mathrm{mmol} / \mathrm{L})$ & $1.62 \pm 0.43$ & $3.86 \pm 1.49^{*}$ & $4.75 \pm 1.88^{*}$ & $4.75 \pm 2.07^{*}$ & $4.17 \pm 2.06^{*}$ & $3.54 \pm 1.9^{*}$ \\
\hline Hemoglobin $(\mathrm{g} / \mathrm{L})$ & $12.05 \pm 1.37$ & $11.22 \pm 1.39^{*}$ & $10.6 \pm 1.52^{*}$ & $9.53 \pm 1.29^{*}$ & $8.58 \pm 1.49^{* \#}$ & $8.45 \pm 1.1^{\text {*\# }}$ \\
\hline
\end{tabular}

Table 1. Blood gas parameters during hemorrhage and fluid resuscitation.Data are expressed as mean \pm standard deviation; $*=(\mathrm{p}<0.05)$ significantly different from $\mathrm{t}_{\mathrm{bsl}}$; \#= $(\mathrm{p}<0.05)$ significantly different from $\mathrm{t}_{0}$ 


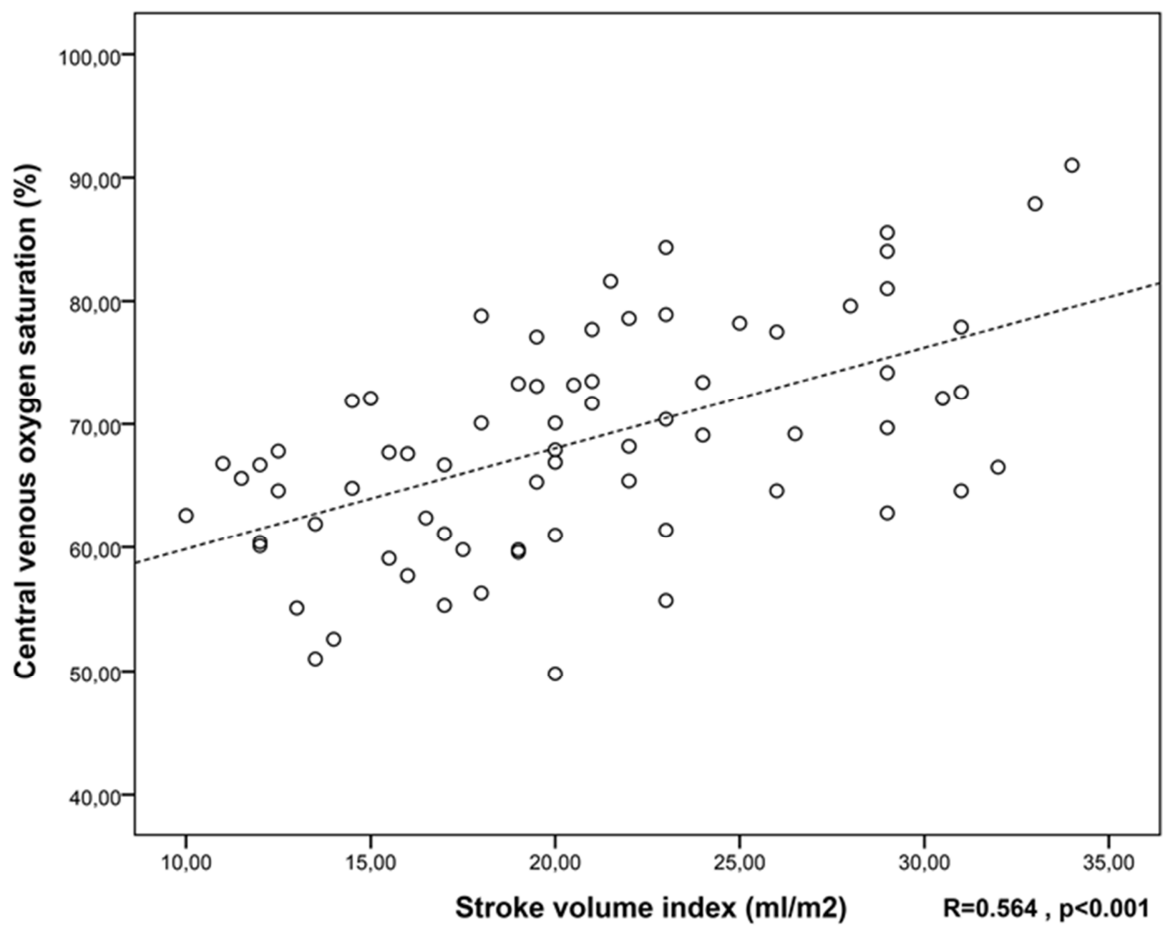

Figure 8. Correlation between stroke volume index and $\mathrm{ScvO}_{2}$

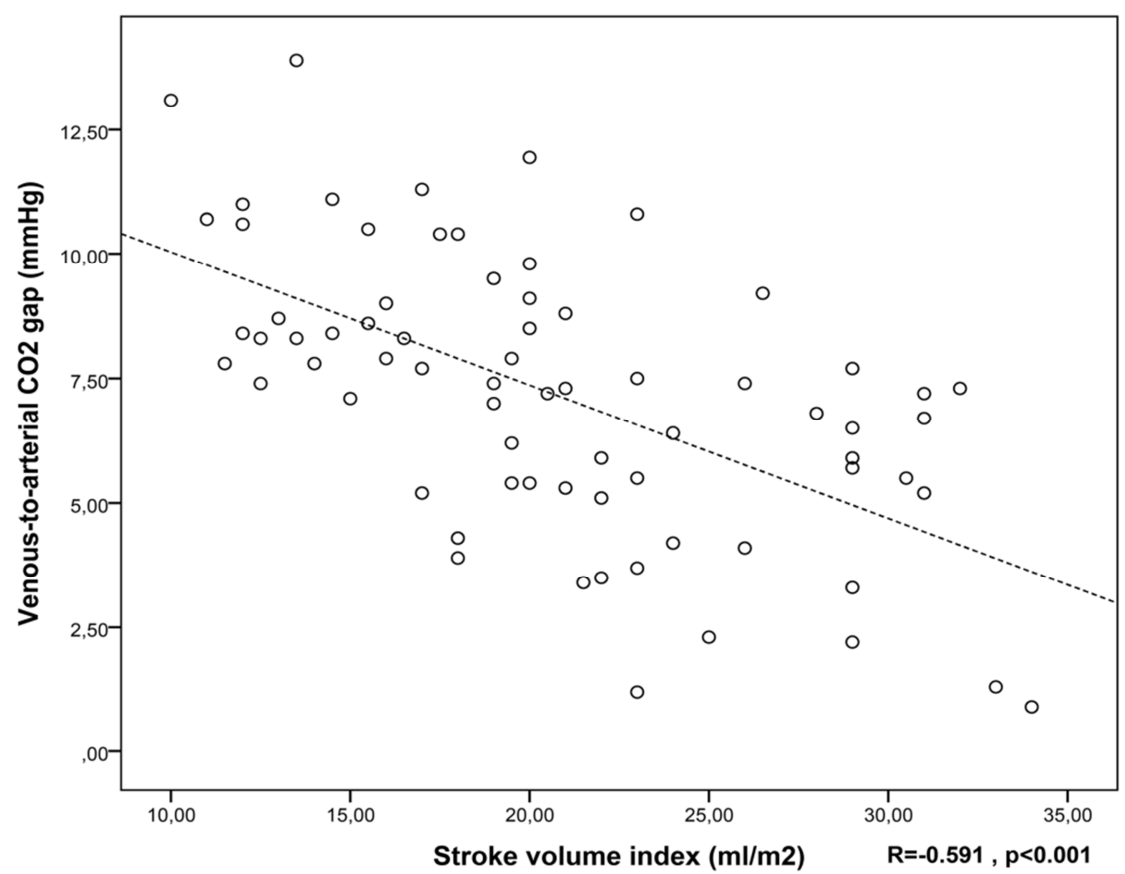

Figure 9. Correlation between stroke volume index and $\mathrm{dCO}_{2}$ 


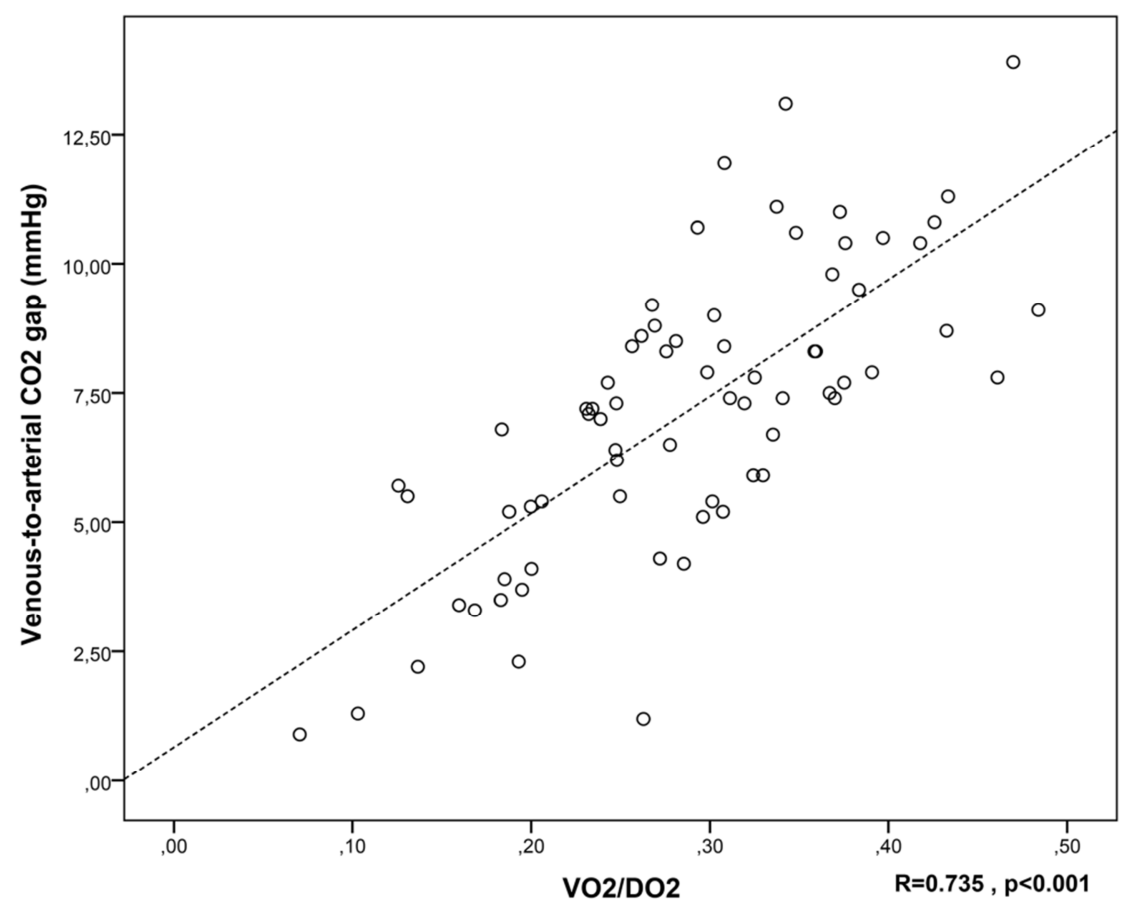

Figure 10. Correlation between $\mathrm{dCO}_{2}$ and $\mathrm{VO}_{2} / \mathrm{DO}_{2} \cdot \mathrm{VO}_{2} / \mathrm{DO}_{2}$ : oxygen extraction 


\section{Cardiac index based resuscitation: Experiment-2}

12 animals weighing $27.54 \pm 5.46 \mathrm{~kg}$ went through the same procedure like animals in experiment-1. For a 50\% decrease of SVI $479 \pm 101 \mathrm{ml}$ blood had to be drained and 900 (8501780) $\mathrm{ml}$ had to be replaced in the cardiac index based group to reach baseline cardiac index.

\section{Measures of Oxygen Debt}

During cardiac index based resuscitation at the end, $\mathrm{DO}_{2}$ remained significantly lower at $\mathrm{T}_{4}$ as compared to $\mathrm{T}_{\mathrm{bsl}}$ (Table 2). This can be partially explained by the significant and steady decrease in the hemoglobin level. $\mathrm{VO}_{2} / \mathrm{DO}_{2}$ increased after bleeding and showed a similar kinetic as in Experiment-1. Arterial pH, oxygen partial pressure and oxygen saturation remained stable throughout the experiment. $\mathrm{ScvO}_{2}$ was in the normal range at $\mathrm{T}_{\mathrm{bs}}$; while after bleeding there was a drop, which remained significantly lower at the end of the experiment. The mean decrease from $\mathrm{T}_{\text {bsl }}$ to $\mathrm{T}_{0}$ was $22.5 \%$ and at $\mathrm{T}_{4}$ it was $15.1 \%$ lower as compared to $\mathrm{T}_{\mathrm{bsl}}$.

$\mathrm{dCO}_{2}$ was normal at $\mathrm{T}_{\mathrm{bsl}}$, and after bleeding it increased significantly and although it remained elevated throughout the experiment, but at $\mathrm{T}_{2-4}$ his difference was not statistically significant as compared to $\mathrm{T}_{\mathrm{bs} l}$. 


\begin{tabular}{|c|c|c|c|c|c|c|c|}
\hline & Group & $\overline{T_{b s l}}$ & $\mathrm{~T}_{0}$ & $\mathrm{~T}_{1}$ & $\mathrm{~T}_{2}$ & $\mathrm{~T}_{3}$ & $\mathrm{~T}_{4}$ \\
\hline \multirow{2}{*}{ Stroke volume index $\left(\mathrm{ml} / \mathrm{m}^{2}\right)$} & SVI & $27.5 \pm 5.4$ & $13.8 \pm 2.6 *$ & $16.5 \pm 2.8 *$ & $19.5 \pm 3.7 *^{\#}$ & $23.6 \pm 5.1^{\#}$ & $28.0 \pm 5.0^{\#}$ \\
\hline & CI & $31.4 \pm 4.7$ & $14.4 \pm 9.0 *$ & $18.1 \pm 3.6 *$ & $19.2 \pm 3.6 *$ & $23.2 \pm 1.3 *^{\#}$ & $23.8 \pm 5.9 * \# @$ \\
\hline \multirow{2}{*}{ Cardiac index $\left(1 / \mathrm{min} / \mathrm{m}^{2}\right)$} & SVI & $2.6 \pm 0.3$ & $1.8 \pm 0.3 *$ & $2.1 \pm 0.4 *$ & $2.4 \pm 0.3^{\#}$ & $2.7 \pm 0.4^{\#}$ & $2.9 \pm 0.4 *^{\#}$ \\
\hline & $\mathrm{CI}$ & $2.8 \pm 0.3$ & $1.7 \pm 0.5 *$ & $2.1 \pm 0.3 *$ & $2.4 \pm 0.2^{\#}$ & $2.6 \pm 0.4^{\#}$ & $2.7 \pm 0.3^{\#}$ \\
\hline \multirow{2}{*}{$\begin{array}{l}\text { Oxygen consumption } \\
\text { (index } \mathrm{ml} / \mathrm{min} / \mathrm{m}^{2} \text { ) }\end{array}$} & SVI & $82 \pm 27$ & $118 \pm 63 *$ & $111 \pm 19$ & $102 \pm 24$ & $98 \pm 24$ & $94 \pm 23$ \\
\hline & CI & $71 \pm 43$ & $115 \pm 48 *$ & $111 \pm 29$ & $108 \pm 21$ & $103 \pm 18$ & $99 \pm 13$ \\
\hline \multirow{2}{*}{ Oxygen extraction $\left(\mathrm{VO}_{2} / \mathrm{DO}_{2}\right)$} & SVI & $0.20 \pm 0.06$ & $0.40 \pm 0.11 *$ & $0.36 \pm 0.06 *$ & $0.33 \pm 0.11 *$ & $0.29 \pm 0.09 *^{\#}$ & $0.27 \pm 0.13^{\#}$ \\
\hline & $\mathrm{CI}$ & $0.17 \pm 0.09$ & $0.40 \pm 0.18 *$ & $0.38 \pm 0.09 *$ & $0.36 \pm 0.08 *$ & $0.34 \pm 0.14 *$ & $0.33 \pm 0.11 *$ \\
\hline \multirow{2}{*}{ Arterial $\mathrm{pH}$} & SVI & $7.48 \pm 0.04$ & $7.46 \pm 0.07$ & $7.44 \pm 0.06$ & $7.41 \pm 0.11$ & $7.45 \pm 0.04$ & $7.46 \pm 0.04$ \\
\hline & $\mathrm{CI}$ & $7.44 \pm 0.04$ & $7.43 \pm 0.06$ & $7.42 \pm 0.05$ & $7.47 \pm 0.03$ & $7.42 \pm 0.05$ & $7.45 \pm 0.05$ \\
\hline \multirow{2}{*}{ Partial pressure of oxygen in arterial blood $(\mathrm{mmHg})$} & SVI & $94.5 \pm 26.5$ & $94.9 \pm 27.8$ & $90.1 \pm 20.2$ & $94.9 \pm 27.1$ & $93.1 \pm 27.1$ & $95.5 \pm 30.1$ \\
\hline & $\mathrm{CI}$ & $88.3 \pm 28.8$ & $89.8 \pm 28.8$ & $97.6 \pm 30.2$ & $89.2 \pm 22.5$ & $93.8 \pm 32.6$ & $88.2 \pm 27.6$ \\
\hline \multirow{2}{*}{ Arterial oxygen saturation (\%) } & SVI & $97.3 \pm 1.5$ & $96.7 \pm 2.1$ & $96.3 \pm 2.0$ & $97.0 \pm 1.5$ & $97.0 \pm 1.7$ & $96.9 \pm 1.8$ \\
\hline & $\mathrm{CI}$ & $95.4 \pm 3.6$ & $95.3 \pm 5.0$ & $96.1 \pm 4.2$ & $98.6 \pm 1.5$ & $95.6 \pm 4.8$ & $96.0 \pm 3.2$ \\
\hline \multirow{2}{*}{ Central venous oxygen saturation $(\%)$} & SVI & $77.4 \pm 6.6$ & $57.5 \pm 10.8 *$ & $60.9 \pm 4.8 *$ & $64.3 \pm 9.2 *$ & $68.4 \pm 8.6 *^{\#}$ & $72.9 \pm 7.5$ \\
\hline & $\mathrm{CI}$ & $79.2 \pm 8.1$ & $56.7 \pm 17.0 *$ & $58.5 \pm 10.6$ & $59.7 \pm 8.0$ & $63.0 \pm 14.7$ & $64.1 \pm 11.6$ \#@ \\
\hline \multirow{2}{*}{ Venous to arterial carbon dioxide gap ( $\mathrm{mmHg}$ ) } & SVI & $5.7 \pm 2.4$ & $10.1 \pm 2.6 *$ & $8.9 \pm 1.7$ & $7.5 \pm 2.4$ & $7.2 \pm 2.7$ & $5.3 \pm 2.3^{\#}$ \\
\hline & $\mathrm{CI}$ & $4.0 \pm 3.1$ & $9.9 \pm 6.0 *$ & $8.8 \pm 2.4 *$ & $8.5 \pm 3.0$ & $8.1 \pm 3.1$ & $7.6 \pm 4.3$ \\
\hline \multirow{2}{*}{ Lactate $(\mathrm{mmol} / \mathrm{l})$} & SVI & $2.54 \pm 1.01$ & $3.97 \pm 1.80 *$ & $4.72 \pm 2.29 *$ & $4.37 \pm 2.37 *$ & $3.90 \pm 2.25 *$ & $3.26 \pm 1.95$ \\
\hline & $\mathrm{CI}$ & $3.32 \pm 1.26$ & $4.49 \pm 1.83$ & $4.50 \pm 2.40$ & $4.32 \pm 0.69$ & $4.05 \pm 2.52$ & $3.77 \pm 2.32$ \\
\hline \multirow{2}{*}{ Hemoglobin $(\mathrm{g} / \mathrm{dl})$} & SVI & $11.6 \pm 1.5$ & $10.7 \pm 1.5$ & $10.4 \pm 1.46^{*}$ & $9.4 \pm 1.2 *^{\#}$ & $8.3 \pm 1.5 *^{\#}$ & $8.1 \pm 0.9 * \#$ \\
\hline & CI & $11.2 \pm 0.7$ & $10.4 \pm 1.2$ & $9.5 \pm 1.2 *$ & $9.2 \pm 0.9 *^{* \#}$ & $8.4 \pm 0.6$ *\# & $8.2 \pm 1.5$ *\# \\
\hline
\end{tabular}

Table 2. Blood gas parameters during hemorrhage and fluid resuscitation. SVI - stroke volume index, SVI-group; CI - cardiac index, CI-group. Data are presented as mean \pm standard deviation. ${ }^{*} \mathrm{p}<0.05$ significantly different from $\mathrm{t}_{\mathrm{bss}},{ }^{\#} \mathrm{p}<0.05$ significantly different from $\mathrm{t}_{0} .{ }^{@} \mathrm{p}<0.05$ significantly different between groups. 


\section{Discussion}

\section{Changes of $\mathrm{ScvO}_{2}$ during stroke volume and cardiac index controlled hemorrhage and resuscitation}

The primary goal of fluid resuscitation in hypovolaemia is to maintain adequate $\mathrm{DO}_{2}$ to the tissues. During stroke volume guided exsanguination oxygen delivery decreased significantly and returned to a significantly lower value at the end of the study. This finding can mainly be explained by the lower hemoglobin levels caused by hemodilution. During bleeding impaired oxygen delivery was accompanied by increased oxygen extraction, which was reflected in the changes of $\mathrm{ScvO}_{2}$.

Under physiological circumstances the normal range for $\mathrm{SvO}_{2}$ is 68 to $77 \%$ and for $\mathrm{ScvO}_{2}$ is considered to be 5\% higher (Reinhart et al., 2004). As mentioned earlier, low $\mathrm{ScvO}_{2}$ is an alarming signal of inadequate oxygen delivery, therefore, it is generally agreed that in the presence of this warning sign, diagnostic approaches and interventions are needed. However, interpretation of normal and supranormal $\mathrm{ScvO}_{2}$ is more challenging. In critically ill patients supraphysiological $\mathrm{ScvO}_{2}$ is also associated with poor outcome similar to that of accompanied with low $\mathrm{ScvO}_{2}$. Among cardiac surgical patients in the postoperative period $\mathrm{ScvO}_{2}$ over $77.4 \%$ was found to have very good perdictive value for complications. These patients also had higher lactate levels and more signs of systemic inflammatory response (Perz et al., 2011).The connection between high $\mathrm{ScvO}_{2}$ and organ dysfunction can be found on the level of the microcirculation and oxygen extraction of the cells. Shunting of the blood from the arterial to the venous side without reaching the capillary system can alter oxygen extraction (De Backer et al., 2010; Walley et al., 1996). In patients under general anesthesia $\mathrm{ScvO}_{2}$ is often higher than $80 \%$, which is due to the reduced oxygen demand and consumption, hence the range of "normal" value should be considered higher in the operating room as in other scenarios (Goepfert et al., 2013).

The landmark study of Rivers (2001), first suggested that incorporating $\mathrm{ScvO}_{2}$ in the early resuscitation algorhythm in critically ill patients with septic shock could improve outcome. Patients treated according to the "early goal-directed therapy" approach received more fluids, more positive inotropic agents and more transfusion in the first six hours of treatment. There 
was a significant decrease in mortality in the $\mathrm{ScvO}_{2}$-group as compared to the control group (Rivers et al., 2001).

Regarding the perioperative period, in high risk surgical patients postoperative low $\mathrm{ScvO}_{2}$ was associated with increased number of complications. The best cut off value for discriminating patients who will develop complications was $73 \%$ for $\mathrm{ScvO}_{2}$. Lower $\mathrm{ScvO}_{2}$ was also independently associated with increased number of complications (Collab Study group. et al., 2006). In a recent study aiming to achieve oxygen extraction $<27 \%$ as target endpoint, which means keeping $\mathrm{ScvO}_{2}>73 \%$, reduced the number of organ failures and hospital stay after surgery (Donatiet al., 2007). In a novel clinical study carried out by our research group, intraoperative $\mathrm{ScvO}_{2}$ assisted hemodynamic optimization also resulted better organ function and 28-days survival compared to conventional treatment (Mikor et al.,2015). Our previous experiments demonstrated, that $\mathrm{ScvO}_{2}$ showed good correlation with oxygen extraction (Kocsi et al., 2012; Kocsi et al., 2013).

One of the most important findings of our current study is, that $\mathrm{ScvO}_{2}$ remained significantly lower at the end of resuscitation as compared to baseline with a mean of $5 \%$, despite that stroke volume has reached its baseline value. This difference was even more pronounced during the cardiac index based resuscitation model, where $\mathrm{ScvO}_{2}$ remained almost $15 \%$ below the baseline value. In both experiments one possible factor of this difference between the baseline and final $\mathrm{ScvO}_{2}$ is the significant decrease of the hemoglobin level due to hemodilution, that was also observed in previous studies (Vallet et al., 2010). When bleeding is present both hemoglobin and fluid is lost which alters oxygen transport capacity. Fluid loss impairs cardiac output and lower hemoglobin level decreases blood oxygen content. With fluid replacment only one component is treated, therefore oxygen delivery is only partially restored. This is what we saw in Experiment-1, that although stroke volume was normalized but hemodilution had a significant effect on the hemoglobin levels, hence on oxygen delivery. In Experiment-2 however, animals may have remained severely under-resuscitated, indicated by the very low $\mathrm{ScvO}_{2}$ value at the end of the trial period. Bleeding can cause an inreased symphatetic activation, which also increases oxygen consumption and this is what we found in both experiments during the bleeding phase, which more-or-less normalized during the resuscitation phase. The net effect of reduced delivery and increased or unchanged consumption are mirrored in the lower $\mathrm{ScvO}_{2}$ throughout the experiment.

These findings have very important clinical implications. Our results indicate that taking baseline $\mathrm{ScvO}_{2}$, measured for example at the beginning of surgery, should not be considered 
as a "target" or "goal" during fluid resuscitation, because this can potentially lead to fluid overload, as "low" $\mathrm{ScvO}_{2}$ may indicate inadequate resuscitation, although the circulation and stroke volume is already restored. Our results also draw the attention to the fact, that treating one single parameter, such as $\mathrm{ScvO}_{2}$ in this case, can be misleading. Taking other parameters of oxygen delivery and perfusion into account and tailoring patient management in this multimodal fashion should have a very important role in the future. 


\section{Blood transfusion and $\mathrm{ScvO}_{2}$}

In addition to fluid replacement transfusion is another, potentially life saving intervention in bleeding management. It is well documented that low hemoglobin levels in the perioperative period are accompanied by increased mortality, therefore early treatment of anemia is mandatory, especially when treating high risk surgical patients (Shander et al., 2014). However, as we already mentioned, blood transfusion is also a double edged sword. Low hemoglobin levels impair $\mathrm{DO}_{2}$, leading to tissue hypoxia, while unnecessary blood tansfusion increases the risk of transfusion related complications, such as infections (Jeffrey et al., 2014), the incidence of allergic and immune transfusion reactions (Yeh et al., 2011) or transfusion related acute lung injury (Bux et al., 2005). Recently, arbitrary cut off values, like the "10/30" rule (Wang et al., 2010), were interchanged with a restrictive concept, where hemoglobin levels between 70-90 g/l were targeted as transfusion thresholds depending on the patients' co-morbid condition (see below) (Napolitano et al., 2009). The paradigm shift was also strenghtened by the TRICC trial, a large randomized controlled study, which could not show any benefit when used liberal blood transfusion strategy compared to restrictive protocols. In the restrictive group, transfusion was indicated only below 70g/l (Paul et al., 1999). Patients with "special" underlying diseases like ischemic heart diseases, or brain ischemia forms another subgroup. In these patient population tissue oxygenation should be monitored to determine the critical threshold of blood transfusion.

It is important to note that our primary goal with blood transfusion is not to increase hemoglobin, but to increase oxygen delivery and so to restore the balance between the oxygen supply and demand. To monitor these changes $\mathrm{ScvO}_{2}$ may be a valuable parameter. In a recent clinical investigation during blood transfusion, physicians were allowed to use local protocols and $\mathrm{ScvO}_{2}$ to decide whether to transfuse or not. In patients with low inital $\mathrm{ScvO}_{2}$ level there was an improvement in their oxygen imbalance, while patients with normal $\mathrm{ScvO}_{2}$ had no improvement despite the increase in their hemoglobin level (Adamczyk et al., 2003).

If the patient is adequately resuscitated (i.e.: PPV, $\mathrm{SVV}$ and $\mathrm{dCO}_{2}$ are also normalized) but the $\mathrm{ScvO}_{2}$ remains low, it can be an alarming sign that the low hemoglobin causes decreased oxygen delivery, which may require transfusion. This is in accord with our recent findings in an isovolemic anemia model, where blood loss was immediately restored with the same amount of colloid, and we found that $\mathrm{ScvO}_{2}$ showed very good correlation with $\mathrm{VO}_{2} / \mathrm{DO}_{2}$. 
These results underscore the importance of $\mathrm{ScvO}_{2}$ in the assessment $\mathrm{VO}_{2} / \mathrm{DO}_{2}$ and give the rationale for its applicationas an alternative transfusion trigger (Kocsi et al., 2012). However, as our results suggest, $\mathrm{ScvO}_{2}$, which is a very useful indicator of the $\mathrm{VO}_{2} / \mathrm{DO}_{2}$ imbalance, on its own is unable to answer all questions during the bleeding-resuscitation process. One of the possible complementary tools to be used as resuscitation endpoint is the central venous-toarterial $\mathrm{CO}_{2}$ gap, the $\mathrm{dCO}_{2}$. 


\section{Kinetics of $\mathrm{dCO}_{2}$ during stroke volume and cardiac index based hemorrhage and fluid replacement}

During stroke volume based resuscitation $\mathrm{dCO}_{2}$ increased during bleeding, and then returned to its baseline value. After bleeding both SVI and hemoglobin levels decreased, while lactate increased more than two fold predisposing anaerob carbon dioxide production due to tissue hypoxia. With the stepwise normalization of the SVI the clearence of the carbon dioxide from the tissues resolved. On the contrary, during cardiac index guided fluid replacement in Experiment-2, $\mathrm{dCO}_{2}$ remained higher compared to its baseline value, although this difference became non-significant after $\mathrm{T}_{2}$. Nevertheless, our data give further support that the higher $\mathrm{dCO}_{2}$ may indicate inadequate flow, hence in Experiment- 2 this could have been a warning signal of residual hypovolemia.

Several authors have reported increased $\mathrm{dCO}_{2}$ in different low flow states (Mecher et al., 1990; Weil et al., 1986; Cuschieri et al., 2005; Benjamin et al., 1987). In hypoxemia caused anaerob metabolism, hydrogen ions are generated in two ways. The hydrolysis of adenosine triphosphate to adenosin diphosphate, and by the increased production of lactic acid (Weil et al.,1986). These hydrogen ions are buffered by bicarbonate present in the cells, and this process will generate $\mathrm{CO}_{2}$ production (Cuschieri et al., 2005). Pulmonary gas exchange and ventilation drive are determinants of $\mathrm{PaCO}_{2}$, while central venous $\mathrm{PvCO}_{2}$ is dependent on the capability of blood flow to wash out carbon dioxide from the tissues. The Fick principle adapted to carbon dioxide, demonstrates the inverse relationship between the cardiac output and $\mathrm{dCO}_{2}$ (Lamia et al., 2006). It has been postulated that increased $\mathrm{dCO}_{2}$ reflects decreased flow.

In the perioperative setting $\mathrm{dCO}_{2}$ is a good predictive factor. Preoperatively, patients with high $\mathrm{dCO}_{2}$ had significantly higher mortality compared to patients with normal values $(36.4 \%$ versus 4.5\%; Silva et al., 2011). High risk surgical patients admitted to intensive care unit postoperatively with high $\mathrm{dCO}_{2}$ also developed more complications. The cut off value was 5.8 mmHg (Robin et al., 2015). A dCO $>5 \mathrm{mmHg}$ had $96 \%$ sensitivity to predict the occurence of postoperative complications in patients with normal ( $\geq 71 \%) \mathrm{ScvO}_{2}$ (Futier et al., 2010). In critically ill patients the $\mathrm{dCO}_{2}$ is in good inverse correlation with the cardiac output (Cuschieri et al., 2005) and it has also been shown to be a good predictor a bad outcome in patients with septic shock (Bakker et al., 1992). 
However, if the flow is normal or elevated (hyperdynamic states), the $\mathrm{CO}_{2}$ produced by anaerobic metabolism can be washed out hence there will be no increase in the $\mathrm{dCO}_{2}$. This phenomenon was being demonstrated on isolated hind limb of dogs. The results suggest, that $\mathrm{dCO}_{2}$ increases only in the presence of ischaemic hypoxia, but not in hypoxemic hypoxia with intact flow (Vallet et al., 2000). This also means that reaching the physiological value of the $\mathrm{dCO}_{2}$ does not mean adequate tissue oxygenation. In a recent animal experiment we found that adding $\mathrm{dCO}_{2}$ to $\mathrm{ScvO}_{2}$ for predicting hypovolemia caused increase of oxygen extraction>30\% improved positive predictive value from 85 to 100\% (Kocsi et al., 2013).

In both current experiments $\mathrm{dCO}_{2}$ increased significantly during bleeding reflecting inadequate flow, due to low cardiac output at $\mathrm{T}_{0}$. When blood loss was corrected stepwise, $\mathrm{dCO}_{2}$ decreased also gradually and returned to its baseline at the end of stroke volume based resuscitation, however when fluid therapy was targeted according to cardiac index $\mathrm{dCO}_{2}$ remained higher suggesting persisting "low flow" state. However, this low flow state was not indicated by the measured cardiac index, which was very similar in both groups at each measurement point and could be regarded as "normal" in both groups at the end of the experiments. Nevertheless, in the cardiac index targeted group stroke volume remained significantly lower by the end of the experiment, both compared to baseline and to the stroke volume resuscitated animals, indicating that although cardiac index "normalized", but this was due to tachycardia rather than the restoration of stroke volume.

Therefore, our current results give further evidence that combining $\mathrm{dCO}_{2}$ with $\mathrm{ScvO}_{2}$ can be complementary tools not just in the diagnosis in hypovolemia but also during the management of bleeding patient in the perioperative setting. 


\section{Lactate clearance as resuscitation endpoint during hemorrhage}

In our experiment lactate increased more than two fold during bleeding and further increased during the first two resuscitation steps. At the end of resuscitation it showed a $25 \%$ decrease compared to the highest value, but remained significantly higher compared to the physiological range.

Increased lactate production is mainly due to anareobic metabolism caused by tissue hypoxia. High lactate concentrations are common findings during the management of hemodynamically unstable, bleeding patients (Régnier et al., 2012). Surgical patients admitted to the intensive care unit with high initial and 24 hours lactate level had higher mortality compared to patients with normal levels (Husain et al., 2003).Furthermore, there is mounting evidence, the lactate clearance is superior to single values, and mirrors better the effect of therapy not only in septic, but also in surgical patients. Patients with longer duration of high lactate levels, had worse outcome, compared to patients, who responded to resuscitation and had a declining lactate levels (Bakker et al., 1996). These results were further confirmed by trauma victims, wherein patients in whom lactate levels normalized within the first 24 hours, the mortality was $10 \%$, as compared to those patients in whom it took 48 hours, where mortality was as high as 67\% (Husain et al., 2003). In our experiment lactate levels increased further during the first two resuscitation steps. This can be explained by various theories. Resuscitation resulted transient increase followed by decrease in the circulating level of lactate because of the wash out phenomen. Another explanation for these transient high lactate levels can be the ongoing tissue hypoxia during the early phases of resuscitation. Finally, lactate levels decreased to the $75 \%$ of the highest value showing a $25 \%$ clearence. In a previous clinical investigation, every $10 \%$ increase in lactate clearance reduced the likelihood of mortality with 11\% (Nguyen et al., 2004). Reduced lactate clearence in the first 2 hours of trauma patients also resulted better outcome (Régnier et al., 2012). In our experiment improvement in the hemodynamic parameters and oxygenation was followed by a decrease in the lactate levels. This can be explained by the increased oxygen transport capacity, which shifted anaerobic metabolism to areobic.

In our experiment lactate levels showed a steady decline towards the end of the study protocol and it is possible that with longer observation time it would have also decreased to its normal value. However, its kinetic was slower as compared to $\mathrm{dCO}_{2}$ and $\mathrm{ScvO}_{2}$, so it can not signal when to stop fluid replacement, rather it should be applied as a very strong "retrospective 
indicator" of effective therapy. By and large it seems, and it also follows physiological rationale, that lactate one step behind $\mathrm{ScvO}_{2}$ and $\mathrm{dCO}_{2}$, as it only increases when there is oxygen debt and anerobic metabolism, while $\mathrm{ScvO}_{2}$ and $\mathrm{dCO}_{2}$ give signals well before oxygen debt occurs. Nevertheless, our data on the pattern how lactate changes during bleeding and resuscitation also has some very important clinical implications. Current guidelines consider and recommend the normalization of lactate levels within the first 6 hours after the beginning of resuscitation. Our results suggest that significant changes can take place within 15-20 minutes during resuscitation, therefore, waiting for 6 hours to assess the efficacy of resuscitation may be far too long. According to our data, changes can occur within minutes and by applying two simple blood gas tests of the arterial and central venous blood and taking all of the above mentioned indices of $\mathrm{ScvO}_{2}, \mathrm{dCO}_{2}$ and lactate levels into account and use them as complementary measures may provide very fast and effective measures to monitor and even guide resuscitation.

\section{Limitations}

First of all, the results can only partially be extrapolated for the real clinical settings. Reducing the stroke volume by $50 \%$ is a strictly controlled scenario, rarely happening in the everyday practice. The observation period at the end of the experiment was also short, therefore long term effects of stroke volume based fluid resuscitation on hemodynamics and oxygen delivery and consumption were not assessed. Another limitation of the model is, that bleeding was relatively fast, causing a symphatetic burst, while in the operating room intravascular volume loss and bleeding caused hypovolemia usually occurs over a longer period of time. 


\section{Conclusions}

\section{The main findings of our experiments are:}

1) $\mathrm{ScvO}_{2}$ is affected by fluid resuscitation caused hemodilution, reflected in significantly lower level at the end of resuscitation than at baseline, therefore, it cannot be used as a single parameter for resuscitation endpoint. $\mathrm{dCO}_{2}$ mirrored both the decrease and the restoration of stroke volume during hemorrhage and volume replacement. Therefore, $\mathrm{dCO}_{2}$ can be used as a complementary tool to assess the efficacy of fluid resuscitation and restoration of flow.

2) Lactate levels change rapidly during bleeding and resuscitation, but in general lactate levels remain higher at the end of resuscitation as compared to $\mathrm{ScvO}_{2}$ and $\mathrm{dCO}_{2}$. Our data also suggest that lactate levels change significantly within minutes, therefore can be a very useful tool in monitoring the progress of patients well within the currently recommended time frame of 6 hours.

3) During moderate hemorrhage and fluid resuscitation, normalization of the flow driven parameter of $\mathrm{dCO}_{2}$ with other hemodynamic parameters like pulse pressure variation and stroke volume variation can indicate termination of fluid therapy, but low levels of $\mathrm{ScvO}_{2}$ can be an alarming sign of persisting oxygen debt indicating blood transfusion.

4) During stroke volume guided resuscitation $\mathrm{dCO}_{2}$ normalized with the restoration of stroke volume index and $\mathrm{ScvO}_{2}$ mirrored increased oxygen extraction. When cardiac index was targeted during resuscitation, elevated levels of $\mathrm{dCO}_{2}$ and low levels of $\mathrm{ScvO}_{2}$ indicated inadequate resuscitation despite normalization of cardiac index. 


\section{Acknowledgements}

First and foremost, I would like to express my thanks to my supervisor, Professor Dr Zsolt Molnár for his guidance throughout my $\mathrm{PhD}$ research and for his patience, motivation and assistance during the writing of these thesis.

I owe especial thanks to Dr. József Kaszaki and Professor Dr. Mihály Boros for their personal guidance and support during experimental work. I am grateful for all employees of the Department of Anesthesiology and Intensive Therapy and Institute of Surgical Research at University of Szeged.

Finally, I would like to thank the love and spiritual support of my family. 


\section{References}

1. Adamczyk S, Robin E, Barreau O. Contribution of central venous oxygen saturation in postoperative blood transfusion decision] Ann Fr Anesth Reanim2009;28:522-530.

2. Alter HJ, Klein HG. The hazards of blood transfusion in historical perspective. Blood 2008;112:2617-26.

3. Bakker J, Vincent JL, Gris P, Leon M, Coffernils M, Kahn RJ. Veno-arterial carbon dioxide gradient in human septic shock. Chest 1992;101:509-15.

4. Balogh Z, McKinley BA, Cocanour CS, Kozar RA, Holcomb JB, Ware DN, Moore FA.Secondary abdominal compartment syndrome is an elusive early complication of traumatic shock resuscitation. Am J Surg 2002;184:538-43; discussion 543-4.

5. Barrie Phypers, and JM Tom Pierce. Lactate physiology in health and disease. Contin Educ Anaesth Crit Care Pain 2006;6: 128-132.

6. Baysal BE, Ferrell RE, Willett-Brozick JE, et al. Mutations in SDHD, a mitochondrial complex II gene, in hereditary paraganglioma. Science 2000;287(5454):848-51.

7. Benjamin E, Paluch TA, Berger SR, Premus G, Wu C, Iberti TJ. Venous hypercarbia in canine hemorrhagic shock. Crit Care Med 1987;15:516-8.

8. Brandstrup B, Tønnesen H, Beier-Holgersen R, Hjortsø E, Ørding H, Lindorff-Larsen K, Rasmussen MS, Lanng C, Wallin L, Iversen LH, Gramkow CS, Okholm M, Blemmer T, Svendsen PE, Rottensten HH, Thage B, Riis J, Jeppesen IS, Teilum D, Christensen AM, Graungaard B, Pott F; Danish Study Group on Perioperative Fluid Therapy. Effects of intravenous fluid restriction on postoperative complications: 
comparison of two perioperative fluid regimens: a randomized assessor-blinded multicenter trial.Ann Surg 2003;238:641-8.

9. Brown SD, Clark C, Gutierrez G. Pulmonary lactate release in patients with sepsis and the adult respiratory distress syndrome. J Crit Care 1996;11(1):2-8.

10. Bux J. Transfusion-related acute lung injury (TRALI): a serious adverse event of blood transfusion. Vox Sang 2005;89:1-10.

11. Collaborative Study Group on Perioperative $\mathrm{ScvO}_{2}$ Monitoring. Multicentre study on peri- and postoperative central venous oxygen saturation in high-risk surgical patients. Crit Care 2006;10:R158.

12. Cuschieri J, Rivers EP, Donnino MW, Katilius M, Jacobsen G, Nguyen HB, Pamukov N, Horst HM.Central venous-arterial carbon dioxide difference as an indicator of cardiac index. Intensive Care Med 2005;31:818-22.

13. Cuschieri J, Rivers EP, Donnino MW, Katilius M, Jacobsen G, Nguyen HB, Pamukov N, Horst HM.Central venous-arterial carbon dioxide difference as an indicator of cardiac index. Intensive Care Med 2005;31:818-22.

14. De Backer D, Ospina-Tascon G, Salgado D, Favory R, Creteur J, Vincent JL. Monitoring the microcirculation in the critically ill patient: current methods and future approaches. Intensive Care Med 2010; 36: 1813-25.

15. Demling RH, Manohar M, Will JA.Response of the pulmonary microcirculation to fluid loading after hemorrhagic shock and resuscitation. Surgery 1980;87:552-9.

16. DiMauro S, Schon EA. Mitochondrial respiratory-chain diseases. N Engl J Med 2003;348:2656-68.

17. Donati A, Loggi S, Preiser JC, Orsetti G, Münch C, Gabbanelli V, Pelaia P, Pietropaoli P. Goal-directed intraoperative therapy reduces morbidity and length of hospital stay in high-risk surgical patients. Chest 2007;132:1817-24.

18. Dueck MH, Klimek M, Appenrodt S, Weigand C, Boerner U.Trends but not individual values of central venous oxygen saturation agree with mixed venous 
oxygen saturation during varying hemodynamic conditions. Anesthesiology 2005;103:249-57.

19. Emanuel Rivers, M.D., M.P.H., Bryant Nguyen, M.D., Suzanne Havstad, M.A., Julie Ressler, B.S., Alexandria Muzzin, B.S., Bernhard Knoblich, M.D., Edward Peterson, Ph.D., and Michael Tomlanovich, M.D., for the Early Goal-Directed Therapy Collaborative Group. N Engl J Med 2001; 345:1368-1377

20. Evans DC, Doraiswamy VA, Prosciak MP, Silviera M, Seamon MJ, Rodriguez Funes V, Cipolla J, Wang CF, Kavuturu S, Torigian DA, Cook CH, Lindsey DE, Steinberg SM, Stawicki SP.Complications associated with pulmonary artery catheters: a comprehensive clinical review. Scand J Surg 2009;98:199-208.

21. Field M, Block JB, Levin R, et al. Significance of blood lactate elevations among patients with acute leukemia and other neoplastic proliferative disorders. Am J Med 1966;40:528-47.

22. Finch CA, Gollnick PD, Hlastala MP, et al. Lactic acidosis as a result of iron deficiency. J Clin Invest 1979;64:129-37.

23. Fodale V, La Monaca E. Propofol infusion syndrome: an overview of a perplexing disease. Drug Saf 2008;31:293-303.

24. Friedenberg AS, Brandoff DE, Schiffman FJ. Type B lactic acidosis as a severe metabolic complication in lymphoma and leukemia: a case series from a single institution and literature review. Medicine 2007;86:225-32

25. Futier E, Robin E, Jabaudon M, Guerin R, Petit A, Bazin JE, Constantin JM, Vallet B. Central venous $\mathrm{O}_{2}$ saturation and venous-to-arterial $\mathrm{CO}_{2}$ difference as complementary tools for goal-directed therapy during high-risk surgery. Crit Care 2010;14(5):R193.

26. Giammarco RA. The athlete, cocaine, and lactic acidosis: a hypothesis. Am J Med Sci 1987;294:412-4.

27. Giovannini I, Chiarla C, Boldrini G, Castagneto M. Calculation of venoarterial $\mathrm{CO}_{2}$ concentration difference. J Appl Physiol 1993;74:959-64.

28. Goepfert MS, Richter HP, Zu Eulenburg C, Gruetzmacher J, Rafflenbeul E, Roeher K, von Sandersleben A, Diedrichs S, Reichenspurner H, Goetz AE, Reuter DA. Individually optimized hemodynamic therapy reduces complications and length of 
stay in the intensive care unit: a prospective, randomized controlled trial. Anesthesiology 2013;119:824-36.

29. Husain FA, Martin MJ, Mullenix PS, Steele SR, Elliott DC. Serum lactate and base deficit as predictors of mortality and morbidity. Am J Surg 2003;185:485-91.

30. Kable AK, Gibberd RW, Spigelman AD. Adverse events in surgical patients in Australia. Int J Qual Health Care 2002;14:269-76.

31. Karkouti K, Wijeysundera DN, Beattie WS. Reducing Bleeding in Cardiac Surgery (RBC) Investigators.Risk associated with preoperative anemia in cardiac surgery: a multicenter cohort study. Circulation 2008;117:478-84.

32. Kocsi S Molnar Z. Transfusion in the Intensive Care Unit 2014; pp71-75.

33. Kocsi S, Demeter G, Erces D, Nagy E, Kaszaki J, Molnar Z.Central Venous-toArterial $\mathrm{CO}_{2}$ Gap Is a Useful Parameter in Monitoring Hypovolemia-Caused Altered Oxygen Balance: Animal Study. Crit Care Res Pract 2013;2013:583598.

34. Kocsi S, Demeter G, Fogas J, Erces D, Kaszaki J, Molnár Z. Central venous oxygen saturation is a good indicator of altered oxygen balance in isovolemic anemia. Acta Anaesthesiol Scand 2012;56:291-7.

35. Lamia B, Monnet X, Teboul JL.Meaning of arterio-venous $\mathrm{PCO}_{2}$ difference in circulatory shock. Minerva Anestesiol 2006;72:597-604.

36. Levraut J, Ciebiera JP, Chave S, Rabary O, Jambou P, Carles M, Grimaud D. Mild hyperlactatemia in stable septic patients is due to impaired lactate clearance rather than overproduction. Am J Respir Crit Care Med 1998;157:1021-6.

37. Mecher CE, Rackow EC, Astiz ME, Weil MH. Venous hypercarbia associated with severe sepsis and systemic hypoperfusion. Crit Care Med 1990;18:585-9.

38. Weil MH, Rackow EC, Trevino R, Grundler W, Falk JL, Griffel MI.Difference in acid-base state between venous and arterial blood during cardiopulmonary resuscitation. N Engl J Med 1986 17;315:153-6.

39. Mekontso-Dessap A, Castelain V, Anguel N, Bahloul M, Schauvliege F, Richard C, Teboul JL.Combination of venoarterial $\mathrm{PCO}_{2}$ difference with arteriovenous $\mathrm{O}_{2}$ content difference to detect anaerobic metabolism in patients. Intensive Care Med 2002;28:272-7. 
40. Mikkelsen ME, Miltiades AN, Gaieski DF, et al. Serum lactate is associated with mortality in severe sepsis independent of organ failure and shock. Crit Care Med 2009;37:1670-7.

41. Mikor A, Trásy D, Németh MF, Osztroluczki A, Kocsi S, Kovács I, Demeter G, Molnár Z.Continuous central venous oxygen saturation assisted intraoperative hemodynamic management during major abdominal surgery: a randomized, controlled trial. BMC Anesthesiol 2015;15:82.

42. Misbin RI. Phenformin-associated lactic acidosis: pathogenesis and treatment. Ann Intern Med 1977;87:591-5.

43. Mizock BA, Falk JL: Lactic acidosis in critical illness. Crit Care Med 1992, 20:80-83.

44. Mukunda BN. Lactic acidosis caused by thiamine deficiency in a pregnant alcoholic patient. Am J Med Sci 1999;317:261-2.

45. Napolitano LM, Kurek S, Luchette FA, Corwin HL, Barie PS, Tisherman SA, Hebert PC, Anderson GL, Bard MR, Bromberg W, Chiu WC, Cipolle MD, Clancy KD, Diebel L, Hoff WS, Hughes KM, Munshi I, Nayduch D, Sandhu R, Yelon JA; American College of Critical Care Medicine of the Society of Critical Care Medicine; Eastern Association for the Surgery of Trauma Practice Management Workgroup.Clinical practice guideline: red blood cell transfusion in adult trauma and critical care. Crit Care Med 2009;37:3124-57.

46. Nevière R, Chagnon JL, Teboul JL, Vallet B, Wattel F. Small intestine intramucosal $\mathrm{PCO}(2)$ and microvascular blood flow during hypoxic and ischemic hypoxia. Crit Care Med 2002;30:379-84.

47. Nguyen HB, Rivers EP, Knoblich BP, Jacobsen G, Muzzin A, Ressler JA, Tomlanovich MC. Early lactate clearance is associated with improved outcome in severe sepsis and septic shock. Crit Care Med 2004;32:1637-42.

48. Niskanen MM, Takala. Use of resources and postoperative outcome. JA. Eur J Surg 2001;167:643-9.

49. Paul C. Hébert, M.D., George Wells, Ph.D., Morris A. Blajchman, M.D., John Marshall, M.D., Claudio Martin, M.D., Giuseppe Pagliarello, M.D., Martin Tweeddale, M.D., Ph.D., Irwin Schweitzer, M.Sc., Elizabeth Yetisir, M.Sc., and *the Transfusion Requirements in Critical Care Investigators for the Canadian Critical Care 
Trials GroupA Multicenter, Randomized, Controlled Clinical Trial of Transfusion Requirements in Critical Care.N Engl J Med 1999; 340:409-417.

50. Perz S, Uhlig T, Kohl M, Bredle DL, Reinhart K, Bauer M, Kortgen A. Low and "supranormal" central venous oxygen saturation and markers of tissue hypoxia in cardiac surgery patients: a prospective observational study. Intensive Care Med 2011;37:52-9.

51. Régnier MA, Raux M, Le Manach Y, Asencio Y, Gaillard J, Devilliers C, Langeron O, Riou B.Prognostic significance of blood lactate and lactate clearance in trauma patients. Anesthesiology 2012;117:1276-88.

52. Reinhart K, Kuhn HJ, Hartog C, Bredle DL. Continuous central venous and pulmonary artery oxygen saturation monitoring in the critically ill. Intensive Care Med 2004;30:1572-8.

53. Reinhart K, Rudolph T, Bredle DL, Hannemann L, Cain SM. Comparison of centralvenous to mixed-venous oxygen saturation during changes in oxygen supply/demand. Chest 1989;95:1216-21.

54. Rivers EP, Ander DS, Powell D.Central venous oxygen saturation monitoring in the critically ill patient. Curr Opin Crit Care 2001;7:204-11.

55. Rivers EP, Katranji M, Jaehne KA, Brown S, Abou Dagher G, Cannon C, Coba V.Early interventions in severe sepsis and septic shock: a review of the evidence one decade later. Minerva Anestesiol 2012;78:712-24.

56. Robin E, Futier E, Pires O, Fleyfel M, Tavernier B, Lebuffe G, Vallet B Central venous-to-arterial carbon dioxide difference as a prognostic tool in high-risk surgical patients. Crit Care 2015;13;19:227.

57. Rohde JM, Dimcheff DE, Blumberg N, Saint S, Langa KM, Kuhn L, Hickner A, Rogers MA.Health care-associated infection after red blood cell transfusion: a systematic review and meta-analysis. JAMA 2014;311:1317-26.

58. Schnüriger B, Inaba K, Wu T, Eberle BM, Belzberg H, Demetriades D.Crystalloids after primary colon resection and anastomosis at initial trauma laparotomy: excessive volumes are associated with anastomotic leakage. J Trauma 2011;70:603-10. 
59. Shander A, Javidroozi M, Naqvi S, Aregbeyen O, Caylan M, Demir S, Juhl A.An update on mortality and morbidity in patients with very low postoperative hemoglobin levels who decline blood transfusion (CME). Transfusion 2014;54:2688-95.

60. Silva JM Jr, Oliveira AM, Segura JL, Ribeiro MH, Sposito CN, Toledo DO, Rezende E, Malbouisson LM. A large Venous-Arterial $\mathrm{PCO}(2)$ Is Associated with Poor Outcomes in Surgical Patients. Anesthesiol Res Pract 2011;2011:759792.

61. Taurá P, Martinez-Palli G, Martinez-Ocon J, Beltran J, Sanchez-Etayo G, Balust J, Anglada T, Mas A, Garcia-Valdecasas JC.Hyperlactatemia in patients with nonacetaminophen-related acute liver failure. World J Gastroenterol 2006;12:1949-53.

62. Torella F, Haynes SL, McCollum CN. Cerebral and peripheral near-infrared spectroscopy: an alternative transfusion trigger? Vox Sang 2002;83:254-7.

63. Transfusion Requirements in Critical Care Investigators, Canadian Critical Care Trials Group. Hébert PC1, Wells G, Blajchman MA, Marshall J, Martin C, Pagliarello G, Tweeddale M, Schweitzer I, Yetisir E. A multicenter, randomized, controlled clinical trial of transfusion requirements in critical care. N Engl J Med 1999;340:409-17.

64. Vallet B, Robin E, Lebuffe G. Venous oxygen saturation as a physiologic transfusion trigger. Crit Care 2010;14:213.

65. Vallet B, Teboul JL, Cain S, Curtis S. Venoarterial CO(2) difference during regional ischemic or hypoxic hypoxia.J Appl Physiol (1985). 2000;89:1317-21.

66. van Beest P, Wietasch G, Scheeren T, Spronk P, Kuiper M.Clinical review: use of venous oxygen saturations as a goal - a yet unfinished puzzle. Crit Care 2011;15:232.

67. Vernon C, Letourneau JL. Lactic acidosis: recognition, kinetics, and associated prognosis. Crit Care Clin 2010;26:255-83.

68. Vincent JL, Sakr Y, Sprung CL, Ranieri VM, Reinhart K, Gerlach H, Moreno R, Carlet J, Le Gall JR, Payen D. Sepsis occurrence in acutely Ill patients investigators: European intensive care units: results of the SOAP study. Crit Care Med 2006; 34 : 344-53.

69. Walley KR. Heterogeneity of oxygen delivery impairs oxygen extraction by peripheral tissues: theory. J Appl Physiol 1996; 81: 885-94. 
70. Wang JK, Klein HG. Red blood cell transfusion in the treatment and management of anaemia: the search for the elusive transfusion trigger. Vox Sang 2010;98:2-11.

71. Weil MH, Rackow EC, Trevino R, Grundler W, Falk JL, Griffel MI. Difference in acid-base state between venous and arterial blood during cardiopulmonary resuscitation. N Engl J Med 1986;315:153-6.

72. Weiser TG, Regenbogen SE, Thompson KD, Haynes AB, Lipsitz SR, Berry WR, Gawande AA. An estimation of the global volume of surgery: a modelling strategy based on available data. Lancet 2008;372:139-44.

73. Wu WC, Trivedi A, Friedmann PD, Henderson WG, Smith TS, Poses RM, Uttley G, Vezeridis M, Eaton CB, Mor V. Association between hospital intraoperative blood transfusion practices for surgical blood loss and hospital surgical mortality rates. Ann Surg 2012;255:708-14.

74. Yeh SP, Chang CW, Chen JC, Yeh WC, Chen PC, Chuang SJ, Lin CP, Hsu LN, Chen HM, Lu JJ, Peng CT.A well-designed online transfusion reaction reporting system improves the estimation of transfusion reaction incidence and quality of care in transfusion practice. Am J Clin Pathol 2011;136:842-7.

75. Levy B. Lactate and shock state: the metabolic view. Curr Opin Crit Care 2006;12:315-21. 
Appendix 


\title{
Central venous oxygen saturation and carbon dioxide gap as resuscitation targets in a hemorrhagic shock
}

\author{
M. Németh ${ }^{1}$, K. TÁnczos ${ }^{1}$, G. Demeter ${ }^{1}$, D. Érces ${ }^{2}$, J. Kaszaki $^{2}$, A. Mikor $^{1}$ and Z. Molnár ${ }^{1}$ \\ ${ }^{1}$ Department of Anaesthesiology and Intensive Therapy and ${ }^{2}$ Institute of Surgical Research, University of Szeged, Szeged, Hungary
}

\begin{abstract}
Background: Fluid resuscitation is still a major challenge. We aimed to describe changes in central venous oxygen saturation $\left(\mathrm{ScvO}_{2}\right)$ and venous-to-arterial carbon dioxide gap $\left(\mathrm{dCO}_{2}\right)$ during an experimental stroke volume (SV) index (SVI)-guided hemorrhage and fluid resuscitation model in pigs.

Methods: Twelve anesthetized, mechanically ventilated pigs were bled till baseline SVI $\left(\mathrm{T}_{\text {bsl }}\right)$ dropped by $50 \%\left(\mathrm{~T}_{0}\right)$, thereafter fluid resuscitation was performed with balanced crystalloid in four steps until initial SVI was reached $\left(\mathrm{T}_{4}\right)$. Statistical analysis was performed with Statistical Program for Social Sciences version 18.0; data are expressed as mean \pm standard deviation. Results: After bleeding, $\mathrm{ScvO}_{2}$ dropped $\left(\mathrm{T}_{\mathrm{bsl}}=78 \pm 7\right.$ vs. $\left.\mathrm{T}_{0}=61 \pm 5 \% \quad P<0.05\right)$ and oxygen extraction ratio increased $\left(\mathrm{T}_{\text {bsl }}=0.20 \pm 0.07\right.$ vs. $\left.\mathrm{T}_{0}=0.36 \pm 0.05, P<0.05\right)$. By $\mathrm{T}_{4}$ the $\mathrm{ScvO}_{2}$ normalized, but on average it remained $5 \%$ lower than at $\mathrm{T}_{\mathrm{bsl}}$ $\left(\mathrm{T}_{4}=73 \pm 9 \% \quad P<0.05\right)$ and oxygen extraction also remained higher as compared with $\mathrm{T}_{\mathrm{bsl}}\left(\mathrm{T}_{4}=0.24 \pm 0.09 P=0.001\right)$. $\mathrm{ScvO}_{2}$ showed significant correlation with SVI $(r=0.564, P<0.001)$.
\end{abstract}

$\mathrm{dCO}_{2}$ increased during hypovolemia $\left(\mathrm{T}_{\mathrm{bsl}}: 5.3 \pm 2.0\right.$ vs. $\left.\mathrm{T}_{0}: 9.6 \pm 2.3 \mathrm{mmHg}, P=0.001\right)$, then returned to normal by $\mathrm{T}_{4}=5.1 \pm 2.6 \mathrm{mmHg}$, and it also showed significant correlation with SVI $(R=-0.591, P<0.001)$ and oxygen extraction $(R=0.735$, $P<0.001)$.

Conclusions: In this SV-guided bleeding and fluid resuscitation model, both $\mathrm{ScvO}_{2}$ and $\mathrm{dCO}_{2}$ correlated well with changes in $\mathrm{SV}$, but only the $\mathrm{dCO}_{2}$ returned to its baseline, normal value, while $\mathrm{ScvO}_{2}$ remained significantly lower than at baseline. These results suggest that $\mathrm{dCO}_{2}$ may be a good hemodynamic endpoint of resuscitation, while $\mathrm{ScvO}_{2}$ is not strictly a hemodynamic parameter, but rather an indicator of the balance between oxygen delivery and consumption.

Accepted for publication 10 February 2014

(c) 2014 The Acta Anaesthesiologica Scandinavica Foundation.

Published by John Wiley \& Sons Ltd
$\mathbf{M}$ AJOR surgery in high-risk patients is associated with increased risk of morbidity and mortality. ${ }^{1}$ Perioperative hypovolemia, blood loss and hypoxia can decrease oxygen delivery, while pain and shivering can increase oxygen consumption resulting in oxygen debt. ${ }^{2,3}$ Cumulative oxygen debt shows direct relationship with hospital mortality. ${ }^{4}$ In hypovolemia, fluid resuscitation is the cornerstone of maintaining and correcting oxygen delivery in hemodynamically unstable patients.

However, fluid resuscitation is a double-edged sword. On the one hand, hypovolemia-induced tissue hypoxia is the major cause of post-operative organ failure, ${ }^{5}$ while on the other hand positive fluid balance also impairs organ function and increases the number of complications. ${ }^{6}$ It has also been shown

Márton Németh and Krisztián Tánczos contributed equally to this paper that optimization of oxygen delivery $\left(\mathrm{DO}_{2}\right)$ during major surgery reduces post-operative complications and improves outcome in high-risk patients. ${ }^{7,8}$

Although cardiac output (CO) is the main determinant of oxygen delivery, the results of a recent survey from the United States and Europe demonstrated that, for example, in high-risk surgical patients intraoperative CO-monitoring has only limited availability in our everyday practice. ${ }^{9}$ Most physicians still rely on mean arterial pressure (MAP) and central venous pressure (CVP) to guide their treatment. ${ }^{9}$ However, it has been shown by several studies that conventional preload parameters like CVP are insufficient indicators of hypovolemia and fluid responsiveness. ${ }^{10,11}$

Central venous oxygen saturation $\left(\mathrm{ScvO}_{2}\right)$, which is a good substitute of mixed venous oxygen saturation, is a sensitive indicator of the balance between oxygen supply and demand..$^{12,13}$ There is consensus 
that low $\mathrm{ScvO}_{2}$ is an important warning sign of inadequacy of $\mathrm{DO}_{2} \cdot{ }^{14}$ Furthermore, in critically ill patients, $\mathrm{ScvO}_{2}$ is often elevated because of impaired oxygen extraction, which is also associated with unfavorable outcome. ${ }^{15-17}$ However, in patients under general anesthesia, the $\mathrm{ScvO}_{2}$ can be even higher than $80 \%$, which is due to the reduced oxygen demand and consumption $\left(\mathrm{VO}_{2}\right)$; hence, values should be interpreted differently. ${ }^{18}$

Another easily obtainable blood gas parameter is the central venous-to-arterial carbon dioxide gap $\left(\mathrm{dCO}_{2}\right)$. It has been shown that in sepsis, in heart failure and in severe hypovolemia, its value can be elevated. ${ }^{19,20}$

As the effects of a stroke volume (SV)-guided hemorrhage and resuscitation on $\mathrm{ScvO}_{2}$ and $\mathrm{dCO}_{2}$ has not been investigated yet, we hypothesized that changes in flow and $\mathrm{VO}_{2} / \mathrm{DO}_{2}$ caused by bleeding may be reflected in changes of $\mathrm{ScvO}_{2}$ and $\mathrm{dCO}_{2}$.

\section{Materials and methods}

The experiments were carried out in strict adherence to the National Institutes of Health guidelines for the use of experimental animals, and the study was approved by the Ethical Committee for the Protection of Animals in Scientific Research at the University of Szeged, with the license number: V./01882/0000/2009-V./142/2013.

\section{Animals and instrumentation}

The experiments were performed on Vietnamese mini pigs. The animals weighing $23 \pm 5 \mathrm{~kg}$ underwent a 6-h fast pre-operatively but with free access to water. Anesthesia was induced by intramuscular injection of a mixture of ketamine $(20 \mathrm{mg} / \mathrm{kg})$ and xylazine $(2 \mathrm{mg} / \mathrm{kg})$ and maintained with a continuous infusion of propofol $(6 \mathrm{mg} / \mathrm{kg} / \mathrm{h}$ iv.), while analgesia was maintained with nalbuphine $(0.1 \mathrm{mg} /$ $\mathrm{kg})$. A tracheal tube was inserted, and the animals' lungs were ventilated mechanically with Harvard Apparatus Dual Phase Control Respirator (Harvard Apparatus, South Natick, MA, USA). The tidal volume was set at $10 \mathrm{ml} / \mathrm{kg}$, and the respiratory rate was adjusted to maintain the end-tidal carbon dioxide and partial pressure of arterial carbon dioxide in the range of $35-45 \mathrm{mmHg}$ and the arterial $\mathrm{pH}$ between 7.35 and 7.45. The adequacy of the depth of anesthesia was assessed by monitoring the jaw tone. After induction of anesthesia, the right jugular vein and the right femoral artery and vein were dissected and catheterized. The central venous catheter was positioned by the guidance of intracavital electrocardiogram. Animals were kept warm $\left(37 \pm 1^{\circ} \mathrm{C}\right)$ by an external warming device.

For invasive hemodynamic monitoring, a transpulmonary thermodilution catheter (PiCCO, PULSION Medical Systems SE, Munich, Germany) was placed in the femoral artery. The femoral artery served as the site for arterial blood gas sampling, and the central venous line was used for taking central venous blood gas samples and for the injection of cold saline boluses for the thermodilution measurements.

\section{Hemodynamic and blood gas measurements}

$\mathrm{SV}$, heart rate (HR), MAP, CO, global end-diastolic volume (GEDV), SV variation (SVV), pulse pressure variation (PPV), left ventricular contractility (dPmax) and systemic vascular resistance were measured by transpulmonary thermodilution and/or pulse contour analysis at baseline and after equilibration of each step. All hemodynamic parameters were indexed for body surface area. The average of three random measurements following 10-ml bolus injections of ice-cold $0.9 \%$ saline were recorded. CVP was determined by the analysis. From the arterial and central venous blood gas samples (Cobas b 221, Roche Ltd, Basel, Switzerland) that were drawn and analyzed by cooximetry simultaneously at baseline and at the end of each step, $\mathrm{ScvO}_{2}$ and $\mathrm{dCO}_{2}$ were determined. From these parameters, the following variables were calculated:

$$
\begin{gathered}
\mathrm{DO}_{2}=\mathrm{CI} \times\left(\mathrm{Hb} \times 1.34 \times \mathrm{SaO}_{2}+0.003 \times \mathrm{PaO}_{2}\right) \\
\mathrm{DO}_{2}=\mathrm{CI} \times \mathrm{CaO}_{2} \\
\mathrm{VO}_{2}=\mathrm{CI} \times\left[\mathrm{CaO}_{2}-\left(\mathrm{Hb} \times 1.34 \times \mathrm{ScvO}_{2}\right.\right. \\
\left.\left.+0.003 \times \mathrm{PcvO}_{2}\right)\right] \\
\text { Oxygen extraction }=\mathrm{VO}_{2} / \mathrm{DO}_{2}
\end{gathered}
$$

\section{Experimental protocol}

The flowchart of the experiment is summarized in Fig. 1. After the catheterizations, animals were allowed to rest for $30 \mathrm{~min}$, after which baseline $\left(\mathrm{T}_{\mathrm{bsl}}\right)$ hemodynamic measurements, blood gas analyses and laboratory testing were performed. After these measurements, blood was drained until the SV index (SVI) dropped by $50 \%$ of its baseline value $\left(T_{0}\right)$, then measurements were repeated. The difference of the $\mathrm{SVI}_{\mathrm{bsl}}-\mathrm{SVI}_{\mathrm{T}}$ was divided into four equal target values, which was aimed to reach in four steps during fluid resuscitation $\left(\mathrm{T}_{1-4}\right)$ to reach the initial 


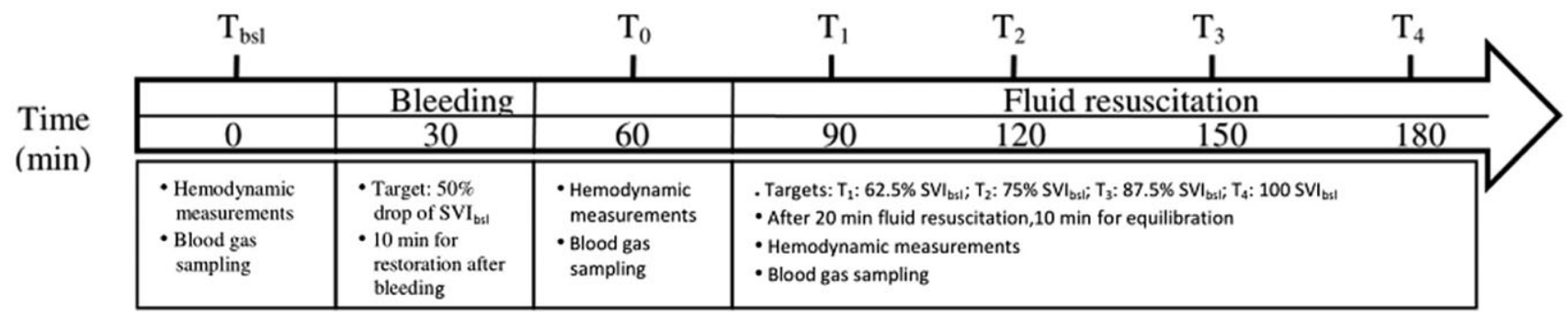

Fig. 1. Schematic diagram illustrating the flowchart of the experimental protocol. After baseline measurment, animals were bled until the stroke volume index (SVI) decreased by $50 \%\left(T_{0}\right)$, then measurements were repeated. The difference of the $S V I_{b s l}-S V I_{T 0}$ was divided into four equal target values $\left(T_{1-4}\right)$, and fluid resuscitated to reach the initial SVI by $T_{4}$.

Table 1

\begin{tabular}{|c|c|c|c|c|c|c|}
\hline & $\mathrm{T}_{\mathrm{bsl}}$ & $\mathrm{T}_{0}$ & $\mathrm{~T}_{1}$ & $\mathrm{~T}_{2}$ & $\mathrm{~T}_{3}$ & $\mathrm{~T}_{4}$ \\
\hline Stroke volume index $\left(\mathrm{ml} / \mathrm{m}^{2}\right)$ & $26.8 \pm 4.7$ & $13.4 \pm 2.3^{*}$ & $16.3 \pm 2.6^{*} \dagger$ & $19.2 \pm 3.5 \dagger$ & $22.3 \pm 4.1 \dagger$ & $26.6 \pm 4.1 \dagger$ \\
\hline Cardiac index $\left(\mathrm{l} / \mathrm{min} / \mathrm{m}^{2}\right)$ & $2.6 \pm 0.4$ & $1.8 \pm 0.3^{*}$ & $2.0 \pm 0.4^{\star} \dagger$ & $2.3 \pm 0.4 \dagger$ & $2.6 \pm 0.4 \dagger$ & $2.9 \pm 0.5^{*} \dagger$ \\
\hline Mean arterial pressure $(\mathrm{mmHg})$ & $112 \pm 23$ & $74 \pm 18^{*}$ & $73 \pm 20^{\star}$ & $78 \pm 20^{*}$ & $84 \pm 19^{*} \dagger$ & $91 \pm 19^{*} \dagger$ \\
\hline Heart rate (beats/min) & $95 \pm 12$ & $131 \pm 27^{*}$ & $128 \pm 31^{*}$ & $121 \pm 22^{*}$ & $114 \pm 18^{*} \dagger$ & $107 \pm 16^{\star} \dagger$ \\
\hline Central venous pressure $(\mathrm{mmHg})$ & $6.0 \pm 1.1$ & $4.8 \pm 0.8^{*}$ & $5.5 \pm 2.1$ & $5.6 \pm 1.5$ & $6.0 \pm 1.3$ & $6.1 \pm 1.4 \dagger$ \\
\hline Global end-diastolic volume $\left(\mathrm{ml} / \mathrm{m}^{2}\right)$ & $309 \pm 57$ & $231 \pm 61^{*}$ & $237 \pm 54^{*}$ & $245 \pm 45^{*}$ & $268 \pm 48^{*} \dagger$ & $287 \pm 49^{*} \dagger$ \\
\hline Stroke volume variation (\%) & $13.6 \pm 4.3$ & $22.6 \pm 5.6^{*}$ & $21.8 \pm 5^{*}$ & $18.6 \pm 5.2 \dagger$ & $16.6 \pm 5.4 \dagger$ & $12.2 \pm 4.3 \dagger$ \\
\hline Pulse pressure variation (\%) & $13.0 \pm 4.5$ & $24.5 \pm 7.6^{*}$ & $23 \pm 7.3^{*}$ & $18.4 \pm 6.4 \dagger$ & $16 \pm 5.6 \dagger$ & $13 \pm 4.2 \dagger$ \\
\hline $\begin{array}{l}\text { Systemic vascular resistance index } \\
\left(\text { dyn } \times \mathrm{s} / \mathrm{cm}^{5} / \mathrm{m}^{2}\right)\end{array}$ & $3425 \pm 816$ & $3257 \pm 966$ & $2711 \pm 733^{*} \dagger$ & $2506 \pm 680^{*} \dagger$ & $2460 \pm 561^{*} \dagger$ & $2340 \pm 526^{*} \dagger$ \\
\hline $\mathrm{dPmax}(\mathrm{mmHg} / \mathrm{s})$ & $583 \pm 227$ & $596 \pm 367$ & $636 \pm 413$ & $708 \pm 403$ & $670 \pm 298$ & $657 \pm 265$ \\
\hline
\end{tabular}

Data are expressed as mean \pm standard deviation.

${ }^{\star} P<0.05$ significantly different from $\mathrm{T}_{\mathrm{bs}}$.

$\dagger P<0.05$ significantly different from $\mathrm{T}_{0}$.

SVI by $\mathrm{T}_{4}$. Fluid replacement was carried out with boluses of balanced cryristalloid Lactated Ringer (B. Braun AG., Melsungen, Germany). After reaching each step, $20 \mathrm{~min}$ were allowed for equilibrium, then hemodynamic and blood gas parameters were measured. At the end of the experiment, the animals were euthanized with sodium pentobarbital.

\section{Data analysis and statistics}

Data are presented as mean \pm standard deviations unless indicated otherwise. For testing normal distribution, the Kolmogorov-Smirnov test was used. Changes in all parameters throughout the experiment were tested by repeated measures analysis of variance. For pairwise comparisons, Pearson's correlation was used. Post hoc calculation showed a power of 0.90 with an effect of $10 \%$ drop in the $\mathrm{ScvO}_{2}$ following hemorrhage for a sample size of 12 and $\alpha<.05$. For statistical analysis, Statistical Program for Social Sciences version 18.0 for Windows (SPSS, Chicago, IL, USA) was used, and $P<0.05$ was considered statistically significant.

\section{Results}

\section{Macrohemodynamics}

During bleeding, $314 \pm 65 \mathrm{ml}$ of blood had to be drained to reach the target of $50 \%$ reduction in SVI. For resuscitation, $951 \pm 307 \mathrm{ml}$ of crystalloid infusion was administered in total by $\mathrm{T}_{4}$ to achieve the target value obtained at $\mathrm{T}_{\mathrm{bs}}$. Hemodynamic changes during the experiment are summarized in Table 1. After bleeding, the SVI decreased by the planned $50 \%$ at $\mathrm{T}_{0}$ and returned to its initial value by $\mathrm{T}_{4}$. The cardiac index (CI) also decreased and reached a higher value by $\mathrm{T}_{4}$ as compared with $\mathrm{T}_{\text {bsl }}$. There was an increase in HR from $T_{\text {bsl }}$ to $T_{0}$, which remained elevated during the whole experiment. MAP fell during the hemorrhage and remained lower until the end of the experiment as compared with $\mathrm{T}_{\mathrm{bsl}}$. GEDV decreased at $\mathrm{T}_{0}$ and increased during resuscitation, but remained lower as compared with $\mathrm{T}_{\text {bsl. }}$. The CVP also decreased from $T_{\text {bsl }}$ to $T_{0}$ and returned to its baseline value at $T_{4}$. There was a tendency of gradually increasing myocardial contractility as indicated by 
Table 2

Blood gas parameters during hemorrhage and fluid resuscitation.

\begin{tabular}{|c|c|c|c|c|c|c|}
\hline & $\mathrm{T}_{\mathrm{bsl}}$ & $\mathrm{T}_{0}$ & $\mathrm{~T}_{1}$ & $\mathrm{~T}_{2}$ & $\mathrm{~T}_{3}$ & $\mathrm{~T}_{4}$ \\
\hline Oxygen delivery index $\left(\mathrm{ml} / \mathrm{min} / \mathrm{m}^{2}\right)$ & $419 \pm 62$ & $272 \pm 56^{*}$ & $285 \pm 58^{*}$ & $305 \pm 47^{*}$ & $305 \pm 55^{*}$ & $341 \pm 62^{*} \dagger$ \\
\hline Oxygen consumption index $\left(\mathrm{ml} / \mathrm{min} / \mathrm{m}^{2}\right)$ & $77 \pm 26$ & $96 \pm 19^{*}$ & $89 \pm 15$ & $90 \pm 17$ & $82 \pm 31$ & $82 \pm 27$ \\
\hline Oxygen extraction $\left(\mathrm{VO}_{2} / \mathrm{DO}_{2}\right)$ & $0.20 \pm 0.07$ & $0.36 \pm 0.05^{\star}$ & $0.33 \pm 0.07^{*}$ & $0.31 \pm 0.07^{*}$ & $0.28 \pm 0.09^{*}$ & $0.24 \pm 0.09^{*}$ \\
\hline Arterial $\mathrm{pH}$ & $7.50 \pm 0.63$ & $7.45 \pm 0.7$ & $7.42 \pm 0.6$ & $7.38 \pm 011^{*}$ & $7.44 \pm 0.42$ & $7.45 \pm 0.43$ \\
\hline $\begin{array}{l}\text { Partial pressure of oxygen in arterial } \\
\text { blood }(\mathrm{mmHg})\end{array}$ & $84.5 \pm 8.1$ & $84.6 \pm 9.7$ & $84.9 \pm 11.8$ & $84.9 \pm 8.8$ & $83.0 \pm 8.8$ & $83.6 \pm 8.8$ \\
\hline Arterial oxygen saturation (\%) & $96.8 \pm 1.0$ & $96.2 \pm 1.7$ & $96.1 \pm 1.8$ & $96.5 \pm 1.1$ & $96.5 \pm 1.3$ & $96.4 \pm 1.4$ \\
\hline Central venous oxygen saturation (\%) & $78 \pm 7$ & $61 \pm 5^{\star}$ & $64 \pm 3^{\star}$ & $67 \pm 7^{\star}$ & $70 \pm 9^{\star}$ & $73 \pm 9^{*} \dagger$ \\
\hline $\begin{array}{l}\text { Venous to arterial carbon dioxide gap } \\
(\mathrm{mmHg})\end{array}$ & $5.3 \pm 2$ & $9.6 \pm 2.3^{*}$ & $8.9 \pm 1.7$ & $7.3 \pm 2.7$ & $6.7 \pm 2.6$ & $5.1 \pm 2.6 \dagger$ \\
\hline Lactate $(\mathrm{mmol} / \mathrm{l})$ & $1.62 \pm 0.43$ & $3.86 \pm 1.49^{*}$ & $4.75 \pm 1.88^{*}$ & $4.75 \pm 2.07^{\star}$ & $4.17 \pm 2.06^{*}$ & $3.54 \pm 1.9^{*}$ \\
\hline Hemoglobin (g/dl) & $12.05 \pm 1.37$ & $11.22 \pm 1.39^{*}$ & $10.6 \pm 1.52^{*}$ & $9.53 \pm 1.29^{*}$ & $8.58 \pm 1.49^{\star} \dagger$ & $8.45 \pm 1.1^{*} \dagger$ \\
\hline
\end{tabular}

Data are expressed as mean \pm standard deviation.

${ }^{\star} P<0.05$ significantly different from $\mathrm{T}_{\mathrm{bs}}$.

$\dagger P<0.05$ significantly different from $\mathrm{T}_{0}$.

dPmax, but it did not achieve statistical significance. Pulse contour analysis driven SVV and PPV increased from $\mathrm{T}_{\mathrm{bsl}}$ to $\mathrm{T}_{0}$ and normalized by $\mathrm{T}_{4}$. Both the SVV and the PPV showed significant negative correlation with SVI determined by thermodilution $(R=-0.53 ; P<0.001 ; R=-0.615 ; P<0.001)$.

\section{Blood gas parameters}

Parameters of oxygen delivery and consumption are summarized in Table 2. Oxygen delivery decreased after the bleeding but remained lower as compared with $\mathrm{T}_{\mathrm{bsl}}$ despite improvement during resuscitation. Hemoglobin levels also decreased from $T_{\text {bsl }}$ to $T_{0}$ and remained lower at the end of resuscitation as compared with $\mathrm{T}_{\text {bsl }}$. Oxygen comsumption increased after the bleeding, and although remained elevated until the end of the experiment, it did not reach statistical significance. Oxygen extraction $\left(\mathrm{VO}_{2} / \mathrm{DO}_{2}\right)$ also increased by $\mathrm{T}_{0}$ and improved during resuscitation; however, it did not return to its baseline value by $\mathrm{T}_{4}$. Lactate levels increased from $\mathrm{T}_{\mathrm{bsl}}$ to $\mathrm{T}_{0}$ and remained elevated throughout, with a non-significant decrease from $\mathrm{T}_{0}$ to $\mathrm{T}_{4}$.

$\mathrm{ScvO}_{2}$ decreased from $\mathrm{T}_{\text {bsl }}$ to $\mathrm{T}_{0}$ and although increased by $\mathrm{T}_{4}$, it remained lower, with a mean difference of $5 \%$ as compared with $\mathrm{T}_{\mathrm{bsl}}$. There was significant correlation between SVI and $\mathrm{ScvO}_{2}$ and $\mathrm{dCO}_{2}$ (Figs. 2 and 3). There was also a strong significant correlation between $\mathrm{dCO}_{2}$ and oxygen extraction (Fig. 4).

\section{Discussion}

The main findings of our experiments are that: (1) $\mathrm{ScvO}_{2}$ and $\mathrm{dCO}_{2}$ showed good correlation with SV during bleeding-caused hypovolemia and fluid resuscitation; 2) while $\mathrm{dCO}_{2}, \mathrm{PPV}$ and SVV together with SVI, returned to the baseline physiological value, $\mathrm{ScvO}_{2}$ did not.

\section{$S V$ as resuscitation endpoint}

Several clinical investigations found that perioperative goal-directed therapy had positive effects on overall outcome after surgery. ${ }^{7,8}$ Most of these algorhythms focused on optimization of $\mathrm{CO}$, oxygen delivery ${ }^{21,22}$ or $\mathrm{SV}^{23,24}$ Although MAP and CVP remain the most often used hemodynamic parameters during high-risk surgery, ${ }^{9}$ there is mounting evidence that neither MAP nor CVP are appropriate and reliable indices of changes in $\mathrm{CO}$ and SV during fluid resuscitation in the critically ill. ${ }^{10,11}$

During bleeding to restore homeostasis, the symphatetic nervous system becomes activated and releases epinephrine and norepinephrine. As a result, venous return will increase, while on the arterial side norepinephrine-caused vasoconstriction tries to maintain perfusion. Because of the symphatetic activation, HR and myocardial contractility will also increase. During resuscitation, our pivotal goal is to restore circulating blood volume by increasing SV to improve oxygen delivery. Recent clinical investigations ${ }^{23,24}$ showed positive effects of SV optimization, and there is frank evidence that PPV and SV variation are well-established indicators of fluid responsiveness. ${ }^{25}$ In our experiment, both parameters determined by pulse contour analysis became significantly elevated during hypovolemia and returned to their baseline values by the end of resuscitation.

Conventional parameters such as HR, MAP and CVP failed to follow the changes in SV; therefore, 

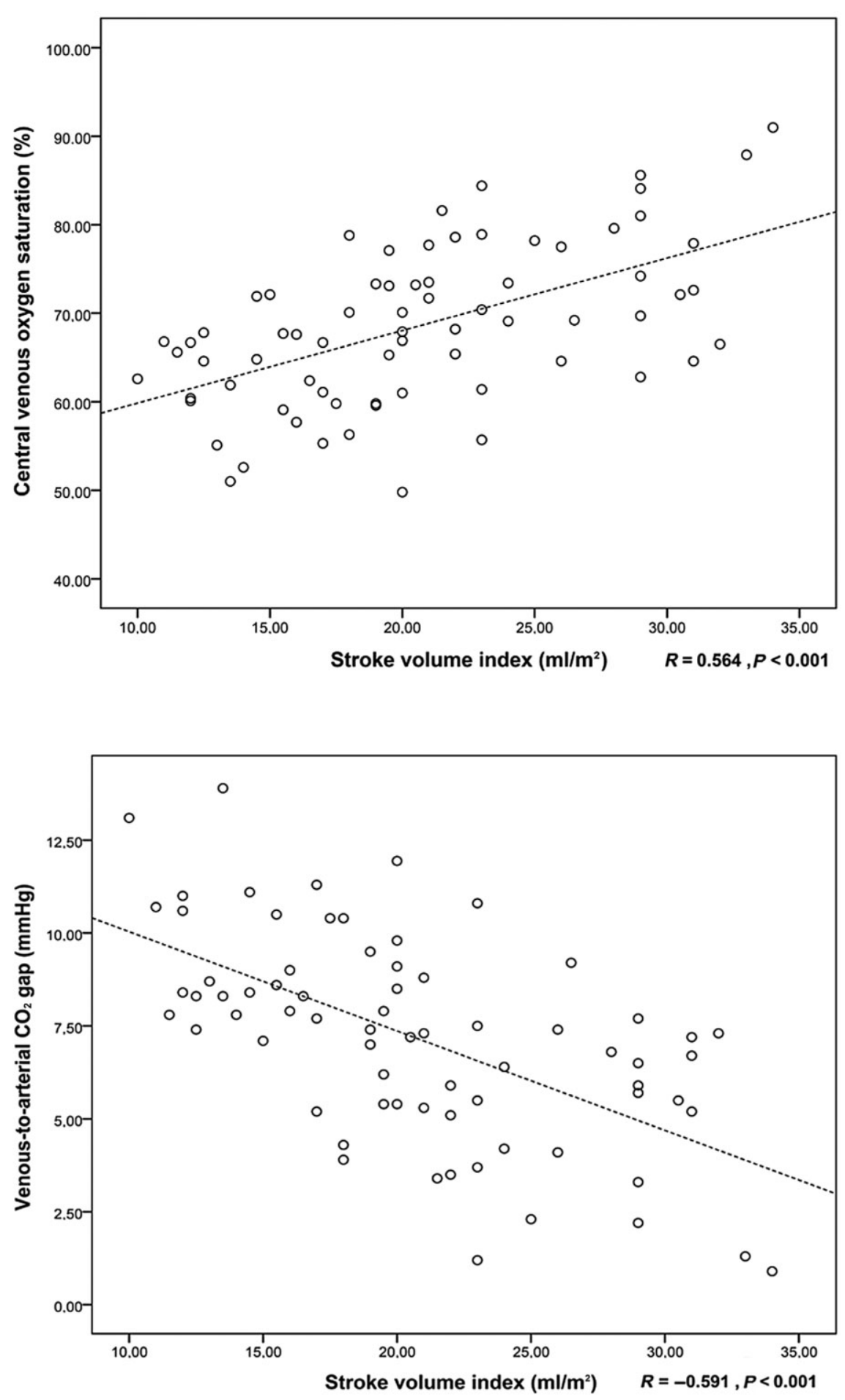

Fig. 2. Correlation between central venous oxygen saturation and stroke volume index. Data are presented as scatter with a linear regression line.
Fig. 3. Correlation between venous-toarterial $\mathrm{CO}_{2}$ gap and stroke volume index. Data are presented as scatter with a linear regression line. our results do not support their routine use as accurate resuscitation endpoints. These are also in accord with the findings of several recent clinical studies. ${ }^{10,11,25}$ It is also important to note that normalizing SVI resulted in higher CO by the end of resuscitation as compared with baseline, possibly because of the bleeding-induced sympathetic response, which caused tachycardia and a tendency of increased contractility, which was present until the end of the experiment. These results suggest the superiority of SV as primary goal of resuscitation instead of $\mathrm{CO}$, as the latter may mask hypovolemia 


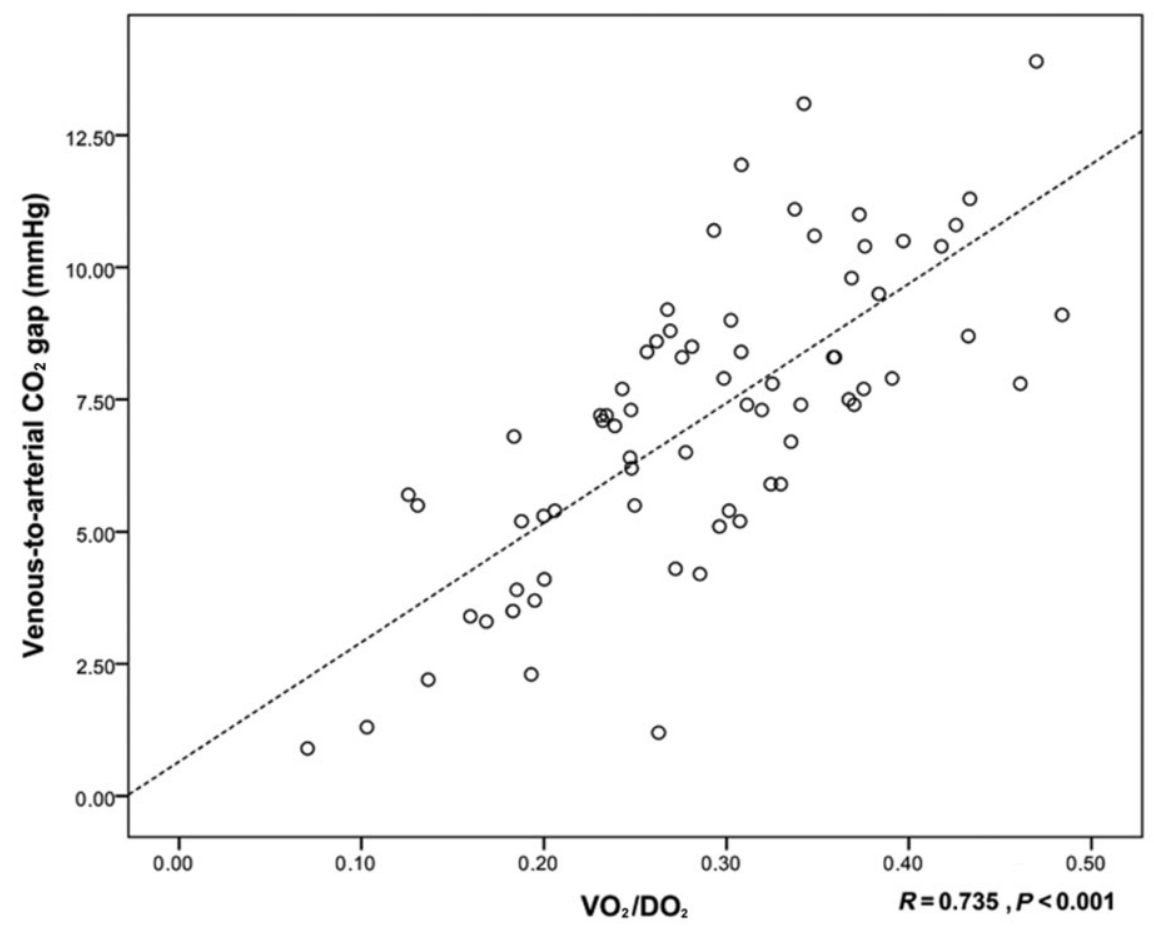

Fig. 4. Correlation between venous-toarterial $\mathrm{CO}_{2}$ gap and $\mathrm{VO}_{2} / \mathrm{DO}_{2}$ (oxygen extraction). Data are presented as scatter with a linear regression line. due to the increased HR, which is not caused by hypovolemia per se, but the sympathetic response for bleeding. However, this postulate has to be tested in the future.

\section{$\mathrm{ScvO}_{2}$ as therapeutic endpoint}

The primary goal of fluid resuscitation in hypovolemia is to maintain adequate oxygen delivery to the tissues. In our experiment, oxygen delivery decreased significantly during the bleeding and returned to a significantly lower value at the end of the study. This finding can mainly be explained by the lower hemoglobin levels caused by hemodilution, as other determinants of oxygen delivery returned to normal or supranormal values. During bleeding, impaired oxygen delivery was accompanied by increased oxygen extraction, which was reflected in the changes of $\mathrm{ScrO}_{2}$.

Physiological mixed venous oxygen saturation ranges between $68 \%$ and $77 \%$, and $\mathrm{ScvO}_{2}$ is considered to be $5 \%$ higher. ${ }^{26}$ However, in patients under general anesthesia the $\mathrm{ScvO}_{2}$ is often higher than $80 \%$, which is due to the reduced oxygen demand and consumption; hence, higher values should be considered as 'normal'. ${ }^{18}$

Regarding the perioperative period, in high-risk surgical patients postoperative low $\mathrm{ScvO}_{2}$ was associated with increased number of complications. ${ }^{27}$ In a recent study, aiming to achieve oxygen extraction
$<27 \%$ as target endpoint, which means keeping $\mathrm{ScvO}_{2}>73 \%$, reduced the number of organ failures and hospital stay after surgery. ${ }^{28}$ In our previous experiments, $\mathrm{ScvO}_{2}$ showed good correlation with oxygen extraction. ${ }^{29,30}$ However, it is an important finding of the current study that $\mathrm{ScvO}_{2}$ remained significantly lower at the end of resuscitation as compared with baseline despite that SV has reached its baseline value. One possible cause of this difference between the baseline and final $\mathrm{ScvO}_{2}$ is the significant decrease of the hemoglobin level due to hemodilution that was also observed in previous studies. ${ }^{31}$ Therefore, taking baseline $\mathrm{ScvO}_{2}$, measured for example at the beginning of surgery, as a target during fluid resuscitation can potentially lead to fluid overload and should not be aimed for. In contrast, if the patient is hemodynamically stabilized (i.e. PPV, SVV and $\mathrm{dCO}_{2}$ are also normalized) but the $\mathrm{ScvO}_{2}$ remains low, it can be an alarming sign that the low hemoglobin causes decreased oxygen delivery, which may require transfusion. This is in accord with our recent findings in isovolemic anemia. ${ }^{29}$

\section{$\mathrm{dCO}_{2}$ as therapeutic endpoint}

Several authors have reported increased $\mathrm{dCO}_{2}$ in different low flow states. ${ }^{19,20,32,33}$ In hypoxemiacaused anaerob metabolism, hydrogen ions are generated by the hydrolysis of adenosine triphosphate 
to adenosine diphosphate, and by the increased production of lactic acid. ${ }^{20}$ These hydrogen ions are buffered by bicarbonate present in the cells, and this process will generate $\mathrm{CO}_{2}$ production. ${ }^{32}$ Arterial $\mathrm{PaCO}_{2}$ is dependent on pulmonary gas exchange, and central venous $\mathrm{PvCO}_{2}$ is dependent on the capability of blood flow to wash out carbon dioxide from the tissues. The Fick principle adapted to carbon dioxide demonstrates the inverse relationship between the $\mathrm{CO}$ and $\mathrm{dCO}_{2}{ }^{34}$ Thus, it has been postulated that increased $\mathrm{dCO}_{2}$ reflects decreased flow.

In our experiment, $\mathrm{dCO}_{2}$ increased significantly during bleeding and then returned to its baseline value. After bleeding, both SVI and hemoglobin levels decreased significantly, while lactate increased more than twofold predisposing anaerobic $\mathrm{CO}_{2}$ production due to tissue hypoxia. With the stepwise normalization of the SVI, the clearance of the $\mathrm{CO}_{2}$ from the tissues was resolved.

In the clinical setting, $\mathrm{dCO}_{2}$ seems to be a promising target endpoint. $\mathrm{A} \mathrm{dCO}_{2}>5 \mathrm{mmHg}$ had $96 \%$ sensitivity to predict the occurence of post-operative complications in patients with normal $(\geq 71 \%)$ $\mathrm{ScvO}_{2} \cdot{ }^{35}$ In critically ill patients, the $\mathrm{dCO}_{2}$ is in a good inverse correlation with the $\mathrm{CO},{ }^{32}$ and its high value has a bad prognostic factor. ${ }^{36}$

However, if the flow is normal or elevated (hyperdynamic states), the $\mathrm{CO}_{2}$ produced by anaerobic metabolism can be washed out; hence, there will be no increase in the $\mathrm{dCO}_{2}$. This phenomenon was demonstrated by Vallet et al. on isolated hind limb of dogs. Their results suggest that $\mathrm{dCO}_{2}$ increases only in the presence of ischamic hypoxia, but not in hypoxemic hypoxia with intact flow. ${ }^{37}$ This also means that reaching the physiological value of the $\mathrm{dCO}_{2}$ does not mean adequate tissue oxygenation. In a recent animal experiment, we found that adding $\mathrm{dCO}_{2}$ to $\mathrm{ScvO}_{2}$ for predicting hypovolemia-caused increase of $\mathrm{VO}_{2} / \mathrm{DO}_{2}>30 \%$ improved positive predictive value from $85 \%$ to $100 \% .{ }^{30}$

Nevertheless, our current results give further evidence that combining $\mathrm{dCO}_{2}$ with $\mathrm{ScvO}_{2}$ can be complementary tools not just in the diagnosis in hypovolemia, but also during fluid resuscitation in the perioperative setting.

\section{$P P V$ and SVV to guide fluid therapy}

PPV and SV variation are the result of the cyclic lung-heart interactions, and they have been shown to be excellent dynamic indices of fluid responsiveness in mechanically ventilated patients with sinus rhythm. ${ }^{25}$ In a recent study, we also found that PPVguided fluid therapy resulted a decrease in the number of complications in patients undergoing major abdominal surgery. ${ }^{38}$ In the current experiment, both SVV and PPV increased significantly following hemorrhage indicating hypovolemia, and at the end of fluid resuscitation they returned to normal values and correlated well with SVI. When SVI was completely restored, PPV, SVV and $\mathrm{dCO}_{2}$ also returned to the baseline physiological value, while $\mathrm{ScvO}_{2}$ remained lower. Our results give further evidence that while $\mathrm{ScvO}_{2}$ is a good indicator of the $\mathrm{VO}_{2} / \mathrm{DO}_{2}$ relationship, PPV, SVV and $\mathrm{dCO}_{2}$ are better indicators of changes in SV.

\section{Limitations}

First of all, the results can only partially be extrapolated for the real clinical settings. Reducing the SV by $50 \%$ was a strictly controlled scenario, rarely happening in the everyday practice. The observation period at the end of the experiment was also short; therefore, long-term effects of SV-based fluid resuscitation on hemodynamics and oxygen delivery and consumption were not assessed. Another limitation of the model is that bleeding was relatively fast, causing a symphatetic burst, while in the operating room intravascular volume loss and bleedingcaused hypovolemia usually occurs over a longer period of time.

\section{Conclusion}

In this experiment in an SV-guided bleeding and fluid resuscitation model, both $\mathrm{ScvO}_{2}$ and $\mathrm{dCO}_{2}$ correlated well with changes in SV. However, together with SV, PPV, SVV and $\mathrm{dCO}_{2}$ returned to baseline normal values; $\mathrm{ScvO}_{2}$ still indicated a non-optimal oxygen delivery because of low hemoglobin concentrations. These results suggest that SVI, SVV, PPV and $\mathrm{dCO}_{2}$ are good hemodynamic endpoints of resuscitation, while $\mathrm{ScvO}_{2}$ is not strictly a hemodynamic parameter, but rather an indicator of the balance between oxygen delivery and consumption.

\section{Acknowledgements}

The authors would like to thank the assistants, medical students and staff at the Institute of Surgical Research for their help.

Conflicts of interest: On behalf of all authors, the corresponding author states that there is no conflict of interest.

Funding: The experiment was supported by the research grant TÁMOP-4.2.2.A-11/1/KONV-2012-0035.

\section{References}

1. Cullinane M, Gray AJ, Hargraves CM. The 2003 Report of the National Confidential Enquiry into peri-operative deaths. London: NCEPOD, 2003. 
2. Bland RD, Shoemaker WC, Abraham E, Cobo JC. Hemodynamic and oxygen transport patterns in surviving and nonsurviving postoperative patients. Crit Care Med 1985; 13: 85-90.

3. Poeze M, Ramsay G, Greve JW, Singer M. Prediction of postoperative cardiac surgical morbidity and organ failure within 4 hours of intensive care unit admission using esophageal Doppler ultrasonography. Crit Care Med 1999; 27: 1288-94.

4. Shoemaker WC, Appel PL, Kram HB. Tissue oxygen debt as a determinant of lethal and nonlethal postoperative organ failure. Crit Care Med 1988; 16: 1117-20.

5. Mythen MG, Webb AR. Intraoperative gut mucosal hypoperfusion is associated with increased post-operative complications and cost. Intensive Care Med 1994; 20: 99 104.

6. Vincent JL, Sakr Y, Sprung CL, Ranieri VM, Reinhart K, Gerlach H, Moreno R, Carlet J, Le Gall JR, Payen D. Sepsis occurrence in acutely Ill patients investigators: European intensive care units: results of the SOAP study. Crit Care Med 2006; 34: 344-53.

7. Kern JW, Shoemaker WC. Meta-analysis of hemodynamic optimization in high-risk patients. Crit Care Med 2002; 30: 1686-92.

8. Gurgel ST, do Nascimento P Jr. Maintaining tissue perfusion in high-risk surgical patients: a systematic review of randomized clinical trials. Anesth Analg 2011; 112: 138491.

9. Cannesson M, Pestel G, Ricks C, Hoeft A, Perel A. Hemodynamic monitoring and management in patients undergoing high risk surgery: a survey among North American and European anesthesiologists. Crit Care 2011; 15: R197.

10. Marik PE, Baram M, Vahid B. Does central venous pressure predict fluid responsiveness? A systematic review of the literature and the tale of seven mares. Chest 2008; 134: 172-8.

11. Osman D, Ridel C, Ray P, Monnet X, Anguel N, Richard C, Teboul JL. Cardiac filling pressures are not appropriate to predict hemodynamic response to volume challenge. Crit Care Med 2007; 35: 64-8.

12. Rivers EP, Ander DS, Powell D. Central venous oxygen saturation monitoring in the critically ill patient. Curr Opin Crit Care 2001; 7: 204-11.

13. Rivers E, Nguyen B, Havstad S, Ressler J, Muzzin A, Knoblich B, Peterson E, Tomlanovich M, Early Goal-Directed Therapy Collaborative Group. Early goal-directed therapy in the treatment of severe sepsis and septic shock. N Engl J Med 2001; 345: 1368-77.

14. van Beest P, Wietasch G, Scheeren T, Spronk P, Kuiper M. Clinical review: use of venous oxygen saturations as a goal a yet unfinished puzzle. Crit Care 2011; 15: 232.

15. Perz S, Uhlig T, Kohl M, Bredle DL, Reinhart K, Bauer M, Kortgen A. Low and 'supranormal' central venous oxygen saturation and markers of tissue hypoxia in cardiac surgery patients: a prospective observational study. Intensive Care Med 2011; 37: 52-9.

16. De Backer D, Ospina-Tascon G, Salgado D, Favory R, Creteur J, Vincent JL. Monitoring the microcirculation in the critically ill patient: current methods and future approaches. Intensive Care Med 2010; 36: 1813-25.

17. Walley KR. Heterogeneity of oxygen delivery impairs oxygen extraction by peripheral tissues: theory. J Appl Physiol 1996; 81: 885-94.

18. Goepfert MS, Richter HP, Zu Eulenburg C, Gruetzmacher J, Rafflenbeul E, Roeher K, von Sandersleben A, Diedrichs S, Reichenspurner H, Goetz AE, Reuter DA. Individually optimized hemodynamic therapy reduces complications and length of stay in the intensive care unit: a prospective, randomized controlled trial. Anesthesiology 2013; 119: 82436.

19. Mecher CE, Rackow EC, Astiz ME, Weil MH. Venous hypercarbia associated with severe sepsis and systemic hypoperfusion. Crit Care Med 1990; 18: 585-9.

20. Weil MH, Rackow EC, Trevino R, Grundler W, Falk JL, Griffel MI. Difference in acid-base state between venous and arterial blood during cardiopulmonary resuscitation. N Engl J Med 1986; 315: 153-6.

21. Lobo SM, Lobo FR, Polachini CA, Patini DS, Yamamoto AE, de Oliveira NE, Serrano P, Sanches HS, Spegiorin MA, Queiroz MM, Christiano AC Jr., Savieiro EF, Alvarez PA, Teixeira SP, Cunrath GS. Prospective, randomized trial comparing fluids and dobutamine optimization of oxygen delivery in high-risk surgical patients [ISRCTN42445141]. Crit Care 2006; 10: R72.

22. Pearse R, Dawson D, Fawcett J, Rhodes A, Grounds RM, Bennett ED. Early goal-directed therapy after major surgery reduces complications and duration of hospital stay. A randomised, controlled trial [ISRCTN38797445]. Crit Care 2005; 9: R687-93.

23. Benes J, Chytra I, Altmann P, Hluchy M, Kasal E, Svitak R, Pradl R, Stepan M. Intraoperative fluid optimization using stroke volume variation in high risk surgical patients: results of prospective randomized study. Crit Care 2010; 14: R118.

24. Cecconi M, Fasano N, Langiano N, Divella M, Costa MG, Rhodes A, Della Rocca G. Goal-directed haemodynamic therapy during elective total hip arthroplasty under regional anaesthesia. Crit Care 2011; 15: R132.

25. Michard F, Teboul JL. Using heart-lung interactions to assess fluid responsiveness during mechanical ventilation. Crit Care 2000; 4: 282-9.

26. Reinhart K, Kuhn HJ, Hartog C, Bredle DL. Continuous central venous and pulmonary artery oxygen saturation monitoring in the critically ill. Intensive Care Med 2004; 30: 1572-8.

27. Collaborative Study Group on Perioperative $\mathrm{ScvO}_{2}$ Monitoring. Multicentre study on peri- and postoperative central venous oxygen saturation in high-risk surgical patients. Crit Care 2006; 10: R158.

28. Donati A, Loggi S, Preiser JC, Orsetti G, Münch C, Gabbanelli V, Pelaia P, Pietropaoli P. Goal-directed intraoperative therapy reduces morbidity and length of hospital stay in high-risk surgical patients. Chest 2007; 132: 1817-24.

29. Kocsi S, Demeter G, Fogas J, Erces D, Kaszaki J, Molnár Z. Central venous oxygen saturation is a good indicator of altered oxygen balance in isovolemic anemia. Acta Anaesthesiol Scand 2012; 56: 291-7.

30. Kocsi S, Demeter G, Erces D, Nagy E, Kaszaki J, Molnar Z. Central venous-to-arterial $\mathrm{CO}_{2}$ gap is a useful parameter in monitoring hypovolemia-caused altered oxygen balance: animal study. Crit Care Res Pract 2013; 2013: 583598. doi: $10.1155 / 2013 / 583598$.

31. Vallet B, Robin E, Lebuffe G. Venous oxygen saturation as a physiologic transfusion trigger. Crit Care 2010; 14: 213.

32. Cuschieri J, Rivers EP, Donnino MW, Katilius M, Jacobsen G, Nguyen HB, Pamukov N, Horst HM. Central venous-arterial carbon dioxide difference as an indicator of cardiac index. Intensive Care Med 2005; 31: 818-22.

33. Benjamin E, Paluch TA, Berger SR, Premus G, Wu C, Iberti TJ. Venous hypercarbia in canine hemorrhagic shock. Crit Care Med 1987; 15: 516-8.

34. Lamia B, Monnet X, Teboul JL. Meaning of arterio-venous $\mathrm{PCO}_{2}$ difference in circulatory shock. Minerva Anestesiol 2006; 72: 597-604. 
35. Futier E, Robin E, Jabaudon M, Guerin R, Petit A, Bazin JE, Constantin JM, Vallet B. Central venous $\mathrm{O}_{2}$ saturation and venous-to-arterial $\mathrm{CO}_{2}$ difference as complementary tools for goal-directed therapy during high-risk surgery. Crit Care 2010; 14: R193.

36. Bakker J, Vincent JL, Gris P, Leon M, Coffernils M, Kahn RJ. Veno-arterial carbon dioxide gradient in human septic shock. Chest 1992; 101: 509-15.

37. Vallet B, Teboul JL, Cain S, Curtis S. Venoarterial $\mathrm{CO}_{2}$ difference during regional ischemic or hypoxic hypoxia. J Appl Physiol 2000; 89: 1317-21.

38. Salzwedel C, Puig J, Carstens A, Bein B, Molnar Z, Kiss K, Hussain A, Belda J, Kirov MY, Sakka SG, Reuter DA. Perioperative goal-directed hemodynamic therapy based on radial arterial pulse pressure variation and continuous cardiac index trending reduces postoperative complications after major abdominal surgery: a multi-center, prospective, randomized study. Crit Care 2013; 8: R191.

Address:

Márton Németh

Department of Anaesthesiology and Intensive Therapy

University of Szeged

6 Semmelweis Street

6725 Szeged

Hungary

e-mail: nemethmarton85@gmail.com 


\title{
Goal-Directed Resuscitation Aiming Cardiac Index Masks Residual Hypovolemia: An Animal Experiment
}

\author{
Krisztián Tánczos, ${ }^{1}$ Márton Németh, ${ }^{1}$ Domonkos Trásy,, Ildikó László,, Péter Palágyi, \\ Zsolt Szabó, ${ }^{1}$ Gabriella Varga, ${ }^{2}$ and József Kaszaki ${ }^{2}$ \\ ${ }^{1}$ Department of Anaesthesiology and Intensive Therapy, Faculty of Medicine, University of Szeged, 6 Semmelweis Street, \\ Szeged 6725, Hungary \\ ${ }^{2}$ Institute of Surgical Research, University of Szeged, 6 Semmelweis Street, Szeged 6725, Hungary \\ Correspondence should be addressed to Krisztián Tánczos; tkrisztian78@gmail.com
}

Received 24 July 2015; Accepted 10 September 2015

Academic Editor: Mitja Lainscak

Copyright (C) 2015 Krisztián Tánczos et al. This is an open access article distributed under the Creative Commons Attribution License, which permits unrestricted use, distribution, and reproduction in any medium, provided the original work is properly cited.

\begin{abstract}
The aim of this study was to compare stroke volume (SVI) to cardiac index (CI) guided resuscitation in a bleeding-resuscitation experiment. Twenty six pigs were randomized and bled in both groups till baseline SVI $\left(T_{\text {bsl }}\right)$ dropped by $50 \%\left(T_{0}\right)$, followed by resuscitation with crystalloid solution until initial SVI or CI was reached $\left(T_{4}\right)$. Similar amount of blood was shed but animals received significantly less fluid in the CI-group as in the SVI-group: median $=900$ (interquartile range: 850-1780) versus 1965 (1584-2165) $\mathrm{mL}, p=0.02$, respectively. In the SVI-group all variables returned to their baseline values, but in the CI-group animals remained underresuscitated as indicated by SVI, heart rate (HR) and stroke volume variation (SVV), and central venous oxygen saturation $\left(\mathrm{S}_{\mathrm{cv}} \mathrm{O}_{2}\right)$ at $T_{4}$ as compared to $T_{\mathrm{bsl}}: \mathrm{SVI}=23.8 \pm 5.9$ versus $31.4 \pm 4.7 \mathrm{~mL}, \mathrm{HR}: 117 \pm 35$ versus $89 \pm 11 / \mathrm{min} \mathrm{SVV}: 17.4 \pm 7.6$ versus $11.5 \pm 5.3 \%$, and $\mathrm{S}_{\mathrm{cv}} \mathrm{O}_{2}: 64.1 \pm 11.6$ versus $79.2 \pm 8.1 \%, p<0.05$, respectively. Our results indicate that CI-based goal-directed resuscitation may result in residual hypovolaemia, as bleeding caused stress induced tachycardia "normalizes" CI, without restoring adequate SVI. As the SVI-guided approach normalized most hemodynamic variables, we recommend using SVI instead of CI as the primary goal of resuscitation during acute bleeding.
\end{abstract}

\section{Introduction}

Acute bleeding due to trauma, surgery, or gastrointestinal disorders is a life threatening condition requiring immediate and adequate interventions, of which intravenous fluid therapy is regarded as the first step of resuscitation. Although lifesaving at the time, inadequate fluid resuscitation can lead to hypoor hyper-perfusion causing the development of multiorgan disorders at a later stage, which then severely affects the outcome of these patients $[1,2]$. Therefore, the use of early and efficient therapeutic strategies able to detect and to treat the imbalance between oxygen delivery and consumption is of particular importance in critically ill patients, which has been recognized for decades [3].

Traditional endpoints of resuscitation, such as heart rate, blood pressure, mental status, and urine output can be useful in the initial identification of inadequate perfusion but are limited in their ability to identify ongoing, compensated shock [4]. More detailed assessment of global macrohemodynamic indices such as cardiac output and derived variables, measures of oxygen debt, may be necessary to guide treatment $[5,6]$.

Cardiac output calculated from thermodilution or pulse contour analysis is the most often used end-point during goal-directed therapy $[7,8]$. However, there is no consensus on the best or universally accepted parameter as resuscitation target. In a recent animal experiment we described changes in central venous oxygen saturation $\left(\mathrm{S}_{\mathrm{cv}} \mathrm{O}_{2}\right)$ and venous-toarterial carbon dioxide gap $\left(\mathrm{dCO}_{2}\right)$ during an experimental stroke volume index- (SVI-) guided bleeding and fluid resuscitation model on porcine. We found that $\mathrm{dCO}_{2}$ may be a useful hemodynamic endpoint of resuscitation, while $\mathrm{S}_{c v} \mathrm{O}_{2}$ is 
not strictly a hemodynamic parameter, but rather an indicator of the balance between oxygen delivery and consumption [9]. However, we also noticed that normalizing stroke volume index resulted in higher cardiac index (CI) by the end of resuscitation as compared with baseline, possibly because of the bleeding-induced tachycardia. Hence we hypothesized that normalizing cardiac output only may mask ongoing hypovolemia due to increased heart rate caused by sympathetic response and may result in inadequate fluid resuscitation. Therefore, the objective of the current study was to compare SVI as primary target of fluid resuscitation to CIbased treatment in a bleeding-resuscitation animal model.

\section{Materials and Methods}

The experiments were performed on the EU Directive 2010/63/EU on the protection of animals used for experimental and other scientific purposes and carried out in strict adherence to the NIH guidelines for the use of experimental animals. The study was approved by the National Scientific Ethical Committee on Animal Experimentation (National Competent Authority), with the license number V./142/2013.

2.1. Animals and Instrumentation. Vietnamese mini-pigs $(n=27)$ underwent a 12-hour fasting preoperatively but with free access to water. Anesthesia was induced by intramuscular injection of a mixture of ketamine $(20 \mathrm{mg} / \mathrm{kg})$ and xylazine $(2 \mathrm{mg} / \mathrm{kg})$ and maintained with a continuous intravenous infusion of propofol $(6 \mathrm{mg} / \mathrm{kg} / \mathrm{hr}$ iv. $)$, while analgesia was performed with nalbuphine $(0.1 \mathrm{mg} / \mathrm{kg})$. The animals' trachea was intubated and the lungs were ventilated mechanically with Dräger Evita XL (Dräger, Lübeck, Germany). The tidal volume was set at $10 \mathrm{~mL} / \mathrm{kg}$, and the respiratory rate was adjusted to maintain the end-tidal carbon dioxide and partial pressure of arterial carbon dioxide in the range of 35$45 \mathrm{mmHg}$. The adequacy of the depth of anesthesia was assessed by monitoring the jaw tone. After induction of anesthesia, the right jugular vein, the left carotid artery, and the right femoral artery were dissected and catheterized using aseptic technique. For invasive hemodynamic monitoring, a transpulmonary thermodilution catheter (PiCCO, PULSION Medical Systems SE, Munich, Germany) was placed in the right femoral artery. Central venous catheter was inserted via the right jugular vein and was positioned by the guidance of intracavital ECG. During the bleeding phase blood was drained from a sheat inserted in the left carotid artery. Animals were kept warm $\left(37 \pm 1^{\circ} \mathrm{C}\right)$ by an external warming device.

2.2. Hemodynamic Monitoring and Blood Gas Sampling. Cardiac output (CO), global end-diastolic volume index (GEDI), stroke volume (SV), cardiac function index (CFI), index of left ventricular contractility (dPmax), SV variation (SVV), pulse pressure variation (PPV), heart rate (HR), and mean arterial pressure (MAP) were measured by transpulmonary thermodilution and pulse contour analysis at baseline and at the end of each interval. All hemodynamic parameters were indexed for body surface area or bodyweight. Central venous catheter was used for the injection of cold saline boluses for the thermodilution measurements. The average of three measurements following $10 \mathrm{~mL}$ bolus injections of ice-cold $0.9 \%$ saline was recorded. Central venous pressure (CVP) was measured via central venous catheter at the same times as the other hemodynamic variables.

For blood gas measurements the right femoral artery served as the site for arterial blood gas sampling and the central venous line was used for taking central venous blood gas samples, which were analyzed by cooximetry (Cobas b 221, Roche Ltd., Basel, Switzerland) simultaneously at baseline and at the end of each step. From these parameters the following variables were calculated:

$$
\begin{aligned}
& \text { Delivery of oxygen }\left(\mathrm{DO}_{2}\right) \\
& =\mathrm{CI} *\left(\mathrm{Hb} * 1.34 * \mathrm{SaO}_{2}+0.003 * \mathrm{PaO}_{2}\right) \\
& \text { Oxygen consumption }\left(\mathrm{VO}_{2}\right) \\
& =\mathrm{CI} \\
& \quad *\left(\mathrm{CaO}_{2}-\left(\mathrm{Hb} * 1.34 * \mathrm{~S}_{\mathrm{cv}} \mathrm{O}_{2}+0.003 * \mathrm{P}_{\mathrm{cv}} \mathrm{O}_{2}\right)\right) \\
& \text { Oxygen extraction }=\frac{\mathrm{VO}_{2}}{\mathrm{DO}_{2}}
\end{aligned}
$$

2.3. Experimental Protocol. The flowchart of the experiment is summarized in Figure 1. After the instrumentation, animals were allowed to rest for 30 minutes after which baseline $\left(T_{\text {bsl }}\right)$ hemodynamic, microcirculatory measurements, blood gas analyses, including lactate measurements, and laboratory testing were performed. After these measurements, blood was drained until the stroke volume index dropped by $50 \%$ of its baseline value $\left(T_{0}\right)$; then measurements were repeated. At this point the animals were randomized into two groups. In the SVI-group the difference of the $\mathrm{SVI}_{T_{\text {bsl }}}-\mathrm{SVI}_{T_{0}}$ was divided into four equal target values, which was aimed to reach in 4 steps during fluid resuscitation $\left(T_{1-4}\right)$ to reach the initial SVI by $T_{4}$. While in the CI-group the difference of the $\mathrm{CI}_{T_{\text {bsl }}}-\mathrm{CI}_{T_{0}}$ was divided into 4 target values and then the animals were resuscitated in 4 steps in order to reach the $\mathrm{CI}_{T_{\text {bsl }}}$ by $T_{4}$. Fluid replacement was carried out with boluses of $200 \mathrm{~mL}$ of balanced crystalloid Ringerfundin (B. Braun AG., Melsungen, Germany) over 10 minutes, till the target SVI or CI value was reached. After reaching each step, 20 minutes was allowed for equilibrium; then hemodynamic and blood gas parameters were measured. At the end of the experiment the animals were euthanized with sodium pentobarbital.

2.4. Data Analysis and Statistics. Data are presented as mean \pm standard deviations unless indicated otherwise. For testing normal distribution the Kolmogorov-Smirnov test was used. Changes in all parameters throughout the experiment were tested by two-way repeated measures analysis of variance (RM ANOVA) and for the post hoc test Bonferroni test was used. For pairwise comparisons Pearson's correlation was used. The primary end point of the study was the normalization of SVV, as the one of the best indicators of hypo-, normovolemia 


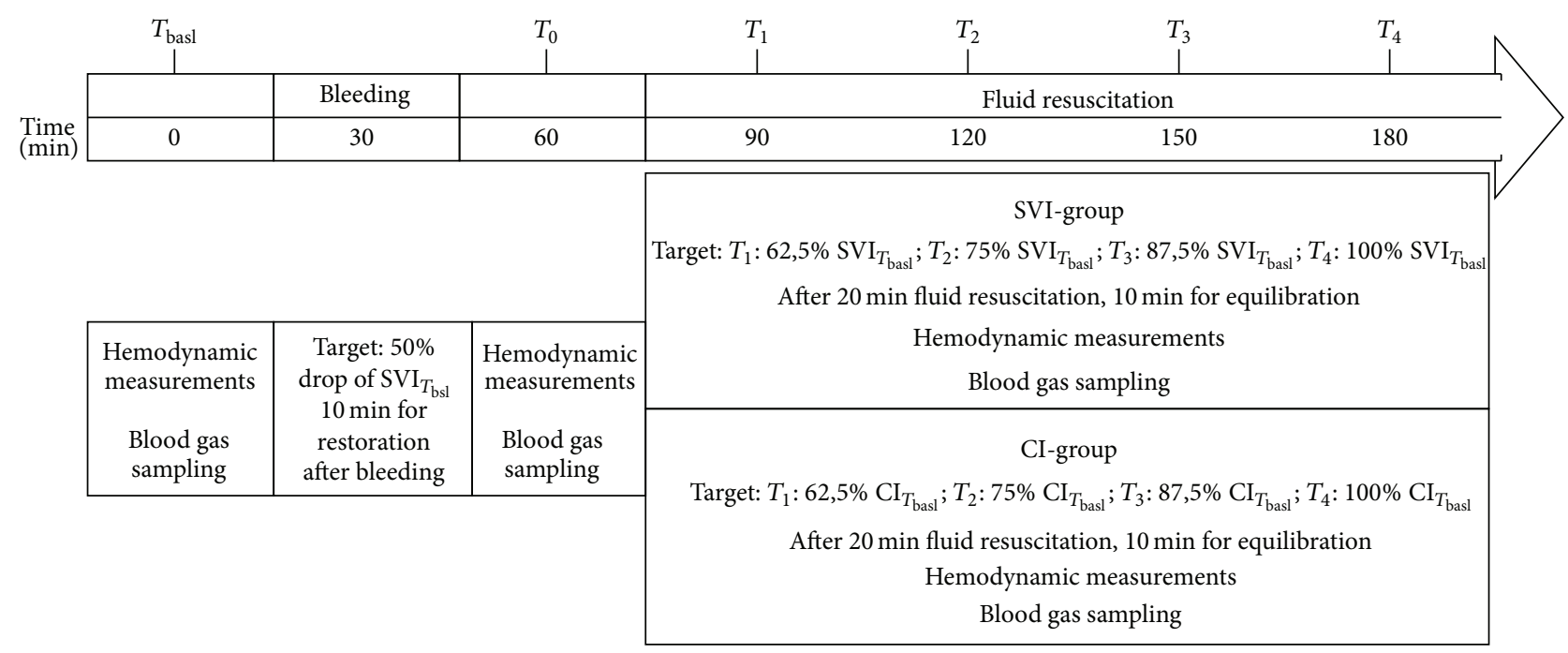

FIGURE 1: Flow chart. Schematic diagram illustrating the flowchart of the experimental protocol. After baseline measurement, animals were bled until the stroke volume index (SVI) decreased by $50 \%\left(T_{0}\right)$; then measurements were repeated and randomized into two group. In the SVI-group the difference of the $\mathrm{SVI}_{T_{\mathrm{bsl}}}-\mathrm{SVI}_{T_{0}}$ was divided into four equal target values $\left(T_{1-4}\right)$, and fluid resuscitated to reach the initial SVI by $T_{4}$. In the CI-group the difference of the $\mathrm{CI}_{T_{\mathrm{bsl}}}-\mathrm{CI}_{T_{0}}$ was divided into 4 target values and then the animals were resuscitated in 4 steps in order to reach the $\mathrm{CI}_{T_{\mathrm{bsl}}}$ by $T_{4}$.

in mechanically ventilated subjects [10]. Based on the results of our previous animal experiment [9] SVV was found to be $12.2 \pm 4.3 \%$ by the end of resuscitation. Considering that CI-based resuscitation remains inadequate, we regarded a clinically significant difference of $4 \%$ (i.e., $12 \%$ in the SVIgroup and $16 \%$ in the CI-group). In order the study to have $80 \%$ power to show a difference between the two groups if $\alpha<0.05$, the required sample size is a minimum of 20 animals (10 in each group). For statistical analysis SPSS version 20.0 for Windows (SPSS, Chicago, IL) was used and $p<0.05$ was considered statistically significant.

\section{Results}

All animals survived the experiment, apart from one (CIgroup), which had sudden cardiac arrest after induction of anesthesia for unknown reasons. Therefore, the results of 14 animals in the SVI-group and 12 animals in the CI-group were analyzed. Demographics and fluid management data are summarized in Table 1. Animals were of similar weight in both groups. For a 50\% decrease of SVI similar blood had to be drained in the two groups. During resuscitation animals in the SVI-group required more fluid in total, and taking into account the volume of crystalloid required to replace a unit of $10 \mathrm{~mL}$ blood loss, animals in the SVI-group also received significantly more fluid (Table 1).

3.1. Macrohemodynamics. Hemodynamic parameters were similar at $T_{\text {bsl }}$ and goals of 50\% reduction in SVI were reached by $T_{0}$ in both groups (Table 2 ). In the SVI-group SVI returned to its baseline value by $T_{4}$ and CI was significantly elevated as compared to $T_{\mathrm{bsl}}$. In the CI-group SVI remained significantly lower as compared to $T_{\text {bsl }}$. Mean arterial pressure and heart rate showed a similar pattern in both groups, but in the CI-group heart rate remained significantly higher by $T_{4}$ as compared to $T_{\text {bsl }}$, while it normalized in the SVI-group. Mean arterial pressure changed significantly in each group with a similar pattern without significant differences between the groups. There was less change in the CVP throughout the experiment, with a significant increase at $T_{3}$ and $T_{4}$ only in the SVI-group. Global end-diastolic volume decreased and then increased in both groups, but while it normalized by $T_{4}$ in the SVI-group, it remained significantly lower in the CI-group as compared to the SVI-group and as compared to $T_{\text {bsl }}$. Stroke volume variation and PPV also followed a similar pattern, and SVV normalized in the SVI-group but it remained significantly elevated in the CI-group, both as compared to $T_{\text {bsl }}$ and between the groups at $T_{4}$. Contractility, as indicated by dPmax values did not show any considerable change over time or between the groups.

3.2. Measures of Oxygen Debt. Oxygen delivery followed a similar pattern in both groups, but in the CI-group it remained significantly lower at $T_{4}$ as compared to $T_{\text {bsl }}$ (Table 3). In the SVI-group there was also a considerable drop by $T_{4}$, although it was not significant. This can be explained by the significant and steady decrease in the hemoglobin levels in both groups. Oxygen consumption was more or less stable throughout the experiment, apart from a significant increase during the bleeding phase in both groups. Oxygen extraction changed accordingly with no major difference between the groups. Arterial pH, oxygen partial pressure, and oxygen saturation remained stable and within the normal range throughout. 
TABLE 1: Demographics and fluid therapy.

\begin{tabular}{lccc}
\hline & SVI-group $(n=14)$ & CI-group $(n=12)$ & $p$ \\
\hline Weight $(\mathrm{kg})$ & $29.00 \pm 5.36$ & $27.54 \pm 5.46$ & $0.93 \pm 0.91$ \\
BSA $\left(\mathrm{m}^{2}\right)$ & $0.98 \pm 0.09$ & $479 \pm 101$ & 0.606 \\
Shed blood $(\mathrm{mL})$ & $485 \pm 91$ & $508 \pm 101$ & 0.859 \\
Shed blood $\left(\mathrm{mL} / \mathrm{m}^{2}\right)$ & $492 \pm 59$ & $900[850-1780]$ & 0.719 \\
Total amount of the replaced fluid $(\mathrm{mL})$ & $1965[1584-2165]$ & $25 \pm 12$ & $0.020^{*}$ \\
Required fluid $(\mathrm{mL}) /$ unit blood loss $(10 \mathrm{~mL})$ & $40 \pm 12$ & $0.027^{*}$ \\
\hline
\end{tabular}

SVI (stroke volume index), SVI-group; CI (cardiac index), CI-group. Data are presented as mean \pm standard deviation or median [interquartile range] as appropriate. ${ }^{*} p<0.05$.

TABLE 2: Hemodynamic parameters during hemorrhage and fluid resuscitation.

\begin{tabular}{|c|c|c|c|c|c|c|c|}
\hline & Group & $T_{\mathrm{bsl}}$ & $T_{0}$ & $T_{1}$ & $T_{2}$ & $T_{3}$ & $T_{4}$ \\
\hline \multirow{2}{*}{ Stroke volume index $\left(\mathrm{mL} / \mathrm{m}^{2}\right)$} & SVI & $27.5 \pm 5.4$ & $13.8 \pm 2.6^{*}$ & $16.5 \pm 2.8^{*}$ & $19.5 \pm 3.7^{* \#}$ & $23.6 \pm 5.1^{\#}$ & $28.0 \pm 5.0^{\#}$ \\
\hline & $\mathrm{CI}$ & $31.4 \pm 4.7$ & $14.4 \pm 9.0^{*}$ & $18.1 \pm 3.6^{*}$ & $19.2 \pm 3.6^{*}$ & $23.2 \pm 1.3^{* \#}$ & $23.8 \pm 5.9^{* \# @ ~}$ \\
\hline \multirow{2}{*}{ Cardiac index $\left(\mathrm{L} / \mathrm{min} / \mathrm{m}^{2}\right)$} & SVI & $2.6 \pm 0.3$ & $1.8 \pm 0.3^{*}$ & $2.1 \pm 0.4^{*}$ & $2.4 \pm 0.3^{\#}$ & $2.7 \pm 0.4^{\#}$ & $2.9 \pm 0.4^{* \#}$ \\
\hline & $\mathrm{CI}$ & $2.8 \pm 0.3$ & $1.7 \pm 0.5^{*}$ & $2.1 \pm 0.3^{*}$ & $2.4 \pm 0.2^{\#}$ & $2.6 \pm 0.4^{\#}$ & $2.7 \pm 0.3^{\#}$ \\
\hline \multirow{2}{*}{ Mean arterial pressure $(\mathrm{mmHg})$} & SVI & $116 \pm 17$ & $72 \pm 17^{*}$ & $75 \pm 19^{*}$ & $78 \pm 18^{*}$ & $86 \pm 17^{*}$ & $92 \pm 16^{* \#}$ \\
\hline & $\mathrm{CI}$ & $124 \pm 12$ & $75 \pm 22^{*}$ & $77 \pm 18^{*}$ & $80 \pm 81^{*}$ & $86 \pm 22^{*}$ & $96 \pm 20^{* \#}$ \\
\hline \multirow{2}{*}{ Heart rate (beats/min) } & SVI & $95 \pm 13$ & $133 \pm 22^{*}$ & $130 \pm 29^{*}$ & $121 \pm 21^{*}$ & $111 \pm 18^{\#}$ & $101 \pm 12^{\#}$ \\
\hline & $\mathrm{CI}$ & $89 \pm 11$ & $139 \pm 37^{*}$ & $131 \pm 13^{*}$ & $127 \pm 28^{*}$ & $121 \pm 24^{*}$ & $117 \pm 35^{*}$ \\
\hline \multirow{2}{*}{ Central venous pressure $(\mathrm{mmHg})$} & SVI & $5.9 \pm 1.0$ & $4.8 \pm 0.7$ & $5.5 \pm 1.9$ & $5.6 \pm 1.4$ & $6.1 \pm 1.2^{\#}$ & $6.2 \pm 1.3^{\#}$ \\
\hline & $\mathrm{CI}$ & $6.0 \pm 0.6$ & $4.7 \pm 0.8$ & $5.3 \pm 0.6$ & $5.6 \pm 0.5$ & $6.2 \pm 1.5$ & $6.5 \pm 0.7$ \\
\hline \multirow{2}{*}{ Global end-diastolic volume $\left(\mathrm{mL} / \mathrm{m}^{2}\right)$} & SVI & $308 \pm 56$ & $237 \pm 61^{*}$ & $243 \pm 59^{*}$ & $251 \pm 46^{*}$ & $282 \pm 58^{\#}$ & $298 \pm 53^{\#}$ \\
\hline & $\mathrm{CI}$ & $312 \pm 33$ & $191 \pm 56^{* @}$ & $204 \pm 32^{*}$ & $211 \pm 27^{*}$ & $243 \pm 32^{* \#}$ & $247 \pm 32^{* \# @ ~}$ \\
\hline \multirow{2}{*}{ Stroke volume variation (\%) } & SVI & $14.7 \pm 4.7$ & $22.1 \pm 5.5^{*}$ & $22.2 \pm 4.9^{*}$ & $18.5 \pm 4.6$ & $16.7 \pm 5.2^{\#}$ & $12.1 \pm 3.6^{\#}$ \\
\hline & CI & $11.5 \pm 5.3$ & $18.6 \pm 5.2^{*}$ & $18.7 \pm 3.7^{*}$ & $21.3 \pm 4.8$ & $19.3 \pm 4.1^{*}$ & $17.4 \pm 7.6^{* @}$ \\
\hline \multirow{2}{*}{ Pulse pressure variation (\%) } & SVI & $14.2 \pm 5.3$ & $24.6 \pm 6.9^{*}$ & $23.3 \pm 6.7^{*}$ & $19.0 \pm 5.8^{\#}$ & $16.7 \pm 5.2^{\#}$ & $13.1 \pm 4.1^{\#}$ \\
\hline & $\mathrm{CI}$ & $12.2 \pm 3.1$ & $25.2 \pm 6.7^{*}$ & $22.8 \pm 5.4^{*}$ & $19.8 \pm 4.5^{\#}$ & $17.4 \pm 5.8^{\#}$ & $16.3 \pm 6.7^{\#}$ \\
\hline \multirow{2}{*}{ Systemic vascular resistance index $\left(\mathrm{dyn} \times \mathrm{s} / \mathrm{cm}^{5} / \mathrm{m}^{2}\right)$} & SVI & $3261 \pm 942$ & $3100 \pm 873$ & $2677 \pm 734$ & $2442 \pm 698^{* \#}$ & $2410 \pm 466^{* \#}$ & $2336 \pm 475^{* \#}$ \\
\hline & $\mathrm{CI}$ & $3507 \pm 597$ & $3191 \pm 709$ & $2767 \pm 630^{*}$ & $2652 \pm 240^{*}$ & $2508 \pm 565^{*}$ & $2481 \pm 495^{* \#}$ \\
\hline \multirow{2}{*}{ EVLWI (mL/kg) } & SVI & $10.1 \pm 1.9$ & $10.0 \pm 2.2$ & $9.9 \pm 1.9$ & $9.0 \pm 1.5$ & $9.3 \pm 1.6$ & $9.8 \pm 1.7$ \\
\hline & $\mathrm{CI}$ & $7.4 \pm 1.2^{@}$ & $7.2 \pm 0.9^{@}$ & $7.2 \pm 1.0^{@}$ & $7.4 \pm 1.0$ & $7.5 \pm 0.9^{@}$ & $8.2 \pm 1.0^{@}$ \\
\hline \multirow{2}{*}{$\mathrm{dPmax}(\mathrm{mmHg} / \mathrm{s})$} & SVI & $561 \pm 226$ & $560 \pm 344$ & $653 \pm 404$ & $682 \pm 390$ & $987 \pm 269$ & $674 \pm 236$ \\
\hline & $\mathrm{CI}$ & $585 \pm 87$ & $595 \pm 206$ & $579 \pm 95$ & $597 \pm 137$ & $551 \pm 105$ & $639 \pm 154$ \\
\hline
\end{tabular}

SVI (stroke volume index), SVI-group; CI (cardiac index), CI-group. Data are presented as mean \pm standard deviation.

${ }^{*} p<0.05$ significantly different from $T_{\mathrm{bsl}}$.

$\# p<0.05$ significantly different from $T_{0}$.

${ }^{\circledR} p<0.05$ significantly different between groups.

Central venous oxygen saturation was in the normal range at $T_{\text {bsl }}$ in both groups; then there was a significant drop after bleeding, which normalized in the SVI-group but remained significantly lower in the CI-group at $T_{4}$ as compared to the SVI-group. The mean decrease in the CI-group from $T_{\text {bsl }}$ to $T_{4}$ was $15.1 \%$ and at $T_{4}$ it was $8.8 \%$ lower as in the SVI-group. Central venous to arterial $\mathrm{CO}_{2}$-gap was normal at $T_{\text {bsl }}$ in both groups. After bleeding it increased significantly and returned to normal in the SVI-group. In the CI-groups levels also decreased but remained elevated, although they did not reach statistical significance.

Lactate levels were slightly elevated at $T_{\text {bsl }}$ in both groups, with significant increase in the SVI-group, which reduced by $T_{4}$. In the CI-group significant changes could not be observed, and there was no significant difference between the groups either. 
TABLE 3: Blood gas parameters during hemorrhage and fluid resuscitation.

\begin{tabular}{|c|c|c|c|c|c|c|c|}
\hline & Group & $T_{\mathrm{bsl}}$ & $T_{0}$ & $T_{1}$ & $T_{2}$ & $T_{3}$ & $T_{4}$ \\
\hline \multirow{2}{*}{ Oxygen delivery index $\left(\mathrm{mL} / \mathrm{min} / \mathrm{m}^{2}\right)$} & SVI & $417 \pm 64$ & $250 \pm 100^{*}$ & $275 \pm 71^{*}$ & $291 \pm 55^{*}$ & $318 \pm 55^{*}$ & $337 \pm 81^{\#}$ \\
\hline & $\mathrm{CI}$ & $410 \pm 54$ & $271 \pm 62^{*}$ & $297 \pm 85^{*}$ & $282 \pm 47^{*}$ & $278 \pm 52^{*}$ & $311 \pm 61^{*}$ \\
\hline \multirow{2}{*}{ Oxygen consumption (index $\mathrm{mL} / \mathrm{min} / \mathrm{m}^{2}$ ) } & SVI & $82 \pm 27$ & $118 \pm 63^{*}$ & $111 \pm 19$ & $102 \pm 24$ & $98 \pm 24$ & $94 \pm 23$ \\
\hline & $\mathrm{CI}$ & $71 \pm 43$ & $115 \pm 48^{*}$ & $111 \pm 29$ & $108 \pm 21$ & $103 \pm 18$ & $99 \pm 13$ \\
\hline \multirow{2}{*}{ Oxygen extraction $\left(\mathrm{VO}_{2} / \mathrm{DO}_{2}\right)$} & SVI & $0.20 \pm 0.06$ & $0.40 \pm 0.11^{*}$ & $0.36 \pm 0.06^{*}$ & $0.33 \pm 0.11^{*}$ & $0.29 \pm 0.09^{* \#}$ & $0.27 \pm 0.13^{\#}$ \\
\hline & $\mathrm{CI}$ & $0.17 \pm 0.09$ & $0.40 \pm 0.18^{*}$ & $0.38 \pm 0.09^{*}$ & $0.36 \pm 0.08^{*}$ & $0.34 \pm 0.14^{*}$ & $0.33 \pm 0.11^{*}$ \\
\hline \multirow{2}{*}{ Arterial $\mathrm{pH}$} & SVI & $7.48 \pm 0.04$ & $7.46 \pm 0.07$ & $7.44 \pm 0.06$ & $7.41 \pm 0.11$ & $7.45 \pm 0.04$ & $7.46 \pm 0.04$ \\
\hline & $\mathrm{CI}$ & $7.44 \pm 0.04$ & $7.43 \pm 0.06$ & $7.42 \pm 0.05$ & $7.47 \pm 0.03$ & $7.42 \pm 0.05$ & $7.45 \pm 0.05$ \\
\hline \multirow{2}{*}{ Partial pressure of oxygen in arterial blood $(\mathrm{mmHg})$} & SVI & $94.5 \pm 26.5$ & $94.9 \pm 27.8$ & $90.1 \pm 20.2$ & $94.9 \pm 27.1$ & $93.1 \pm 27.1$ & $95.5 \pm 30.1$ \\
\hline & $\mathrm{CI}$ & $88.3 \pm 28.8$ & $89.8 \pm 28.8$ & $97.6 \pm 30.2$ & $89.2 \pm 22.5$ & $93.8 \pm 32.6$ & $88.2 \pm 27.6$ \\
\hline \multirow{2}{*}{ Arterial oxygen saturation (\%) } & SVI & $97.3 \pm 1.5$ & $96.7 \pm 2.1$ & $96.3 \pm 2.0$ & $97.0 \pm 1.5$ & $97.0 \pm 1.7$ & $96.9 \pm 1.8$ \\
\hline & $\mathrm{CI}$ & $95.4 \pm 3.6$ & $95.3 \pm 5.0$ & $96.1 \pm 4.2$ & $98.6 \pm 1.5$ & $95.6 \pm 4.8$ & $96.0 \pm 3.2$ \\
\hline \multirow{2}{*}{ Central venous oxygen saturation (\%) } & SVI & $77.4 \pm 6.6$ & $57.5 \pm 10.8^{*}$ & $60.9 \pm 4.8^{*}$ & $64.3 \pm 9.2^{*}$ & $68.4 \pm 8.6^{* \#}$ & $72.9 \pm 7.5$ \\
\hline & $\mathrm{CI}$ & $79.2 \pm 8.1$ & $56.7 \pm 17.0^{*}$ & $58.5 \pm 10.6$ & $59.7 \pm 8.0$ & $63.0 \pm 14.7$ & $64.1 \pm 11.6^{\# @ ~}$ \\
\hline \multirow{2}{*}{ Venous to arterial carbon dioxide gap $(\mathrm{mmHg})$} & SVI & $5.7 \pm 2.4$ & $10.1 \pm 2.6^{*}$ & $8.9 \pm 1.7$ & $7.5 \pm 2.4$ & $7.2 \pm 2.7$ & $5.3 \pm 2.3^{\#}$ \\
\hline & $\mathrm{CI}$ & $4.0 \pm 3.1$ & $9.9 \pm 6.0^{*}$ & $8.8 \pm 2.4^{*}$ & $8.5 \pm 3.0$ & $8.1 \pm 3.1$ & $7.6 \pm 4.3$ \\
\hline \multirow{2}{*}{ Lactate $(\mathrm{mmol} / \mathrm{L})$} & SVI & $2.54 \pm 1.01$ & $3.97 \pm 1.80^{*}$ & $4.72 \pm 2.29^{*}$ & $4.37 \pm 2.37^{*}$ & $3.90 \pm 2.25^{*}$ & $3.26 \pm 1.95$ \\
\hline & $\mathrm{CI}$ & $3.32 \pm 1.26$ & $4.49 \pm 1.83$ & $4.50 \pm 2.40$ & $4.32 \pm 0.69$ & $4.05 \pm 2.52$ & $3.77 \pm 2.32$ \\
\hline \multirow{2}{*}{ Hemoglobin (g/dL) } & SVI & $11.6 \pm 1.5$ & $10.7 \pm 1.5$ & $10.4 \pm 1.46^{*}$ & $9.4 \pm 1.2^{* \#}$ & $8.3 \pm 1.5^{* \#}$ & $8.1 \pm 0.9^{* \#}$ \\
\hline & $\mathrm{CI}$ & $11.2 \pm 0.7$ & $10.4 \pm 1.2$ & $9.5 \pm 1.2^{*}$ & $9.2 \pm 0.9^{* \#}$ & $8.4 \pm 0.6^{* \#}$ & $8.2 \pm 1.5^{* \#}$ \\
\hline
\end{tabular}

SVI (stroke volume index), SVI-group; CI (cardiac index), CI-group. Data are presented as mean \pm standard deviation.

${ }^{*} p<0.05$ significantly different from $T_{\mathrm{bsl}}$.

${ }^{\#} p<0.05$ significantly different from $T_{0}$.

${ }^{\circledR} p<0.05$ significantly different between groups.

\section{Discussion}

In this study CI-based resuscitation resulted in residual hypovolemia compared to SVI-based fluid management as indicated by both macro-hemodynamic indices and measures of oxygen debt in a bleeding-resuscitation animal experiment.

4.1. Fluid Resuscitation. Fluid therapy is often regarded as the first line of support in most shock states and this holds especially true for acute bleeding. Fluid infusions directly increase intravascular volume and subsequently improve global and regional perfusion and oxygen delivery. However, this benefit can only occur in patients who are on the ascending limb of the Frank-Starling curve. In patients, who are regarded hypovolemic, only $50 \%$ respond to fluid, as defined by a $10-$ $15 \%$ increase in stroke volume [11]. Although fluid resuscitation is a potentially lifesaving intervention large volumes can result in severe tissue edema and clinical signs of volume overload. These effects are mainly articulated in encapsulated organs, which have limited capacity to accommodate additional volume without compromising tissue perfusion. There is mounting evidence that both hypovolemia and fluid overload are associated with impaired organ function and increased risk of dying $[2,12,13]$. Therefore, adequate monitoring and defining appropriate resuscitation end points are of pivotal importance. However, according to recent large international surveys physicians apply monitoring and indicate fluid therapy based mainly on parameters, which are unable to predict fluid responsiveness. Several studies showed that mean arterial pressure and static markers of preload such as CVP, pulmonary capillary occlusion pressure have limited value in guiding fluid management; however more than $80 \%$ of physicians working in anesthesiology or in critical care still rely mainly on these parameters $[14,15]$. Over the last 20 years there were 21 clinical trials published on perioperative goal-directed therapy [16]. In these studies hemodynamic goals showed a great variability. The most frequently used parameters to guide fluid management were CI, SV, SVV, PPV, CVP, MAP, echo-derived dynamic indices, pulmonary artery occlusion pressure, $\mathrm{DO}_{2}$, and oxygen extraction ratio. This clearly shows that universally accepted hemodynamic target by which fluid therapy should be tailored is missing.

It is important to note that recent milestones of multicenter clinical trials on fluid therapy [17-20] "neglected" this approach to some extent, and in these studies fluid administration was mainly based on the clinicians' "intuition" or inadequate indices rather than appropriate hemodynamic parameters of intravascular blood volume. Nevertheless, one 
of the most important messages of these large trials, which is also in accord with the results of recent surveys $[14,15]$, is that our everyday routine practice should be revised and may be harmful.

The physiological rationale of intravenous fluid administration to a patient is to increase $\mathrm{SV}$, hence $\mathrm{DO}_{2}$, and also perfusion. In several studies CI was applied as therapeutic goal [21-24], although CO is the product of heart rate and SV; therefore compensatory mechanisms, such as tachycardia, may compensate residual hypovolemia. In the current experiment we found major differences between the SVI- and CIguided groups. The latter received significantly less fluid in total and also required less fluid to replace every unit of lost blood. These results suggest that simply applying invasive hemodynamics as compared to our daily routine monitoring may not be sufficient, and depending on the parameter we chose to follow, subjects can still remain under- or overresuscitated.

\subsection{SVI-versus CI-Guided Goal-Directed Resuscitation: Hemo-} dynamics. During bleeding to restore homeostasis, the sympathetic nervous system becomes activated and releases epinephrine and norepinephrine. As a result, venous return will increase, while on the arterial side norepinephrine-caused vasoconstriction tries to maintain perfusion. Because of this sympathetic activation, heart rate and myocardial contractility will also increase. During resuscitation, our pivotal goal is to restore circulating blood volume by increasing SV to improve oxygen delivery. Recent clinical investigations [25, 26] showed positive effects of SV optimization, and there is frank evidence that PPV and SVV are well-established indicators of fluid responsiveness in mechanically ventilated subjects without cardiac arrhythmias [27]. Therefore in our experiment, SVV was the primary outcome variable as the closest to predict fluid responsiveness, hence hypovolemia. In both groups there was a significant increase after bleeding but values returned to baseline only in the SVI-group. In the CIgroup neither dynamic (SVV/PPV) nor static indicators of preload (GEDI) normalized to their baseline values, indicating, that it was not the circulating blood volume, but heart rate compensated $\mathrm{CO}$, which normalized, leaving residual hypovolemia unnoticed.

It is interesting to note that CVP changed to a lesser degree than any other hemodynamic parameter; hence our results provide further evidence of the limitations to CVP as a goal during fluid resuscitation, also described by others [7]. Although mean arterial pressure followed hemodynamic changes to some extent, there was no difference between the groups, indicating that for fine tuning hemodynamics, just as CVP, MAP also has limited value. This is due to the fact that MAP and CI do not correlate with each other [28].

However, "normalizing" global hemodynamics is one thing, but normalizing the balance between oxygen delivery and consumption is another. Therefore, once the macrohemodynamic parameters look physiological, their effect on $\mathrm{DO}_{2} / \mathrm{VO}_{2}$ should also be assessed.

4.3. SVI-versus CI-Guided Goal-Directed Resuscitation: Oxygen Debt. As it has already been mentioned the primary goal of fluid resuscitation in hypovolemia is to maintain adequate oxygen delivery to the tissues. During bleeding, when oxygen demand/consumption is unchanged (in anesthetized subjects) or increased (in awake subjects), impaired oxygen delivery has to be accompanied by increased oxygen extraction ratio, which can be detected in the changes of $\mathrm{S}_{\mathrm{cv}} \mathrm{O}_{2}$. Physiological mixed venous oxygen saturation ranges between $68 \%$ and $77 \%$, and $\mathrm{S}_{\mathrm{cv}} \mathrm{O}_{2}$ is considered to be $5 \%$ higher [29]. Indeed, in patients under general anesthesia the $\mathrm{S}_{\mathrm{cv}} \mathrm{O}_{2}$ is often higher than $80 \%$, which is due to the reduced oxygen demand and consumption; hence, higher values should be considered as "normal" [30, 31]. Furthermore, in our previous experiments, $\mathrm{S}_{\mathrm{cv}} \mathrm{O}_{2}$ showed good correlation with oxygen extraction $[32,33]$. Therefore, as interpretation of absolute values may prove difficult in different conditions evaluation of the changes of $\mathrm{S}_{\mathrm{cv}} \mathrm{O}_{2}$ may be more helpful. In the current experiment we found that $\mathrm{S}_{\mathrm{cv}} \mathrm{O}_{2}$ improved but remained significantly lower at the end of the experiment as compared to baseline values in both groups. This is most likely due to hemodilution, a feature also found in our previous study [9]. However, in the CI-group $\mathrm{S}_{\mathrm{cv}} \mathrm{O}_{2}$ remained $15 \%$ lower as compared to baseline and more than $10 \%$ lower as in the SVI-group, indicating severe oxygen debt. Although interpreting $\mathrm{S}_{\mathrm{cv}} \mathrm{O}_{2}$ may be difficult when there is problem with extraction typically seen in sepsis, there is international consensus that low levels should be an important warning sign to indicate inadequate $\mathrm{DO}_{2}$ to meet oxygen demands [34]. In our experiment in the CI-group, we measured lower $\mathrm{DO}_{2}, \mathrm{~S}_{\mathrm{cv}} \mathrm{O}_{2}$ and higher oxygen extraction ratio, indicating that animals resuscitated for CI remained in oxygen debt.

Several authors have reported increased $\mathrm{dCO}_{2}$ in different low flow states [35-38]. In hypoxemia caused anaerobic metabolism, hydrogen ions are generated by the hydrolysis of adenosine triphosphate to adenosine diphosphate, and by the increased production of lactic acid [36]. These hydrogen ions are buffered by bicarbonate present in the cells, and this process will generate $\mathrm{CO}_{2}$ production [37]. Arterial $\mathrm{PaCO}_{2}$ is dependent on pulmonary gas exchange, and central venous $\mathrm{PvCO}_{2}$ is dependent on the capability of blood flow to wash out carbon dioxide from the tissues. The Fick principle adapted to carbon dioxide demonstrates the inverse relationship between $\mathrm{CO}$ and $\mathrm{dCO}_{2}$ [39]. Thus, it has been postulated that increased $\mathrm{dCO}_{2}$ reflects decreased flow. In the current experiment $\mathrm{dCO}_{2}$ followed the same pattern, what we observed previously, and returned to the baseline value at the end of resuscitation in the SVI-group. In the CI-group, it remained elevated, above the physiological value of $6 \mathrm{mmHg}$, but this difference did not reach statistical significance. Nevertheless, this tendency gives further evidence that these animals were underresuscitated.

Lactate, the product of anaerobic metabolism, is often referred to as one of the main biochemical targets to be treated during resuscitation [40]. In our experiment, levels were slightly elevated at baseline, possibly due to the relatively long set-up time of the experiment, and there was an increase and then decrease during interventions, but these changes were not as dramatic as one may expect. However, it is important to note, that this experimental model is similar to a "moderate" bleeding event, and animals were resuscitated 
within a relatively short period of time. Due to the physiologic relationship between $\mathrm{DO}_{2}$ and $\mathrm{VO}_{2}$, namely, due to compensatory mechanisms when there is a drop in $\mathrm{DO}_{2}$, up to a certain point $\mathrm{VO}_{2}$ remains stable, in other words independent from $\mathrm{DO}_{2}$. Therefore, although the $\mathrm{VO}_{2} / \mathrm{DO}_{2}$ ratio is increasing, but it does not cause and mean cellular hypoxia, hence aerobic metabolism is not disturbed. To conclude, animals during this experiment were heading towards shock; they were in oxygen debt but remained on the flat part of the $\mathrm{VO}_{2} / \mathrm{DO}_{2}$ curve, not reaching cellular hypoxia and shock, meaning the steep part of the curve. This is also supported by the arterial $\mathrm{pH}$, which remained normal throughout in both groups. In general, this is the rationale and advantage of measuring $\mathrm{S}_{\mathrm{cv}} \mathrm{O}_{2}$, and for similar reasons SVV or PPV, because we are "one step ahead" of cellular hypoxia and circulatory shock.

4.4. Limitations. One of the limitations of this experiment is that we could not provide data on microcirculation and regional blood flow, which would be interesting to see. Furthermore, these results can only partially be extrapolated for the real clinical settings. Reducing the SVI by $50 \%$ is a strictly controlled scenario, rarely happening in the everyday practice. The observation period at the end of the experiment was also short; therefore, long-term effects of SVI or CI-based fluid resuscitation could not be assessed. Another limitation of the model is that bleeding was relatively fast, causing a sympathetic burst, which is a reality in trauma and when major bleeding occurs on the wards, but in the operating room intravascular volume loss and bleeding caused hypovolemia usually occurs over a longer period of time.

\section{Conclusion}

In this experiment we have shown that SVI-based goaldirected resuscitation of a bleeding subject seems superior to CI-guided resuscitation as indicated by both hemodynamic parameters and measures of oxygen debt returning to baseline in the SVI-group, which was incomplete in the CI-group. However, we would like to emphasize that treating one single parameter during resuscitation is not warranted. It is not one single parameter, but the "hemodynamic puzzle" what we have to solve [41]. Therefore, it is necessary to put hemodynamic variables and measures of $\mathrm{VO}_{2} / \mathrm{DO}_{2}$ into context in a way that once macro-hemodynamic parameters are "normalized," adequacy of treatment has to be checked by measures of oxygen debt. Measuring SVV or PPV and simple blood gas driven variables such as $\mathrm{S}_{\mathrm{cv}} \mathrm{O}_{2}$ and $\mathrm{dCO}_{2}$ are valuable tools to solve this puzzle as quickly as possible.

\section{Conflict of Interests}

On behalf of all authors, the corresponding author states that there is no conflict of interests.

\section{Acknowledgments}

The authors would like to thank the assistants, medical students, and staff at the Institute of Surgical Research and the Department of Anaesthesiology and Intensive Therapy for their help. This work was supported by the National Research, Development and Innovation Office (NKFIH K116689).

\section{References}

[1] W. C. Shoemaker, P. L. Appel, and H. B. Kram, "Role of oxygen debt in the development of organ failure sepsis, and death in high-risk surgical patients," Chest, vol. 102, no. 1, pp. 208-215, 1992.

[2] M. Cecconi, D. De Backer, M. Antonelli et al., "Consensus on circulatory shock and hemodynamic monitoring. Task force of the European society of intensive care medicine," Intensive Care Medicine, vol. 40, no. 12, pp. 1795-1815, 2014.

[3] W. C. Schoemaker, P. L. Appel, and H. B. Kram, “Tissue oxygen debt as a determinant of lethal and nonlethal postoperative organ failure," Critical Care Medicine, vol. 16, no. 11, pp. 11171120, 1988.

[4] C. Goodrich, "Endpoints of resuscitation: what should we be monitoring?" AACN Advanced Critical Care, vol. 17, no. 3, pp. 306-316, 2006.

[5] A. Donati, P. Pelaia, P. Pietropaoli, and J. C. Preiser, "Do use $\mathrm{ScvO} 2$ and O2ERe as therapeutical goals," Minerva Anestesiologica, vol. 77, no. 5, pp. 483-484, 2011.

[6] P. E. Marik and H. Desai, "Goal directed fluid therapy," Current Pharmaceutical Design, vol. 18, no. 38, pp. 6215-6224, 2012.

[7] P. E. Marik, M. Baram, and B. Vahid, "Does central venous pressure predict fluid responsiveness? A systematic review of the literature and the tale of seven mares," Chest, vol. 134, no. 1, pp. 172-178, 2008.

[8] F. Michard and J.-L. Teboul, "Predicting fluid responsiveness in ICU patients: a critical analysis of the evidence," Chest, vol. 121, no. 6, pp. 2000-2008, 2002.

[9] M. Németh, K. Tánczos, G. Demeter et al., "Central venous oxygen saturation and carbon dioxide gap as resuscitation targets in a hemorrhagic shock," Acta Anaesthesiologica Scandinavica, vol. 58, no. 5, pp. 611-619, 2014.

[10] P. E. Marik, R. Cavallazzi, T. Vasu, and A. Hirani, “Dynamic changes in arterial waveform derived variables and fluid responsiveness in mechanically ventilated patients: a systematic review of the literature," Critical Care Medicine, vol. 37, no. 9, pp. 26422647, 2009.

[11] P. E. Marik, X. Monnet, and J.-L. Teboul, "Hemodynamic parameters to guide fluid therapy," Annals of Intensive Care, vol. 1, article 1, 2011.

[12] P. E. Marik, "Iatrogenic salt water drowning and the hazards of a high central venous pressure," Annals of Intensive Care, vol. 4, article 21, 2014.

[13] J. R. Prowle, J. E. Echeverri, E. V. Ligabo, C. Ronco, and R. Bellomo, "Fluid balance and acute kidney injury," Nature Reviews Nephrology, vol. 6, no. 2, pp. 107-115, 2010.

[14] M. Cannesson, G. Pestel, C. Ricks, A. Hoeft, and A. Perel, "Hemodynamic monitoring and management in patients undergoing high risk surgery: a survey among North American and European anesthesiologists," Critical Care, vol. 15, no. 4, article R197, 2011.

[15] M. Cecconi, C. Hofer, J.-L. Teboul et al., "Fluid challenges in intensive care: the FENICE study: a global inception cohort study," Intensive Care Medicine, vol. 41, no. 9, pp. 1529-1537, 2015. 
[16] L. H. Navarro, J. A. Bloomstone, J. O. Auler et al., "Perioperative fluid therapy: a statement from the international Fluid Optimization Group," Perioperative Medicine, vol. 4, article 3, 2015.

[17] S. Finfer, R. Bellomo, N. Boyce, J. French, J. Myburgh, and R. Norton, "A comparison of albumin and saline for fluid resuscitation in the intensive care unit," The New England Journal of Medicine, vol. 350, no. 22, pp. 2247-2256, 2004.

[18] F. M. Brunkhorst, C. Engel, F. Bloos et al., "Intensive insulin therapy and pentastarch resuscitation in severe sepsis," The New England Journal of Medicine, vol. 358, no. 2, pp. 125-139, 2008.

[19] A. Perner, N. Haase, A. B. Guttormsen et al., "Hydroxyethyl starch 130/0.42 versus Ringer's acetate in severe sepsis," The New England Journal of Medicine, vol. 367, no. 2, pp. 124-134, 2012.

[20] J. Myburgh, Q. Li, S. Heritier, A. Dan, P. Glass, and Crystalloid versus Hydroxyethyl Starch Trial (CHEST) Management Committee, "Statistical analysis plan for the Crystalloid versus Hydroxyethyl Starch Trial (CHEST)," Critical Care and Resuscitation, vol. 14, no. 1, pp. 44-52, 2012.

[21] J. D. Sandham, R. D. Hull, R. F. Brant et al., "A randomized, controlled trial of the use of pulmonary-artery catheters in highrisk surgical patients," The New England Journal of Medicine, vol. 348, no. 1, pp. 5-14, 2003.

[22] P. M. Kapoor, M. Kakani, U. Chowdhury, M. Choudhury, Lakshmy, and U. Kiran, "Early goal-directed therapy in moderate to high-risk cardiac surgery patients," Annals of Cardiac Anaesthesia, vol. 11, no. 1, pp. 27-34, 2008.

[23] P. J. Van der Linden, A. Dierick, S. Wilmin, B. Bellens, and S. G. De Hert, "A randomized controlled trial comparing an intraoperative goal-directed strategy with routine clinical practice in patients undergoing peripheral arterial surgery," European Journal of Anaesthesiology, vol. 27, no. 9, pp. 788-793, 2010.

[24] A. Feldheiser, P. Conroy, T. Bonomo, B. Cox, T. R. Garces, and C. Spies, "Development and feasibility study of an algorithm for intraoperative goaldirected haemodynamic management in noncardiac surgery," The Journal of International Medical Research, vol. 40, no. 4, pp. 1227-1241, 2012.

[25] J. Benes, I. Chytra, P. Altmann et al., "Intraoperative fluid optimization using stroke volume variation in high risk surgical patients: results of prospective randomized study," Critical Care, vol. 14, no. 3, article R118, 2010.

[26] M. Cecconi, N. Fasano, N. Langiano et al., "Goal-directed haemodynamic therapy during elective total hip arthroplasty under regional anaesthesia," Critical Care, vol. 15, no. 3, article R132, 2011.

[27] F. Michard and J.-L. Teboul, "Using heart-lung interactions to assess fluid responsiveness during mechanical ventilation," Critical Care, vol. 4, no. 5, pp. 282-289, 2000.

[28] R. A. F. Linton, N. W. F. Linton, and F. Kelly, "Is clinical assessment of the circulation reliable in postoperative cardiac surgical patients?" Journal of Cardiothoracic and Vascular Anesthesia, vol. 16, no. 1, pp. 4-7, 2002.

[29] K. Reinhart, H.-J. Kuhn, C. Hartog, and D. L. Bredle, "Continuous central venous and pulmonary artery oxygen saturation monitoring in the critically ill," Intensive Care Medicine, vol. 30, no. 8, pp. 1572-1578, 2004.

[30] M. S. Goepfert, H. P. Richter, C. Z. Eulenburg et al., "Individually optimized hemodynamic therapy reduces complications and length of stay in the intensive care unit: a prospective, randomized controlled trial," Anesthesiology, vol. 119, no. 4, pp. 824836, 2013.
[31] A. Mikor, D. Trásy, M. F. Németh et al., "Continuous central venous oxygen saturation assisted intraoperative hemodynamic management during major abdominal surgery: a randomized, controlled trial," BMC Anesthesiology, vol. 15, article 82, 2015.

[32] S. Kocsi, G. Demeter, J. Fogas, D. Érces, J. Kaszaki, and Z. Molnár, "Central venous oxygen saturation is a good indicator of altered oxygen balance in isovolemic anemia," Acta Anaesthesiologica Scandinavica, vol. 56, no. 3, pp. 291-297, 2012.

[33] S. Kocsi, G. Demeter, D. Erces, E. Nagy, J. Kaszaki, and Z. Molnar, "Central venous-to-arterial $\mathrm{CO}_{2}$ gap is a useful parameter in monitoring hypovolemia-caused altered oxygen balance: animal study," Critical Care Research and Practice, vol. 2013, Article ID 583598, 7 pages, 2013.

[34] P. van Beest, G. Wietasch, T. Scheeren, P. Spronk, and M. Kuiper, "Clinical review: use of venous oxygen saturations as a goal-a yet unfinished puzzle," Critical Care, vol. 15, no. 5, article 232, 2011.

[35] C. E. Mecher, E. C. Rackow, M. E. Astiz, and M. H. Weil, "Venous hypercarbia associated with severe sepsis and systemic hypoperfusion," Critical Care Medicine, vol. 18, no. 6, pp. 585589, 1990.

[36] M. H. Weil, E. C. Rackow, R. Trevino, W. Grundler, J. L. Falk, and M. I. Griffel, "Difference in acid-base state between venous and arterial blood during cardiopulmonary resuscitation," The New England Journal of Medicine, vol. 315, no. 3, pp. 153-156, 1986.

[37] J. Cuschieri, E. P. Rivers, M. W. Donnino et al., "Central venousarterial carbon dioxide difference as an indicator of cardiac index," Intensive Care Medicine, vol. 31, no. 6, pp. 818-822, 2005.

[38] E. Benjamin, T. A. Paluch, S. R. Berger, G. Premus, C. Wu, and T. J. Iberti, "Venous hypercarbia in canine hemorrhagic shock," Critical Care Medicine, vol. 15, no. 5, pp. 516-518, 1987.

[39] B. Lamia, X. Monnet, and J. L. Teboul, "Meaning of arteriovenous PCO2 difference in circulatory shock," Minerva Anestesiologica, vol. 72, no. 6, pp. 597-604, 2006.

[40] R. P. Dellinger, M. M. Levy, A. Rhodes et al., "Surviving sepsis campaign: international guidelines for management of severe sepsis and septic shock: 2012," Critical Care Medicine, vol. 41, no. 2, pp. 580-637, 2013.

[41] K. Tánczos, M. Németh, and Z. Molnár, “The multimodal concept of hemodynamic stabilization," Frontiers in Public Health, vol. 2, article 34, 2014. 


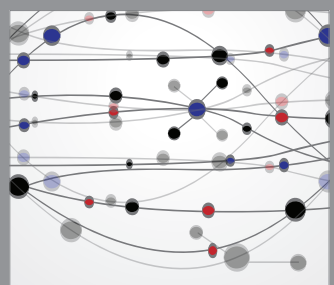

The Scientific World Journal
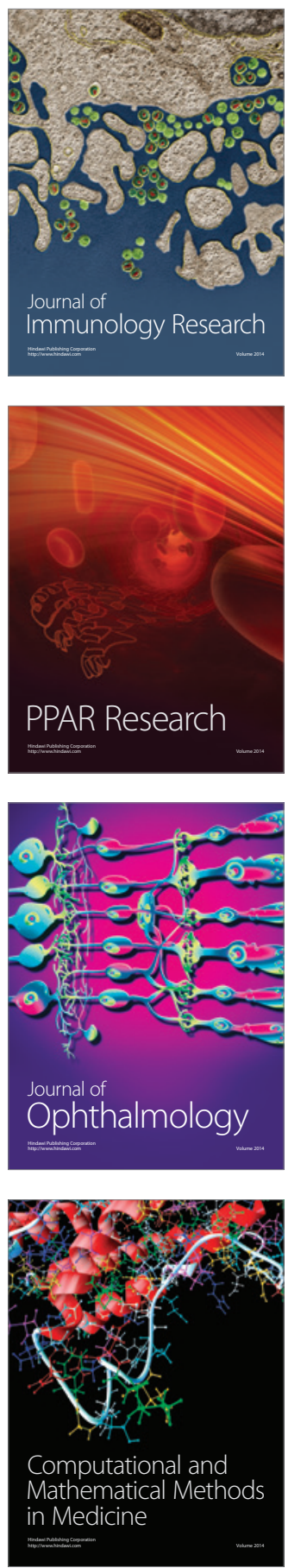

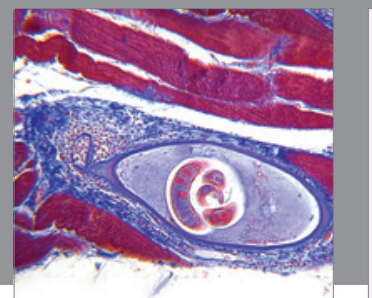

Gastroenterology

Research and Practice
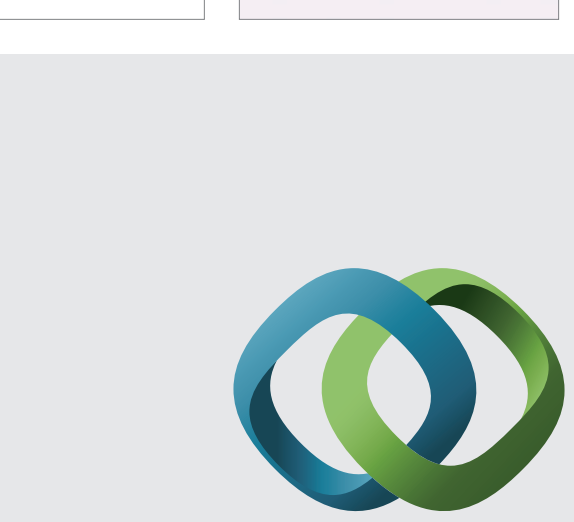

\section{Hindawi}

Submit your manuscripts at

http://www.hindawi.com
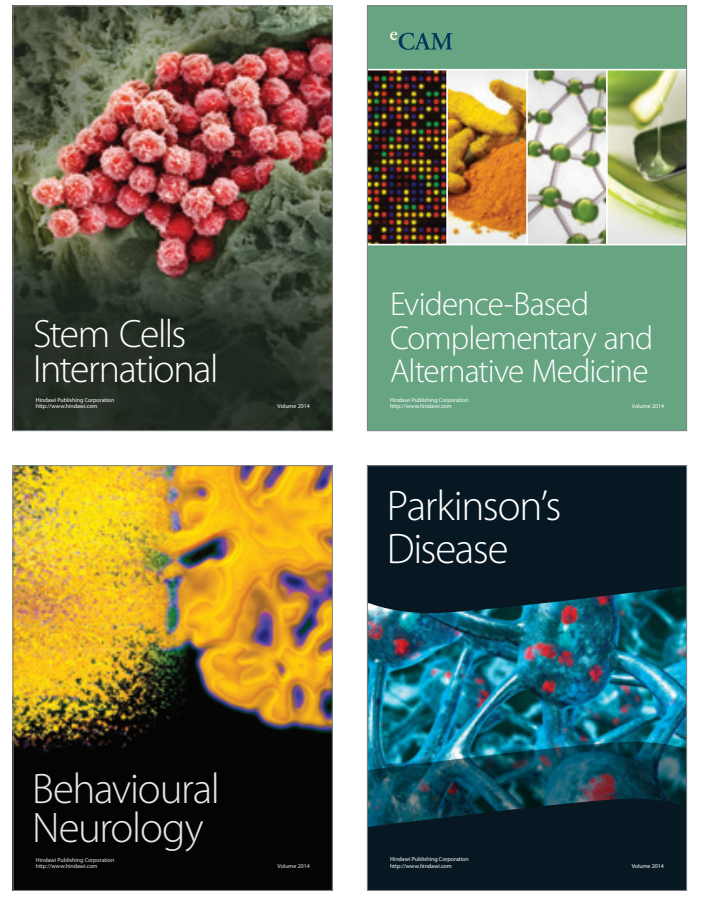
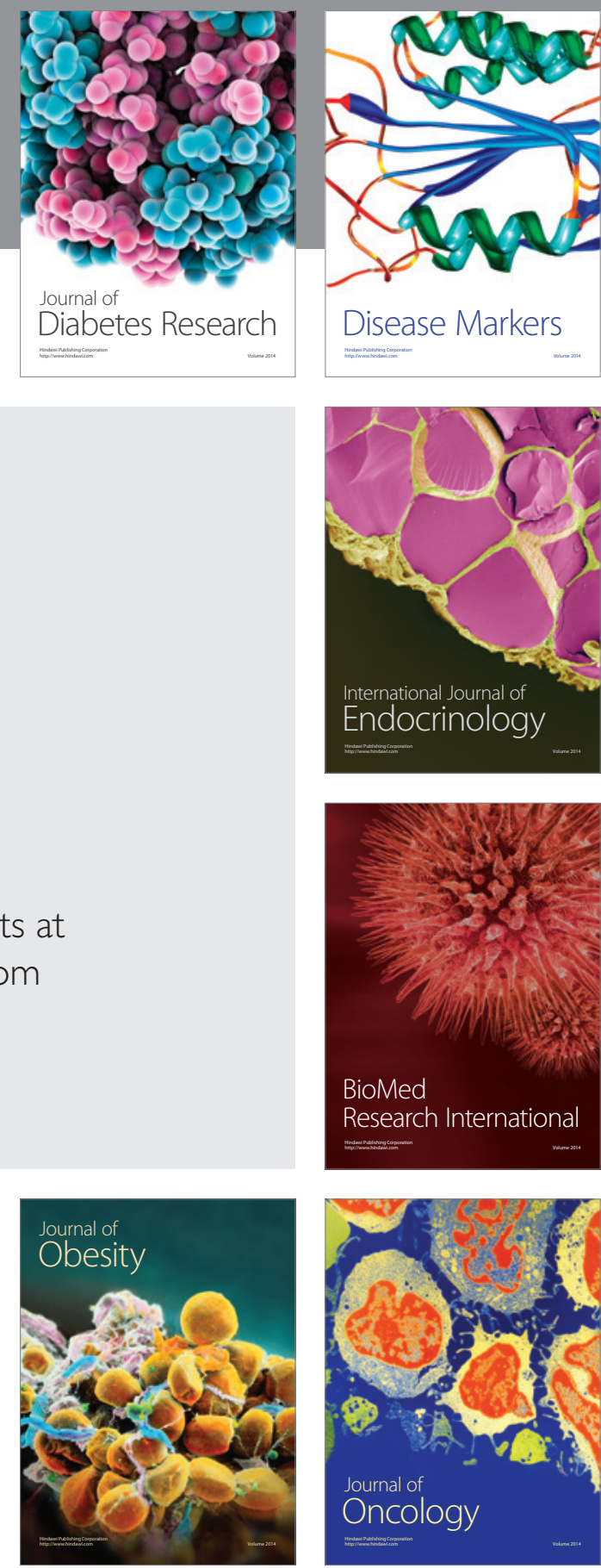

Disease Markers
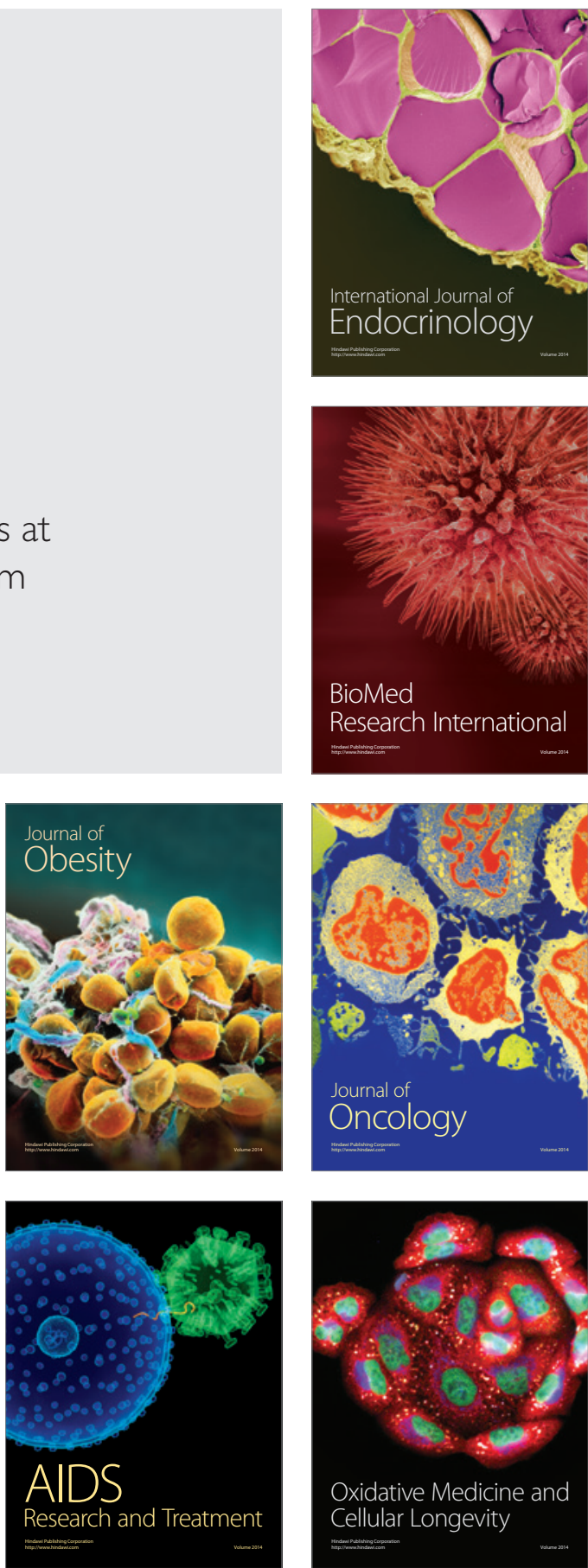


\section{The multimodal concept of hemodynamic stabilization}

\section{Krisztián Tánczos, Márton Németh and Zsolt Molnár*}

Department of Anaesthesiology and Intensive Therapy, University of Szeged, Szeged, Hungary

\author{
Edited by: \\ Evangelos Giamarellos-Bourboulis, \\ University of Athens, Greece \\ Reviewed by: \\ Linda Johansson, Karolinska \\ Institutet, Sweden \\ Peter Pickkers, Radboud University \\ Medical Centre, Netherlands \\ George Dimopoulos, University \\ Hospital Attikon, Greece \\ *Correspondence: \\ Zsolt Molnár, Department of \\ Anaesthesiology and Intensive \\ Therapy, University of Szeged, 6 \\ Semmelweis Street, Szeged 6725, \\ Hungary \\ e-mail: zsoltmolna@gmail.com
}

\begin{abstract}
Hemodynamic instability often leads to hypoperfusion, which has a significant impact on outcome in both medical and surgical patients. Measures to detect and treat tissue hypoperfusion early by correcting the imbalance between oxygen delivery and consumption is of particular importance. There are several studies targeting different hemodynamic endpoints in order to investigate the effects of goal-directed therapy on outcome. A so-called multimodal concept putting several variables in context follows simple logic and may provide a broader picture. Furthermore, rather than treating population based "normal" values of certain indices, this concept can be translated into the individualized patient care to reach adequate oxygen supply and tissue oxygenation in order to avoid under, or over resuscitation, which are equally harmful. The purpose of this review is to give an overview of current data providing the basis of this a multimodal, individualized approach of hemodynamic monitoring and treatment.
\end{abstract}

Keywords: hemodynamic optimization, cardiac output, stroke volume, central venous oxygen saturation, venous to arterial carbon dioxide gap

\section{INTRODUCTION}

Development of multiorgan disorders is often the result of hypoperfusion, which severely affects outcome of medical and surgical patients alike and substantially increases the utilization of resources and costs (1). Therefore, the use of early and efficient therapeutic strategies able to detect tissue hypoperfusion and to treat the imbalance between oxygen consumption and delivery is of particular importance (2). Traditional endpoints such as heart rate, blood pressure, mental status, and urine output can be useful in the initial identification of inadequate perfusion, but are limited in their ability to identify ongoing, compensated shock (3). Therefore, more detailed assessment of global macrohemodynamic indices such as cardiac output (CO) and derived variables and measures of oxygen delivery and uptake, may be necessary to guide treatment $(4,5)$. Furthermore, after the optimization of these parameters, indicators of tissue perfusion should also be assessed to verify the effectiveness of therapy (6).

\section{PHYSIOLOGICALISSUES}

The primary goal of the cardiorespiratory system is to deliver adequate oxygen to the tissues to meet their metabolic requirements. The adequacy of tissue oxygenation is determined by the balance between the rate of oxygen transport to the tissues (oxygen delivery, $\mathrm{DO}_{2}$ ) and the rate at which the oxygen is used by the tissues (oxygen consumption, $\mathrm{VO}_{2}$ ) (7). The standard formulas to determine oxygen delivery and oxygen consumption is shown in Figure 1.

In the critically ill and in the perioperative period, there is often an imbalance between delivery and consumption. Oxygen delivery can be inadequate if arterial oxygen content $\left(\mathrm{CaO}_{2}\right)$ and/or $\mathrm{CO}$ is reduced $(8,9)$. The circulation can compensate to some extent, and $\mathrm{VO}_{2}$ is usually independent in a wide range of $\mathrm{DO}_{2}$. However, beyond a critical point any further drop in $\mathrm{DO}_{2}$ will inevitably result in a decrease in $\mathrm{VO}_{2}$. In other words, after exhausting compensatory resources $\mathrm{VO}_{2}$ becomes dependent on $\mathrm{DO}_{2}$ and aerobic metabolism will have to be switched to anaerobic metabolism, leading to metabolic acidosis and oxygen debt (10).

The principle task of acute care is to avoid or correct oxygen debt by optimization of the oxygen supply and consumption. Furthermore, it is just as important to recognize that $\mathrm{DO}_{2}$ and tissue perfusion has normalized, therefore any further measures to increase $\mathrm{DO}_{2}$ may do harm by unnecessary over resuscitation.

There is also mounting evidence that conventional parameters such as blood pressure, central venous pressure, heart rate are poor indicators of cardiac index or oxygen delivery $(11,12)$, and there is also increasing evidence that, for example, in high-risk surgery perioperative care algorithms based on advanced hemodynamic monitoring are beneficial $(13,14)$.

\section{GOAL-DIRECTED CONCEPT IN HEMODYNAMIC MONITORING}

The multimodal concept in hemodynamic monitoring can be translated into the individualized use of target endpoints for hemodynamic stabilization instead of treating "normal" values, and can help to reach adequate oxygen supply and tissue oxygenation in order to avoid under or over resuscitation, which are equally harmful. It is important to note, that so-called "normal" values may be true for a population, but may be false for an individual patient.

\section{CARDIAC OUTPUT AND DO ${ }_{2}$ AS RESUSCITATION ENDPOINTS}

Several clinical investigations were performed on $\mathrm{CO}$ and derived variables based goals directed hemodynamic support in high-risk surgery. In two recent meta-analyses, it was found that cardiac index and $\mathrm{DO}_{2}$ guided treatment resulted in reduced mortality as compared to high-risk surgical patients receiving standard therapy $(13,14)$. 


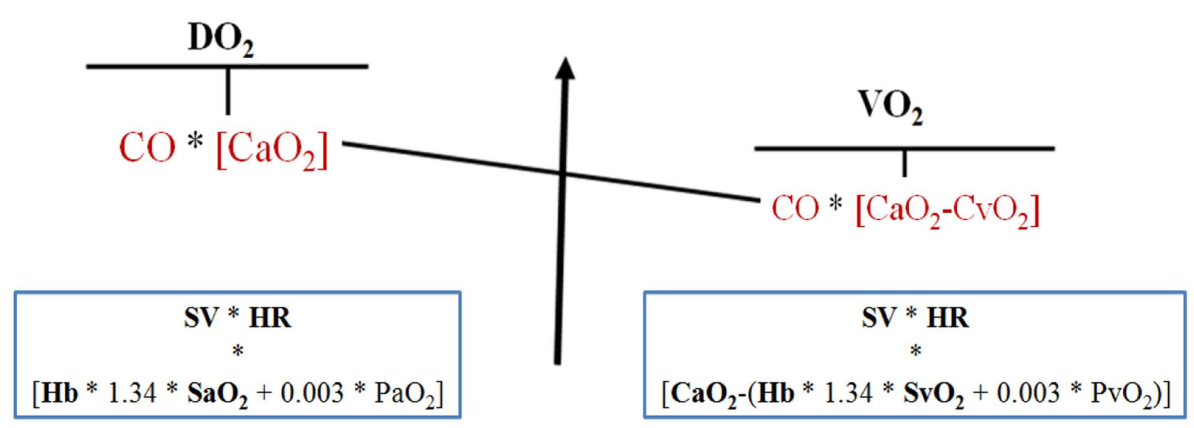

FIGURE 1 | Oxygen delivery and consumption. $\mathrm{DO}_{2}$, oxygen delivery; SV stroke volume; $\mathrm{HR}$, heart rate; $\mathrm{Hb}$, hemoglobin; $\mathrm{SaO}_{2}$, hemoglobin arterial oxygen saturation; $\mathrm{PaO}_{2}$, arterial oxygen partial pressure; $\mathrm{CO}$, cardiac output;
$\mathrm{CaO}_{2}$, arterial oxygen content, $\mathrm{VO}_{2}$; oxygen consumption, $\mathrm{SvO}_{2}$; hemoglobin mixed venous oxygen saturation; $\mathrm{PvO}_{2}$, venous oxygen partial pressure; $\mathrm{CvO}_{2}$, venous oxygen content

\section{STROKE VOLUME VARIATION AND PULSE PRESSURE VARIATION AS RESUSCITATION ENDPOINTS}

Recently, less invasive devices assessing CO by pulse contour analysis based on the radial artery pressure signal have been introduced. Although these devices show lower precision compared to the gold standards of thermodilution, there is some evidence that these methods can adequately show changes and trends in the hemodynamic status (15). As pulse pressure variation and stroke volume variation are well established indicators of fluid responsiveness, these devices seem to be simple and useful alternatives to invasive hemodynamic monitoring (16). Furthermore, in recent studies fluid therapy guided by SVV and PPV proved to be more accurate than static preload indicators-based approaches and has also been shown to improve patient outcome, by reducing postoperative complication rate significantly $(17,18)$. However, pulse pressure variation and stroke volume variation are limited to patients who receive controlled mechanical ventilation with normal sinus rhythm $(19,20)$.

\section{VENOUS TO ARTERIAL $\mathrm{CO}_{2}$ GAP AS THERAPEUTIC ENDPOINT}

Another easily obtainable blood flow related blood gas parameter is the central venous to arterial carbon dioxide gap $\left(\mathrm{dCO}_{2}\right)$. Several authors have reported increased $\mathrm{dCO}_{2}$ in different low flow states (21-23). In oxygen debt caused anaerobic metabolism, hydrogen ions are generated in two ways: (1) hydrolysis of adenosine triphosphate to adenosine diphosphate and (2) increased production of lactic acid (24). Hydrogen ions are buffered by bicarbonate presented in the cells, and this process will generate $\mathrm{CO}_{2}$ production (25). While arterial $\mathrm{PaCO}_{2}$ is variable and dependent on pulmonary gas exchange, central venous $\mathrm{PvCO}_{2}$ is dependent on the capability of the flow (i.e., CO) to wash out carbon dioxide from the tissues. The Fick principle adapted to carbon dioxide demonstrates the inverse relationship between the $\mathrm{CO}$ and $\mathrm{dCO}_{2}$ (26). This postulate that increased $\mathrm{dCO}_{2}$ reflects decreased flow was confirmed in several critically ill conditions such as severe sepsis, heart failure, and severe hypovolemia $(27,28)$. Furthermore, adding the $\mathrm{dCO}_{2}$ to $\mathrm{ScvO}_{2}$ for identifying $\mathrm{VO}_{2} / \mathrm{DO}_{2}>30 \%$, there was an improvement in specificity, positive predictive, and negative predictive values (29).
In cases like severe sepsis, when oxygen uptake is insufficient due to microcirculatory and/or mitochondrial defects, $\mathrm{ScvO}_{2}$ may be elevated (i.e., false negative). Previous studies have suggested that under such circumstances the increased value of $\mathrm{dCO}_{2}$ ( $>5 \mathrm{mmHg}$ ), may help the clinician in detecting inadequate $\mathrm{DO}_{2}$ to tissues, hence the complementary use of $\mathrm{ScvO}_{2}$ and $\mathrm{dCO}_{2}$ is recommended (30-32).

\section{MEASURES OF OXYGEN DELIVERY AND EXTRACTION}

Perhaps the most commonly used methods to assess global $\mathrm{VO}_{2} / \mathrm{DO}_{2}$ are mixed venous oxygen saturation $\left(\mathrm{SvO}_{2}\right)$ and its surrogate $\mathrm{ScvO}_{2}$. Central venous oxygen saturation is an easily obtained parameter via a central venous catheter already in situ in most critically ill patients and it is often used as a marker of the balance between oxygen delivery and consumption. Because of the different positions of the pulmonary artery and central venous catheters (entire body in the case of $\mathrm{SvO}_{2}$ versus brain and the upper part of the body in the case of $\mathrm{ScvO}_{2}$ ) there has been a considerable debate on the interpretation of $\mathrm{ScvO}_{2}$ values as compared to $\mathrm{SvO}_{2}$. Most of the studies that have analyzed the relationship between $\mathrm{ScvO}_{2}$ and $\mathrm{SvO}_{2}$ have shown that $\mathrm{ScvO}_{2}$ is on an average $5 \%$ higher than $\mathrm{SvO}_{2}$ and is considered as a reasonable surrogate marker in the clinical setting (33-35). However, recent clinical trials, mainly on septic patients, were unable to show satisfactory agreement between $\mathrm{ScvO}_{2}$ and $\mathrm{SvO}_{2}$. This could in part be explained by modifications of blood flow distribution and oxygen extraction by brain and splanchnic tissues (36). It seems that $\mathrm{ScvO}_{2}$ and $\mathrm{SvO}_{2}$ are not numerically equivalent but the changes usually occur in a parallel manner (37).

The main factors, which influence $\mathrm{ScvO}_{2}$, are hemoglobin, arterial oxygen saturation of hemoglobin, $\mathrm{CO}$, and oxygen consumption. Theoretically if three of these factors are kept constant, the value of $\mathrm{ScrO}_{2}$ reflects the changes of the latter. There are multiple physiologic, pathologic, and therapeutic factors, which influence venous oxygen saturation, such as anemia, hypovolemia, contractility, bleeding, sedation, fever, pain, etc. (38).

One of the important features of venous saturation is that it can be pathologic both when it is high and when it is low. In a recent large cohort of septic patients in the emergency department, it 
was found that mortality was $40 \%$ in patients admitted with an $\mathrm{ScvO}_{2}<70 \%$ but in patients with an initial $\mathrm{ScvO}_{2}$ of $>90 \%$, it was almost as high $34 \%$. The latter was probably due to impaired oxygen utilization (39). High $\mathrm{ScvO}_{2}$ values may thus represent an inability of the cells to extract oxygen or microcirculatory shunting in sepsis (40). Therefore, additional measures are necessary to help evaluating high $\mathrm{ScvO}_{2}$ values, such as for example lactate, central venous to arterial $\mathrm{dCO}_{2}$, and by applying advanced invasive hemodynamic monitoring.

Lactate, the end product on anaerobic metabolism, has been thoroughly investigated over the last decades in critical care. It has good prognostic value in several clinical scenarios such as trauma, sepsis, and high-risk surgical patients (41). Not just the absolute value, but its change over time (kinetics: determined by production and clearance) seems an even better marker of adequate resuscitation and outcome (42). A lactate decrease by $20 \%$ or more per $2 \mathrm{~h}$ in the initial resuscitation of critically ill patients resulted shorter length of stay in the intensive care unit and a lower mortality rate when adjusted to predefined risk factors (43). However, if lactate kinetics is assessed every $2-6 \mathrm{~h}$, which can be regarded as far too long considering that acute resuscitation should be corrected as soon as possible, it seems that lactate kinetics rather than absolute values should be followed as resuscitation endpoints. In cases, when lactate production or elimination is impaired, the evaluation of lactate clearance is difficult to interpret. These pathological circumstances can be liver failure (44) or seizures (45).

\section{PPV, $\mathrm{dCO}_{2}$, AND STROKE VOLUME GUIDED FLUID RESUSCITATION}

In a recent animal experiment, we tested the effect of stroke volume guided hemorrhage and fluid resuscitation (46). After baseline measurements $\left(T_{\mathrm{bsl}}\right)$, animals were bled until stroke volume index dropped by $50 \%$, then measurements were repeated $\left(T_{0}\right)$. Thereafter animals were resuscitated with lactated Ringer's solution until baseline SVI values were reached, then final measurements were recorded ( $\left.T_{\text {end }}\right)$. After bleeding, the SVI decreased by the planned $50 \%$ at $T_{0}$ and returned to its initial value by $T_{\text {end }}$ (Table 1). The CI also decreased after bleeding and reached a higher value by $T_{\text {end }}$ as compared to $T_{\mathrm{bsl}}$. Pulse contour analysis driven SVV and PPV increased from $T_{\text {bsl }}$ to $T_{0}$ and normalized by $T_{\text {end }}$. $\mathrm{ScvO}_{2}$ decreased from $T_{\text {bsl }}$ to $T_{0}$ and although increased by $T_{\text {end }}$, it remained lower, with a mean difference of $5 \%$ as compared to $T_{\mathrm{bsl}}$.

In these experiments, $\mathrm{ScvO}_{2}$ and $\mathrm{dCO}_{2}$ correlated well with changes in stroke volume. If the hemodynamic instability is corrected, stroke volume, $\mathrm{PPV}, \mathrm{SVV}$, and $\mathrm{dCO}_{2}$ are in the physiological range, the low $\mathrm{ScvO}_{2}$ can indicate a low hemoglobin level due to low oxygen delivery. These data also confirm that more parameters should be taken into account during resuscitation.

\section{CONCLUSION}

Early and adequate hemodynamic stabilization of the critically ill has a significant effect on outcome. Rather than following certain numbers in protocols or algorithms, a multimodal approach, of assessing hemodynamic variables together with the balance between oxygen delivery and consumption, may help to get a detailed picture about the hemodynamic status of our patients and also gives a chance for individualized treatment. The latter
Table 1 | Hemodynamic and blood gas changes during stroke volume based fluid resuscitation.

\begin{tabular}{lccc}
\hline & \multicolumn{1}{c}{$\boldsymbol{T}_{\text {bsl }}$} & $\boldsymbol{T}_{\mathbf{0}}$ & $\boldsymbol{T}_{\text {end }}$ \\
\hline $\begin{array}{l}\text { Stroke volume index } \\
\left(\mathrm{mL} / \mathrm{m}^{2} \text { ) }\right.\end{array}$ & $26.8 \pm 4.7$ & $13.4 \pm 2.3^{*}$ & $26.6 \pm 4.1^{\#}$ \\
$\begin{array}{l}\text { Cardiac index } \\
\text { (L/min/m })\end{array}$ & $2.6 \pm 0.4$ & $1.8 \pm 0.3^{*}$ & $2.9 \pm 0.5^{*, \#}$ \\
$\begin{array}{l}\text { Stroke volume } \\
\text { variation (\%) }\end{array}$ & $13.6 \pm 4.3$ & $22.6 \pm 5.6^{*}$ & $12.2 \pm 4.3^{\#}$ \\
$\begin{array}{l}\text { Pulse pressure } \\
\text { variation (\%) }\end{array}$ & $13.0 \pm 4.5$ & $24.5 \pm 7.6^{*}$ & $13 \pm 4.2^{\#}$ \\
$\begin{array}{l}\text { Venous to arterial } \\
\text { carbon dioxide gap } \\
\text { (mmHg) }\end{array}$ & $5.3 \pm 2$ & $9.6 \pm 2.3^{*}$ & $5.1 \pm 2.6^{\#}$ \\
$\begin{array}{l}\text { Central venous } \\
\text { oxygen saturation (\%) }\end{array}$ & $78 \pm 7$ & $61 \pm 5^{*}$ & $73 \pm 9^{*, \#}$ \\
$\begin{array}{l}\text { Hemoglobin (g/dL) } \\
\text { Hem }\end{array}$ & $12.05 \pm 1.37$ & $11.22 \pm 1.39^{*}$ & $8.45 \pm 1.1^{* \text { *\# }}$ \\
\hline
\end{tabular}

Data are expressed as mean $\pm S D$; ${ }^{*} p<0.05$ significantly different from $T_{b s l}$; \# $p<0.05$ significantly different from $T_{0}$.

$T_{0}$, baseline measurements; $T_{1}$, measurements following the hemorrhage; $T_{\text {end }}$ measurements after the resuscitation. Data are presented as mean $\pm S D$, statistically significant difference was considered $p<0.05$

* Significantly different from $T_{0}$.

\# Significantly different from $T_{\text {end }}$.

means that the evidence, which proved beneficial for a population in clinical studies gives the frame what we fine tune for the patient's individual needs reflected by changes in this complex picture of physiology. Despite that this multimodal approach follows simple logic, it has currently not been completely proven, which renders the need for further clinical trials.

\section{REFERENCES}

1. Shoemaker WC, Appel PL, Kram HB. Role of oxygen debt in the development of organ failure sepsis, and death in high-risk surgical patients. Chest (1992) 102:208-15. doi:10.1378/chest.102.1.208

2. Shoemaker WC, Appel PL, Kram HB. Tissue oxygen debt as determinant of lethal and nonlethal postoperative organ failure. Crit Care Med (1988) 16:1117-20. doi:10.1097/00003246-198811000-00007

3. Goodrich C. Endpoints of resuscitation: what should we be monitoring? AACN Adv Crit Care (2006) 17(3):306-16. doi:10.1097/01256961-200607000-00010

4. Donati A, Pelaia P, Pietropaoli P, Preiser JC. Do use ScvO2 and O2ER as therapeutical goals. Minerva Anestesiol (2011) 77:483-4.

5. Marik PE, Desai H. Goal directed fluid therapy. Curr Pharm Des (2012) 18:6215-24. doi:10.2174/138161212803832399

6. Benes J, Pradl R, Chyrta I. Perioperative hemodynamic optimization: a way to individual goals. In: Vincent JL, editor. Annual Update in Intensive Care and Emergency Medicine 2012. New York: Springer (2012). p. 357-67.

7. Vallet B, Tavernier B, Lund N. Assessment of tissue oxygenation in the critically ill. Eur JAnaesthesiol (2000) 17:221-9. doi:10.1097/00003643-200004000-00003

8. Perner A. Diagnosing hypovolemia in the critically ill. Crit Care Med (2009) 37:2674-5. doi:10.1097/CCM.0b013e3181ad77d8

9. Sakr Y, Dubois MJ, De Backer D, Creteur J, Vincent JL. Persistent microcirculatory alterations are associated with organ failure and death in patients with septic shock. Crit Care Med (2004) 32(9):1825-31. doi:10.1097/01.CCM.0000138558. 16257.3F 
10. Vincent JL. The relationship between oxygen demand, oxygen uptake, and oxygen supply. Intensive Care Med (1990) 16(Suppl 2):145-8. doi:10.1007/ BF01785244

11. Marik PE, Baram M, Vahid B. Does central venous pressure predict fluid responsiveness? A systematic review of the literature and the tale of seven mares. Chest (2008) 134:172-8. doi:10.1378/chest.07-2331

12. Osman D, Ridel C, Ray P, Monnet X, Anguel N, Richard C, et al. Cardiac filling pressures are not appropriate to predict hemodynamic response to volume challenge. Crit Care Med (2007) 35:64-8. doi:10.1097/01.CCM.0000249851. 94101.4F

13. Kern JW, Shoemaker WC. Meta-analysis of hemodynamic optimization in high-risk patients. Crit Care Med (2002) 30:1686-92. doi:10.1097/00003246200208000-00002

14. Gurgel ST, do Nascimento P Jr. Maintaining tissue perfusion in high-risk surgical patients: a systematic review of randomized clinical trials. Anesth Analg (2011) 112:1384-91. doi:10.1213/ANE.0b013e3182055384

15. Michard F, Teboul JL. Using heart-lung interactions to assess fluid responsiveness during mechanical ventilation. Crit Care (2000) 4(5):282-9. doi:10.1186/cc710

16. Marik PE, Cavallazzi R, Vasu T, Hirani A. Dynamic changes in arterial waveform derived variables and fluid responsiveness in mechanically ventilated patients: a systematic review of the literature. Crit Care Med (2009) 37:2642-7. doi:10.1097/CCM.0b013e3181a590da

17. Salzwedel C, Puig J, Carstens A, Bein B, Molnar Z, Kiss K, et al. Perioperative goal-directed hemodynamic therapy based on radial arterial pulse pressure variation and continuous cardiac index trending reduces postoperative complications after major abdominal surgery: a multi-center, prospective, randomized study. Crit Care (2013) 17:R191. doi:10.1186/cc12885

18. Lopes MR, Oliveira MA, Pereira VO, Lemos IP, Auler JO Jr, Michard F. Goaldirected fluid management based on pulse pressure variation monitoring during high-risk surgery: a pilot randomized controlled trial. Crit Care (2007) 11:R100. doi:10.1186/cc6117

19. Michard F, Teboul JL. Predicting fluid responsiveness in ICU patients: a critical analysis of the evidence. Chest (2002) 121:2000-8. doi:10.1378/chest 121.6.2000

20. Monnet X, Osman D, Ridel C, Lamia B, Richard C, Teboul JL. Predicting volume responsiveness by using the end-expiratory occlusion in mechanically ventilated intensive care unit patients. Crit Care Med (2009) 37:951-6. doi:10.1097/CCM.0b013e3181968fe1

21. Grundler W, Weil MH, Rackow EC. Arteriovenous carbon dioxide and pH gradients during cardiac arrest. Circulation (1986) 74:1071-4. doi:10.1161/01.CIR 74.5.1071

22. Cuschieri J, Rivers EP, Donnino MW, Katilius M, Jacobsen G, Nguyen HB, et al. Central venous-arterial carbon dioxide difference as an indicator of cardiac index. Intensive Care Med (2005) 31:818-22. doi:10.1007/s00134-005-2602-8

23. Benjamin E, Paluch TA, Berger SR, Premus G, Wu C, Iberti TJ. Venous hypercarbia in canine hemorrhagic shock. Crit Care Med (1987) 15:516-8. doi:10.1097/00003246-198705000-00013

24. Weil MH. Difference in acid-base state between venous and arterial blood during cardiopulmonary resuscitation. N Engl J Med (1986) 315:1616-8. doi:10.1056/NEJM198612183152519

25. Vallet B, Teboul JL, Cain S, Curtis S. Venoarterial CO2 difference during regional ischemic or hypoxic hypoxia. J Appl Physiol (2000) 89:1317-21.

26. Lamia B, Monnet X, Teboul JL. Meaning of arterio-venous PCO2 difference in circulatory shock. Minerva Anestesiol (2006) 72:597-604.

27. Mecher CE, Rackow EC, Astiz ME, Weil MH. Venous hypercarbia associated with severe sepsis and systemic hypoperfusion. Crit Care Med (1990) 18:585-9. doi:10.1097/00003246-199006000-00001

28. Adrogué HJ, Rashad MN, Gorin AB, Yacoub J, Madias NE. Assessing acid-base status in circulatory failure. Differences between arterial and central venous blood. N Engl J Med (1989) 320:1312-6. doi:10.1056/NEJM198905183202004

29. Kocsi S, Demeter G, Erces D, Nagy E, Kaszaki J, Molnar Z. Central venousto-arterial $\mathrm{CO} 2$ gap is a useful parameter in monitoring hypovolemia-caused altered oxygen balance: animal study. Crit Care Res Pract (2013) 2013:583598. doi:10.1155/2013/583598

30. Vallée F, Vallet B, Mathe O, Parraguette J, Mari A, Silva S, et al. Central venous-to-arterial carbon dioxide difference: an additional target for goaldirected therapy in septic shock? Intensive Care Med (2006) 34:2218-25. doi:10.1007/s00134-008-1199-0
31. Futier E, Robin E, Jabaudon M, Guerin R, Petit A, Bazin JE, et al. Central venous $\mathrm{O} 2$ saturation and venous-to-arterial $\mathrm{CO} 2$ difference as complementary tools for goal-directed therapy during high-risk surgery. Crit Care (2010) 14:R193. doi:10.1186/cc9310

32. Vallet B, Lebuffe G. How to titrate vasopressors against fluid loading in septic shock. Adv Sepsis (2007) 6:34-40.

33. Chawla LS, Zia H, Gutierrez G, Katz NM, Seneff MG, Shah M. Lack of equivalence between central and mixed venous oxygen saturation. Chest (2004) 126:1891-6. doi:10.1378/chest.126.6.1891

34. Reinhart K, Kuhn HJ, Hartog C, Bredle DL. Continuous central venous and pulmonary artery oxygen saturation monitoring in the critically ill. Intensive Care Med (2004) 30:1572-8. doi:10.1007/s00134-004-2337-y

35. Varpula M, Karlsson S, Ruokonen E, Pettilä V. Mixed venous oxygen saturation cannot be estimated by central venous oxygen saturation in septic shock. Intensive Care Med (2006) 32:1336-43. doi:10.1007/s00134-006-0270-y

36. van Beest PA, van Ingen J, Boerma EC, Holman ND, Groen H, Koopmans M, et al. No agreement of mixed venous and central venous saturation in sepsis, independent of sepsis origin. Crit Care (2010) 2010(14):R219. doi:10.1186/cc9348

37. Rivers E. Mixed versus central venous oxygen saturation may be not numerically equal, but both are still clinically useful. Chest (2006) 129:507-8. doi:10.1378/chest.129.3.507

38. van Beest PA, Wietasch G, Scheeren T. Clinical review: use of venous oxygen saturations as a goal - a yet unfinished puzzle. Crit Care (2011) 15:232. doi:10.1186/cc10351

39. Pope JV, Jones AE, Gaieski DF, Arnold RC, Trzeciak S, Shapiro NI, et al. EMShockNet. Multicenter study of central venous oxygen saturation $(\mathrm{ScvO} 2)$ as a predictor of mortality in patients with sepsis. Ann Emerg Med (2010) 55:40-6. doi:10.1016/j.annemergmed.2009.08.014

40. Ince C, Sinaasappel M. Microcirculatory oxygenation and shunting in sepsis and shock. Crit Care Med (1999) 27:1369-77. doi:10.1097/00003246-19990700000031

41. Meregalli A, Oliveira RP, Friedman G. Occult hypoperfusion is associated with increased mortality in hemodynamically stable, high-risk, surgical patients. Crit Care (2004) 8:R60-5. doi:10.1186/cc2527

42. Nguyen HB, Rivers EP, Knoblich BP, Jacobsen G, Muzzin A, Ressler JA, et al. Early lactate clearance is associated with improved outcome in severe sepsis and septic shock. Crit Care Med (2004) 32:1637-42. doi:10.1097/01.CCM.0000132904. 35713.A7

43. Jansen TC, van Bommel J, Schoonderbeek FJ, Sleeswijk Visser SJ, van der Klooster JM, Lima AP, et al. Early lactate-guided therapy in intensive care unit patients: a multicenter, open-label, randomized controlled trial. Am J Respir Crit Care Med (2010) 182:752-61. doi:10.1164/rccm.200912-1918OC

44. Kruse JA, Zaidi SA, Carlson RW. Significance of blood lactate levels in critically ill patients with liver disease. Am J Med (1987) 83:77-82. doi:10.1016/00029343(87)90500-6

45. Orringer CE, Eustace JC, Wunsch CD, Gardner LB. Natural history of lactic acidosis after grand-mal seizures. A model for the study of an aniongap acidosis not associated with hyperkalemia. N Engl J Med (1977) 297:796. doi:10.1056/NEJM197710132971502

46. Nemeth M, Tanczos K, Demeter G, Erces D, Kaszaki J, Mikor A, et al. Central venous oxygen saturation and carbon dioxide-gap as resuscitation targets in a hemorrhagic shock. Acta Anaesthesiol Scand (2014). doi:10.1111/aas.12312

Conflict of Interest Statement: The authors declare that the research was conducted in the absence of any commercial or financial relationships that could be construed as a potential conflict of interest.

Received: 29 January 2014; accepted: 01 April 2014; published online: 30 April 2014. Citation: Tánczos K, Németh M and Molnár Z (2014) The multimodal concept of hemodynamic stabilization. Front. Public Health 2:34. doi: 10.3389/fpubh.2014.00034 This article was submitted to Infectious Diseases, a section of the journal Frontiers in Public Health.

Copyright (C) 2014 Tánczos, Németh and Molnár. This is an open-access article distributed under the terms of the Creative Commons Attribution License (CC BY). The use, distribution or reproduction in other forums is permitted, provided the original author(s) or licensor are credited and that the original publication in this journal is cited, in accordance with accepted academic practice. No use, distribution or reproduction is permitted which does not comply with these terms. 